\title{
Intelligent Control of Parallel Hybrid Electric Vehicles
}

\author{
A Thesis \\ Presented in Partial Fulfillment of the Requirements for \\ the Degree Master of Science in the \\ Graduate School of The Ohio State University
}

By

Bradley C. Glenn

$* * * * *$

The Ohio State University

1999

Master's Examination Committee:

Approved by

Dr. Gregory Washington, Adviser

Dr. Giorgio Rizzoni

Dr. Yann Guezennec

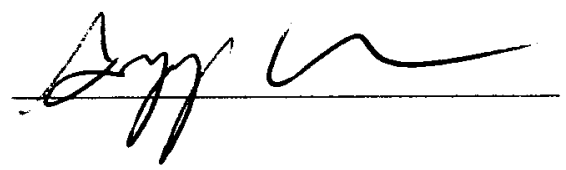

Adviser

Department of Mechanical Engineering 
Copyright by

Bradley C. Glenn

1999 


\section{ABSTRACT}

Currently Hybrid Electric Vehicles (HEV) are being considered as an alternative to conventional automobiles in order to improve fuel efficiency and reduce emissions. However, they will not be able to meet the fuel economy and emissions standards of the $21^{\text {st }}$ century if they are not controlled with an effective strategy. Hybrid electric vehicles present complex control problems because of their highly nonlinear time varying nature, thus introducing the need for intelligent control. To demonstrate the potential of an advanced control strategy for HEV's, a fuzzy logic control strategy has been developed and implemented in simulation in the National Renewable Energy Laboratory's simulator Advisor (version 2.0.2), and on The Ohio State University's 1999 HEV. The Fuzzy Logic Controller (FLC) utilizes the electric motor in a parallel hybrid electric vehicle (HEV) to force the ICE (66KW Volkswagen TDI) to operate at or near its peak point of efficiency or at or near its best fuel economy. Results with Advisor show that the vehicle with the Fuzzy Logic Controller can achieve (56) mpg in the city, while maintaining a state of charge of .68 for the battery pack, compared to (43) mpg for a conventional vehicle. This scheme has also brought to light various rules of thumb for the design and operation of HEV's. 
Dedicated to my mother and father for their encouragement throughout my life and to the late Midgett Parker. 


\section{ACKNOWLEDGMENTS}

I would first like to thank Dr. Washington and Dr. Rizzoni for their advice, encouragement, and patience throughout the course of this project. It was a pleasure to work with such first-rate researchers and educators. I would also like to thank Dr. Guezennec for taking time out of his busy schedule to serve on my examination committee.

I would next like to thank many of my fellow graduate students Pete, Paul Ed, Yoon, Jun, Matt, Rich, and Kwak whose help and friendship and advice made graduate school an enjoyable experience. Most importantly, I want to thank the Devesh Upadyay. Words cannot begin to express my appreciation. It truly would have been impossible for me to complete this work without him.

On a more personal level, my sincere thanks to my friends and family (Rud, Snove, Brez, Stace, Keith Rowe, Illini Keith, Marcus, and the Bore) and especially my parents, Charles and Margaret, who always have given me support when needed. I thank you all. Finally, I would like to thank Sandra Grady for being the most important person in my life. 


\section{VITA}

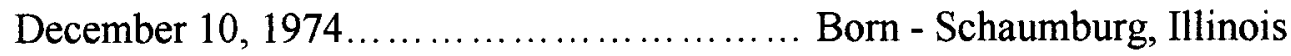

August, 1997 B.S. Mechanical Engineering The Ohio State University Columbus, $\mathrm{OH}$

September 1997 - December 1999 Graduate Research Assistant Department of Mechanical Engineering The Ohio State University Columbus, $\mathrm{OH}$

\section{Fields of Study}

Major Field: Mechanical Engineering

Major Area of Specialization: System Dynamics and Controls 


\section{TABLE OF CONTENTS:}

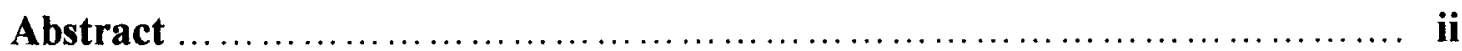

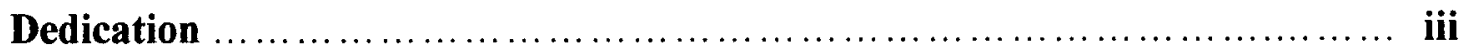

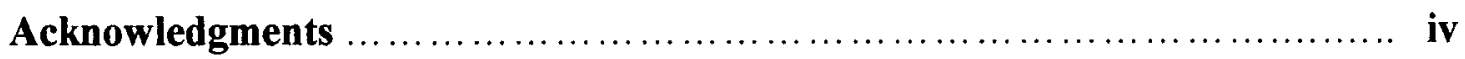

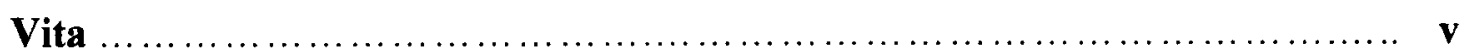

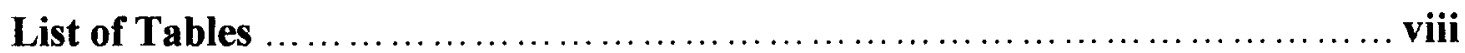

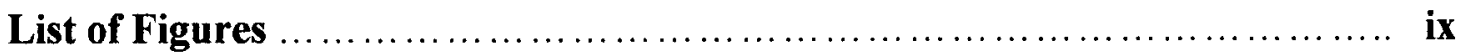

$\begin{array}{ll}\text { Chapters } & \text { Page }\end{array}$

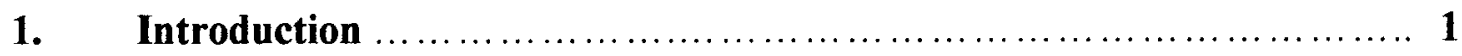

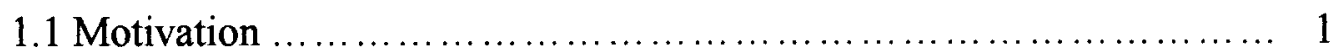

1.2 Thesis Outline ................................................. 2

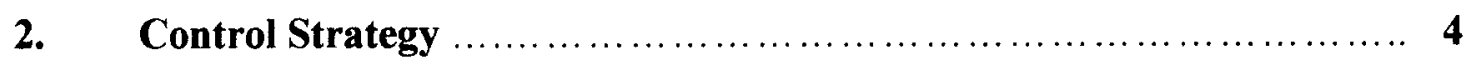

2.1 Efficiency Mode................................................... 5

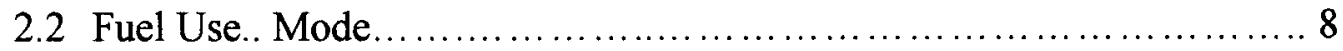

2.3 Fuzzy Logic Control ......................................... 11

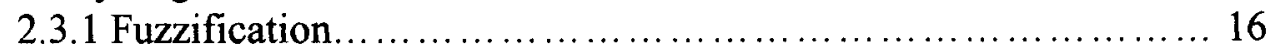

2.3.2 Inference Mechanism...................................... 17

2.3.3 Defuzzification........................................20

3. Control Implementation in Advisor $\ldots \ldots \ldots \ldots \ldots \ldots \ldots \ldots \ldots \ldots \ldots \ldots \ldots$

3.1 Description of Advisor .................................... 22 
3.2 Parallel Electric Assist Control Strategy ........................... 26

3.3 Description of Fuzzy Logic Control Strategy Block ................. 28

3.4 Additional Modifications to Advisor............................... 34

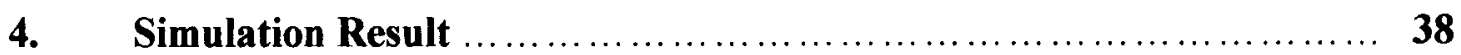

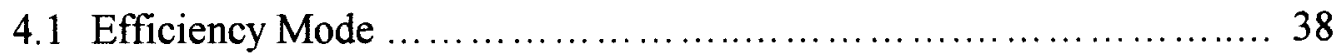

4.2 Fuel Use Mode ............................................... 46

5. Control Implementation on the OSU Hybrid Electric Vehicle .......... 52

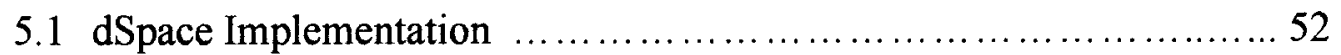

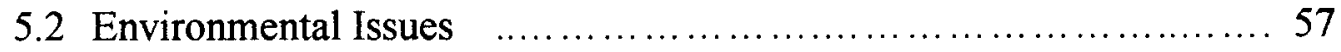

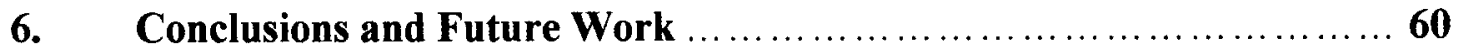

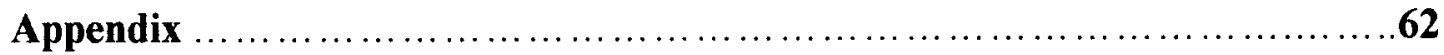

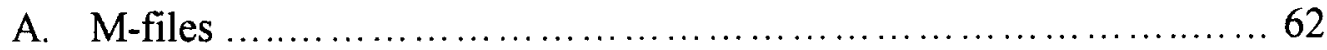

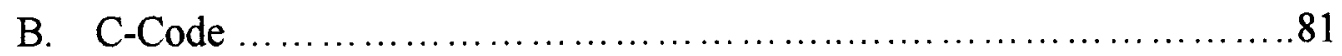

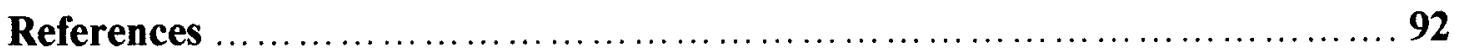




\section{LIST OF TABLES}

TABLE

PAGE

2.1. Qualitative summary of load leveling strategy for a parallel HEV ............7

4.1 Comparison of FLC in the efficiency mode to the existing parallel control strategy of Advisor and a conventional vehicle in the city.

4.2. Comparison of FLC in the efficiency mode to the existing parallel control strategy of Advisor and a conventional vehicle on the highway

4.3 Comparison of FLC in the efficiency mode to the existing parallel control strategy of Advisor and a conventional vehicle in the city

4.4 Comparison of FLC in the efficiency mode to the existing parallel control strategy of Advisor and a conventional vehicle on the highway

4.5 Comparison of FLC in the efficiency mode to the existing parallel control strategy of Advisor and a conventional vehicle in the city

4.6 Comparison of FLC in the efficiency mode to the existing parallel control strategy of Advisor and a conventional vehicle on the highway

4.7 Fuel use mode over ten FUDS cycles compared with PEA and conventional vehicle in the city.

4.8 Fuel use mode over ten HWFET cycles compared with PEA and conventional vehicle on the highway.

4.9 Fuel use mode over ten FUDS cycles compared with PEA and conventional vehicle in the city.

4.10 Fuel use mode over ten HWFET cycles compared with PEA and conventional vehicle on the highway... 
4.11 Fuel use mode over ten FUDS cycles compared with PEA and conventional

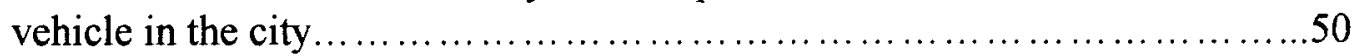

4.12 Fuel use mode over ten HWFET cycles compared with PEA and conventional vehicle on the highway ................................................ 


\section{LIST OF FIGURES}

FIGURE

PAGE

2.1. Hybrid peak shaving conceptualization in urban drive cycle.... 4

2.2. Efficiency map illustrating locations of operating points relative to

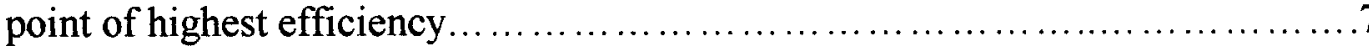

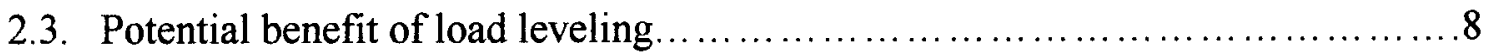

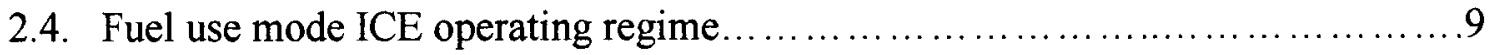

2.5. Driver - vehicle fuzzy logic feedback control system $\ldots \ldots \ldots \ldots \ldots \ldots \ldots \ldots \ldots \ldots$

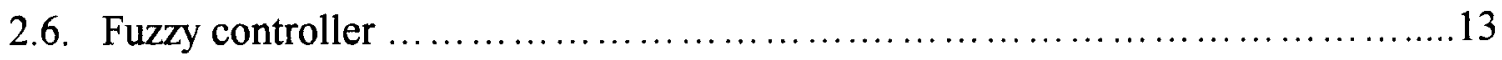

2.7. Membership function composition for inputs of FLC ...................... 14

2.8. Selection of control strategy high and low SOC parameters based on battery internal resistance curves for parallel vehicles ...................... 15

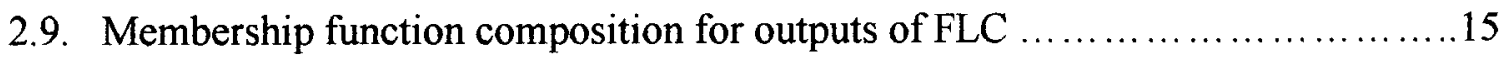

2.10. Example scenario for the supervisory hybrid vehicle fuzzy controller ............16

2.11. Implied fuzzy sets corresponding to each pertinent rule.................... 19

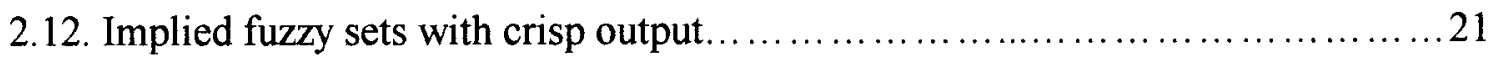

3.1. Parallel configured simulink block diagram........................... 23

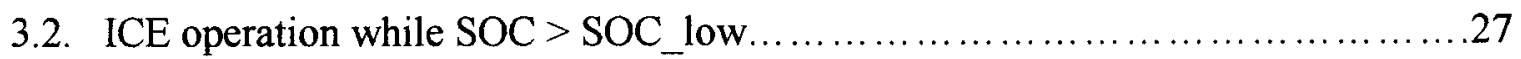

3.3. ICE operation while $\mathrm{SOC}<\mathrm{SOC}$ low................................ 28 
3.4. Advisor parallel simulink block diagram with FLC block .....................29

3.5. Inner workings of fuzzy logic control strategy subsystem .....................30

3.6. Inner workings of fuzzy logic controller subsystem......................... 32

3.7. Addition of Fuzzy_logic_PTC to powertrain controller pull-down menu.

3.8. Fuel converter operation plot showing addition of highest efficiency and $1 \mathrm{~g} / \mathrm{s}$ fuel use line

4.1. Advisor GUI displaying component configuration of efficiency mode example. .39

4.2. ICE operating points for FLC efficiency mode in city .40

4.3 State of charge history for FLC efficiency mode in city .40

4.4 ICE operating points for FLC efficiency mode on highway

4.5 State of charge history for FLC efficiency mode on highway

4.6. ICE operating points for FLC efficiency mode in city.

4.7. State of charge history for FLC efficiency mode in city

4.8. ICE operating points for FLC efficiency mode on highway

4.9. State of charge history for FLC efficiency mode on highway

4.10. Component configuration of 1999 OSU future car

4.11. ICE operating points for FLC efficiency mode in city.

4.12. State of charge history for FLC efficiency mode in city .45

4.13. ICE operating points for FLC efficiency mode on highway

4.14. State of charge history for FLC efficiency mode on highway .45

4.15. Fuel converter operation for the FLC in the fuel use mode over FUDS drive cycle. 
4.16. State of charge history for FLC in the fuel use mode over FUDS

Drive cycle.

4.17. Fuel converter operation for the FLC in the fuel use mode over

HWFET drive cycle.

4.18. State of charge history for FLC in the fuel use mode over HWFET

Drive cycle.

4.19 Fuel converter operation for the FLC in the fuel use mode over FUDS drive cycle.

4.20. State of charge history for FLC in the fuel use mode over FUDS

Drive cycle.

4.21 Fuel converter operation for the FLC in the fuel use mode over HWFET drive cycle.

4.22 State of charge history for FLC in the fuel use mode over HWFET

Drive cycle.

4.23 Fuel converter operation for the FLC in the fuel use mode over FUDS drive cycle.

4.24 State of charge history for FLC in the fuel use mode over FUDS

Drive cycle

4.25 Fuel converter operation for the FLC in the fuel use mode over

HWFET drive cycle.

4.26 State of charge history for FLC in the fuel use mode over HWFET

Drive cycle 51

5.1. Simulink/dSpace block diagram of OSU future car supervisory controller 53

5.2. Normalization subsystem .55

5.3. Dynamic effect of filter on accelerator pot signal. 59 


\section{CHAPTER 1}

\section{INTRODUCTION}

\subsection{Motivation}

At this day in time the world greatly depends on fossil fuels for its primary source of energy. One of the greatest consumers of these fuels is the automobile. A major goal of the United State's government is to produce an automobile that can achieve 80 miles per gallon in order to preserve these resources. Another major concern of the U.S. government is the degradation in the quality of the environment caused by pollution from automobile emissions. Until zero emission alternative fuel vehicles that do not consume fossil fuels become a reality much attention has been given to hybrid vehicles for a shortterm solution to these problems $[6,9]$.

Parallel hybrid electric vehicles (HEV) typically have a powertrain that includes an internal combustion engine and an electric machine [1]. Both components are directly connected to the driveline (transmission). This means that either unit is capable of providing propulsion to the automobile. Without a good supervisory control strategy, initial tests have shown that HEV's can accomplish this task only for a limited period of time, basically until the energy from the battery packs is depleted [3]. With the proper 
charge sustaining control strategy these vehicles have the potential to achieve a much higher fuel economy and produce fewer emissions than modern day conventional vehicles. The potential exists for improved fuel economy because a vehicle with an energy storage system can allow for kinetic energy normally dissipated through braking to be retrieved through regeneration. The use of a load-leveling device, such as an electric motor, would also allow the internal combustion engine to operate more efficiently. In addition, the electric motor would reduce vehicle emissions by preventing the ICE from operating at points that produce a large amount of pollutants.

One of the major problems associated with HEV's is the coordination of the separate powertrain components. The difficulty with control implementation is the highly nonlinear, time varying nature of the plant. These characteristics introduce the need for intelligent control techniques, such as fuzzy logic, to compensate for the nonlinear behavior of the plant.

\subsection{Thesis Outline}

The work conducted in this thesis of a research contract with the National Renewable Energy Laboratory. It deals with the intelligent control of a parallel hybrid electric vehicle powertrain. The outline is as follows; Chapter 2 describes the control strategies to be implemented in simulation and on the 1999 OSU hybrid vehicle. The simulator used is the National Renewable Energy Laboratory's advanced vehicle simulator, Advisor. Several control strategies are presented and a fuzzy logic feedback control system is introduced. In addition, a basic overview of fuzzy logic control is 
included. It contains a detailed example of a fuzzy controller implemented in Advisor and on the OSU Future Car.

Chapter 3 discusses the parallel-configured simulink block diagram of Advisor. It describes NREL's parallel electric assist control strategy as well. Also a discussion of the modifications made to Advisor in order to implement the fuzzy logic control schemes is discussed in detail.

Chapter 4 presents the simulation results for the various control startegies. The results of the implementation are compared to the existing control strategy of Advisor and to a conventional vehicle. Chapter 5 contains information on the physical implementation of the fuzzy logic controller on the 1999 OSU Future Car. It contains a description of the dSpace control software used as well as any environmental issues that hindered real time control. Appendix B is a collection of all the C-code used for the control implementation in Advisor and dSpace. The $\mathrm{m}$-files created or changed in order to modify Advisor are included in appendix A. 


\section{CHAPTER 2}

\section{CONTROL STRATEGY}

One advantage of hybrid powertrains is their ability to load level. Load leveling is used to reduce the peak load on the ICE with the use of an electric motor. Figure 2.1 shows the average power requirements on a full size vehicle over one Federal Urban Driving Schedule (FUDS) drive cycle. It depicts the parallel hybrid load-leveling concept. The high spikes in power demand above the average power line will be shaven off with assistance from the electric motor [10]. Peak shaving has the potential to reduce the amount of fuel the ICE consumes and the amount of harmful emissions it produces.

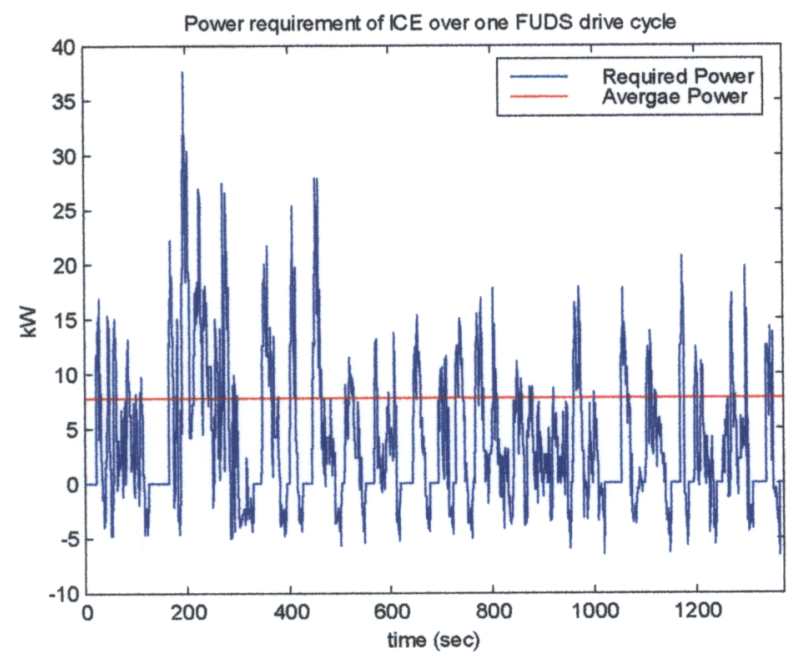

Figure 2.1 Hybrid peak shaving conceptualization in urban drive cycle 
This chapter presents two control strategies that incorporate load leveling for ICE dominated hybrid electric vehicles. Both command the ICE to run in certain regimes. The control policy referred to, as the efficiency mode will force the ICE to run at its peak point of efficiency. The second scheme referred to, as the fuel use mode will prevent the ICE from operating above its $1 \mathrm{~g} / \mathrm{s}$ fuel use line. In addition, this chapter will present a fuzzy logic overview to acquaint the reader with the means by which these control strategies will be implemented.

\subsection{EFFICIENCY MODE}

The second control strategy, the efficiency mode, will force the ICE to run at a peak point of efficiency $[3,11]$. During a normal drive cycle the ICE will be operated at various points on the efficiency map. The preponderance of these operating points will be off from the point of best efficiency by a certain amount of torque as well as engine speed, and consequently by a certain amount of power.

The idea behind load leveling in an ICE dominated HEV is to move the actual operating point of the engine as close to the point of best efficiency for every possible moment in time during the drive cycle. The resulting power difference will be used up or provided by the electric machine.

For the most part there are four possibilities as to how the actual operating point of the ICE can be located relative to the point of best efficiency. The four scenarios, I, II, III, IV, shown in figure 1 are typical instances [3].

\section{Case 1:}


Engine speed and engine torque output are too low. Increasing the throttle command to the ICE can approach the point of best efficiency. To counteract the resulting increase of ICE power output and to maintain the overall powertrain output at a constant level, preventing undesirable acceleration, the electric machine must operate as a generator.

\section{Case II:}

Engine speed is too low while the engine torque output is too high. Decreasing the throttle command to the ICE can approach the point of best efficiency. To adjust for the decrease in the ICE power output and to maintain the overall powertrain output at a constant level the electric machine must run as a motor.

\section{Case III:}

Engine speed is too high while the engine torque is too low. Increasing the throttle command to the ICE can approach the point of best efficiency. To counteract for the excessive ICE power output and to maintain the overall powertrain output at a constant level the electric machine must run as a generator.

\section{Case IV:}

Both Engine speed and engine torque output are too high. Decreasing the throttle command to the ICE can approach the point of best efficiency. To compensate for the reduction in ICE power output and to maintain the overall powertrain output at a constant level the electric machine must run as a motor. Figure 2.3 along with table 2.1 depicts the operation of the strategy. 


\begin{tabular}{|c|c|c|c|c|}
\hline Case & $\begin{array}{c}\text { Engine } \\
\text { Speed } \omega_{\text {ICE }}\end{array}$ & $\begin{array}{c}\text { Engine } \\
\text { Torque } T_{\text {ICE }}\end{array}$ & $\begin{array}{c}\text { Change in } \\
\text { throttle } \\
\text { command } \Delta \alpha\end{array}$ & $\begin{array}{c}\text { Torque } \\
\text { commanded } \\
\text { from electric } \\
\text { machine } T_{\mathrm{EM}}\end{array}$ \\
\hline I & Too low & Too low & $>0$ & $<0$ \\
\hline II & Too low & Too high & $<0$ & $>0$ \\
\hline III & Too high & Too low & $>0$ & $<0$ \\
\hline IV & Too high & Too high & $<0$ & $>0$ \\
\hline
\end{tabular}

Table 2.1 Qualitative summary of load leveling strategy for a parallel HEV.

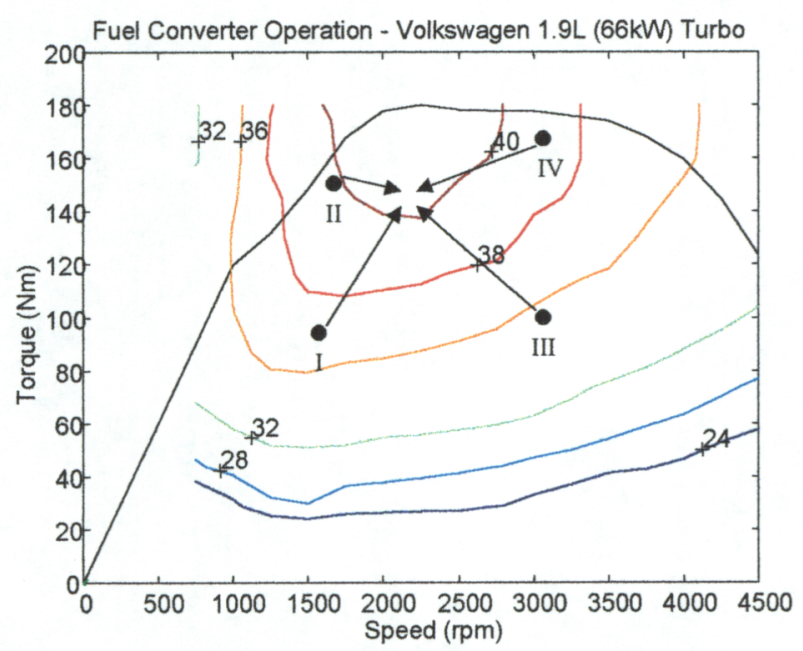

Figure 2.2 Efficiency map illustrating locations of operating points relative to point of highest efficiency

The following calculation will explain when this control strategy will be useful. Assume for a given drive cycle the engine would have the following operating points for a certain amount of time. Figure 4.6 shows the first point is at $10 \mathrm{~kW}$ at $26 \%$ efficiency, the second is $17 \mathrm{~kW}$ at $34 \%$ efficiency, and the third is $20 \mathrm{~kW}$ at $29 \%$. The values of power over efficiency or the amount of fuel consumed, are $40 \mathrm{~kW}, 50 \mathrm{~kW}$, and $69 \mathrm{~kW}$ respectively. Now suppose that the drive cycle requires the engine to operate at $10 \mathrm{~kW}$ for 10 seconds and $20 \mathrm{~kW}$ for 10 seconds. IF the ICE were to operate under these conditions it would consume a total of 1090 Joules of fuel. Now if the engine power were cycled to a constant $17 \mathrm{kw}$ for the entire 20 seconds, with the use of a load-leveling 
device, then only 1000 joules of fuel would be used. Resulting in a saving of 8 percent. Note there is an increase in average power for the load-leveled vehicle from $15 \mathrm{~kW}$ to $17 \mathrm{kw}$. This is necessary in order to maintain the SOC of the battery pack because of the energy storage systems regenerative losses.

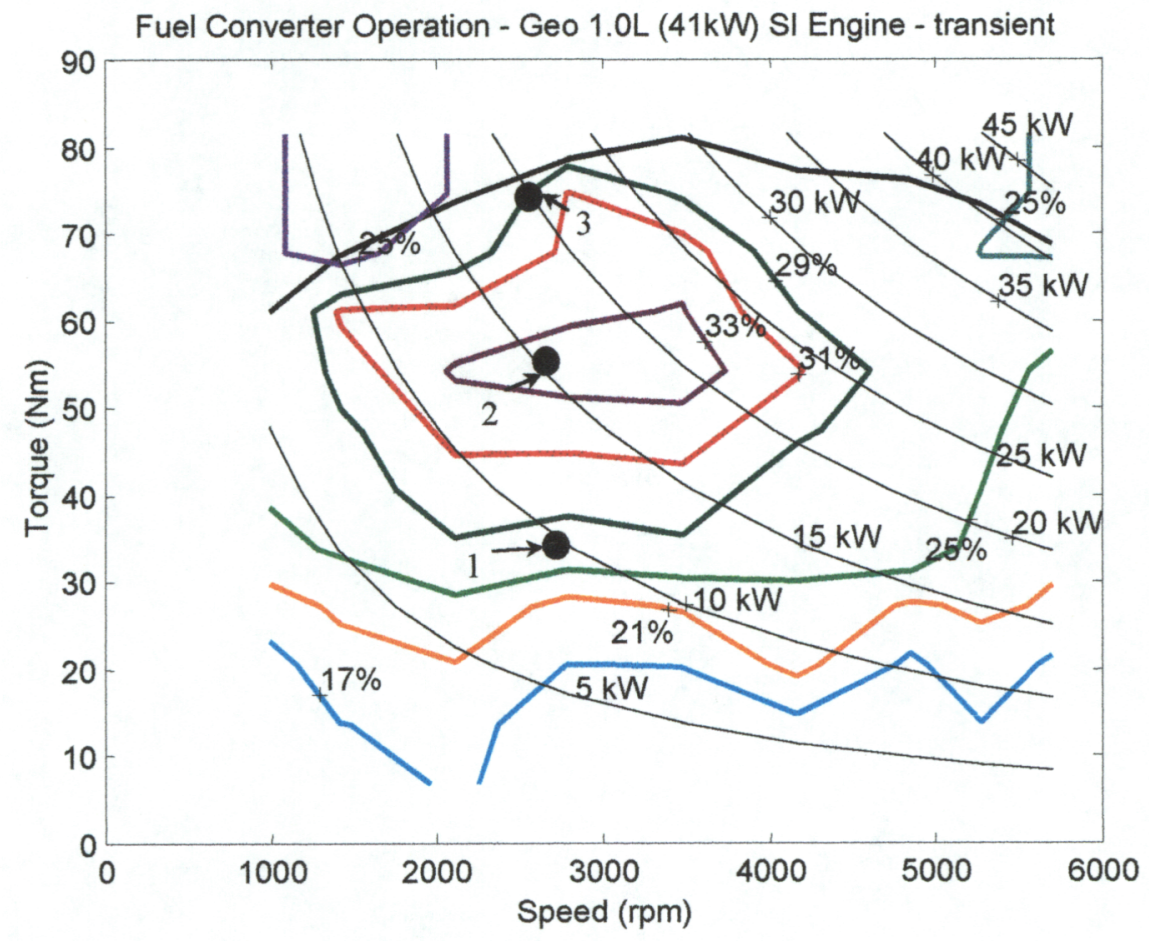

Figure 2.3 Potential benefit of load leveling

\subsection{FUEL USE MODE}

For oversized engines with peak point of efficiencies at or near full load it is unreasonable to load level about the line of highest efficiency. Therefore a simplistic strategy was developed for oversized engines. When driving on the highway the IC engine will output a fraction of its open throttle value because the vehicle does little or no acceleration in this mode, hence using less fuel. On the other hand when a vehicle is 
being driven in the city it is frequently required to operate closer to its full load because of occasional requirements of heavy acceleration. In order to achieve good fuel economy in the city the ICE must be forced to operate as it would on the highway.

When the load required of the ICE, mainly due to acceleration, is high the electric motor will assist. Thus, preventing the ICE from operating at points of high fuel consumption. When required road load is small, equation 2.1 is negative, the electric motor will act as a generator and charge the batteries. This simplified strategy prevents the ICE from operating at points of high fuel consumption.

The idea behind this particular control strategy is not to let the ICE run at an operating point that consumes more than 1 gram of fuel per second. Figure 2.2 depicts this desired operating range for the ICE. Therefore the HEV can use its e-machine to force the engine to operate in a region that consumes less fuel, while maintaining the state of charge (SOC) of the battery pack over the majority of the drive cycle.

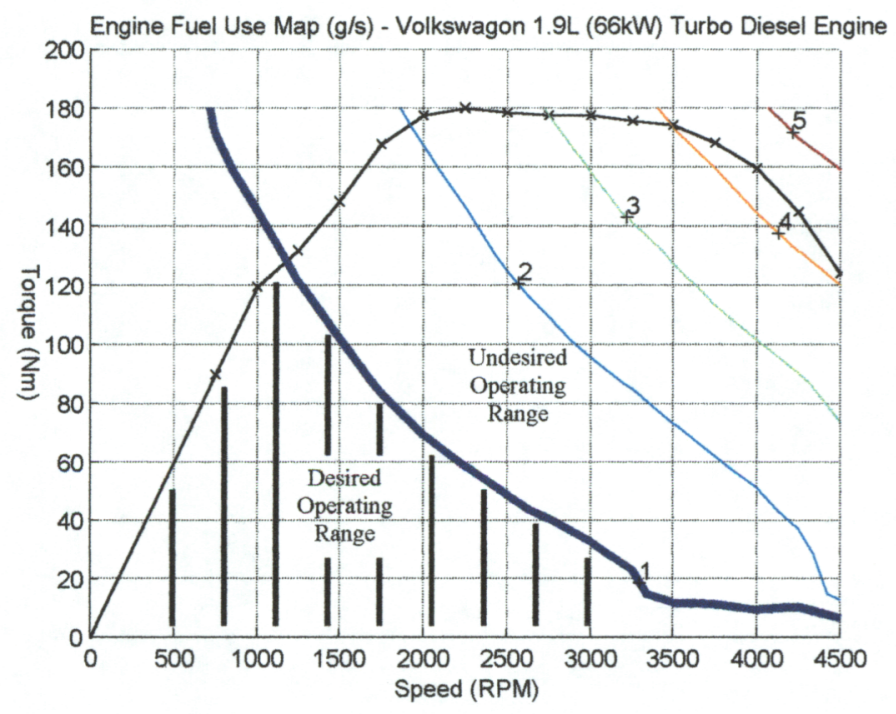

Figure 2.4 Fuel use mode ICE operating regime 
Due to the highly nonlinear, time varying nature of the plant, both control strategies will be implemented with the use of a fuzzy logic controller (FLC). The FLC will use three inputs: $\gamma$, the combination of the throttle $(\alpha)$ and brake $(\beta)$ signals, the battery pack SOC, and the desired e-machine torque. The desired e-machine torque is calculated from the following equation.

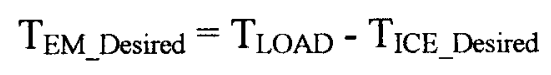

Where $T_{\text {LOAD }}$ is the load required from the drive cycle due to acceleration, drag, road grade, etc., and $\mathrm{T}_{\text {ICE_Desired }}$ is the desired output torque of the ICE. TICE_Desired is defined as either the engines' $1 \mathrm{~g} / \mathrm{s}$ fuel consumption line (fuel use mode), or its maximum efficiency (efficiency mode) at its present rpm. The controller outputs the change of the throttle command, and the operating torque of the e-machine. The generic description of the controller is shown in figure 2.4. A detailed description of the controller is given by Baumann [3]. The FLC will prevent the power in battery packs from being depleted with the use of regenerative braking, and by increasing the throttle command to the ICE while running the e-machine as a generator as $\mathrm{T}_{\mathrm{EM} \_ \text {Desired }}$ long as equation 2.1 is negative.

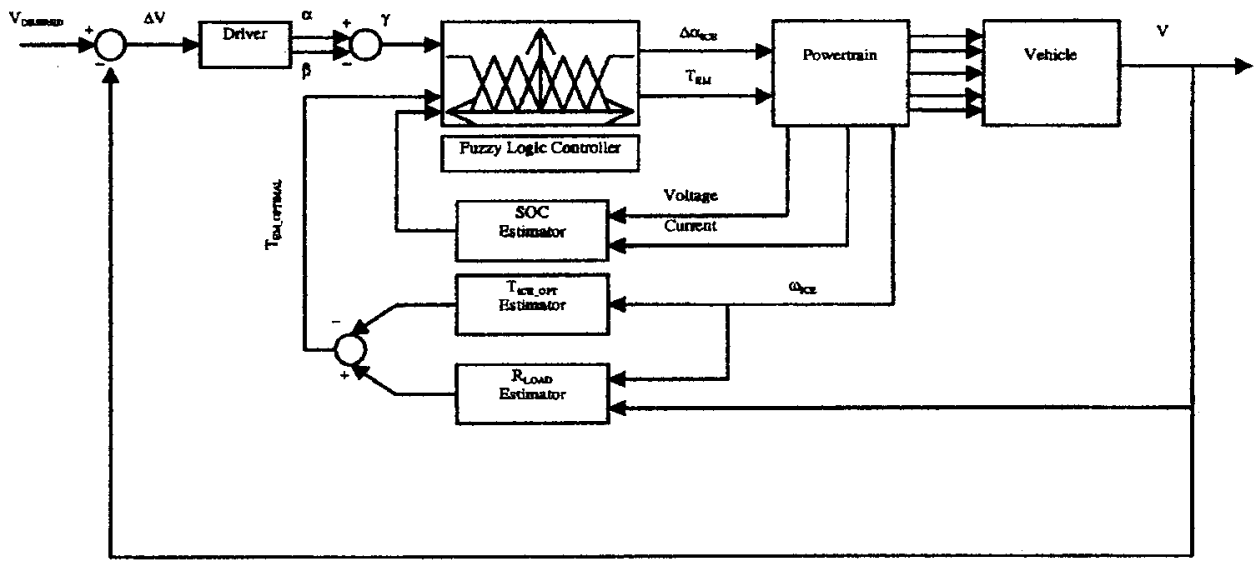

Figure 2.5 Driver - vehicle fuzzy logic feedback control system 


\subsection{Fuzzy Logic Control}

The following overview provides the reader with a basic understanding of fuzzy logic and how it is used in control systems applications. Fuzzy logic control utilizes knowledge based on an expert's perspective on how to control a certain process $[2,4,5]$. The control engineer must have a good understanding of how the closed-loop system should perform and how the physics of the system operate. In constructing a fuzzy controller the designer must be able to identify or determine the control variables. These control variables, otherwise known as linguistic variables, describe the inputs and outputs of the fuzzy controller. A more in-depth and detailed discussion of fuzzy logic control can be found in Passino and Yurkovich [2]. Examples of linguistic variables in a typical feedback control system include the error, change in error, integral of the error, actuation force, voltage, or current. These linguistic variables take on values that change dynamically over time. These values are referred to as linguistic values. For instance, if the inputs to the fuzzy controller are error and the change in the error $\left(e(t), \frac{d e(t)}{d t}\right)$ and the output is a force, $\mathrm{f}(\mathrm{t})$, then each linguistic variable could take on the following values:

$$
\begin{gathered}
\text { "very-large-n" } \\
\text { "large-n" } \\
\text { "small-n" } \\
\text { "zero" } \\
\text { "small-p" } \\
\text { "large-p" }
\end{gathered}
$$




\section{"very-large-p"}

These values are abbreviations to how a human would describe the dynamics of the plant. For any generic controlled process the value "large-n" would represent an error, or change in error, with a large negative magnitude. Also the value "small-p" would represent an error, or change in error, with a small positive magnitude. This same analogy is used for the other abbreviations as well. The linguistic quantification just described is used to create a set of rules based on the knowledge of the expert on how to control the process. The linguistic rules can be precisely quantified since they are founded on abstract human feelings. The general form of the rules are given as:

\section{IF premise THEN consequent}

The entire set of If-Then rules, generally referred to as the rule base, contains the control engineer's complete description on how to control the plant. The rules base for a generic

two input, $\left(e(t), \frac{d e(t)}{d t}\right)$, one output, $f(t)$, system may contain the following rule:

IF the error is "small-n" AND the change in error is "small-n" THEN the force is "large-n"

This means that if the error of the feedback control system is negative small, and the change in error is negative small then the actuation force used to drive the error to zero should be negatively large. Assuming that a negative force is needed to drive the plant to the reference input. The rule base will consist of a finite number of rules covering every possible combination of linguistic values for the input linguistic variables. The direct fuzzy logic controller is also composed of an inference mechanism, a fuzzification interface, and a defuzzification interface. Figure 2.5 shows a block diagram of a direct 
fuzzy controller. The actual operation of each section of the fuzzy controller is understood by the following explanation.

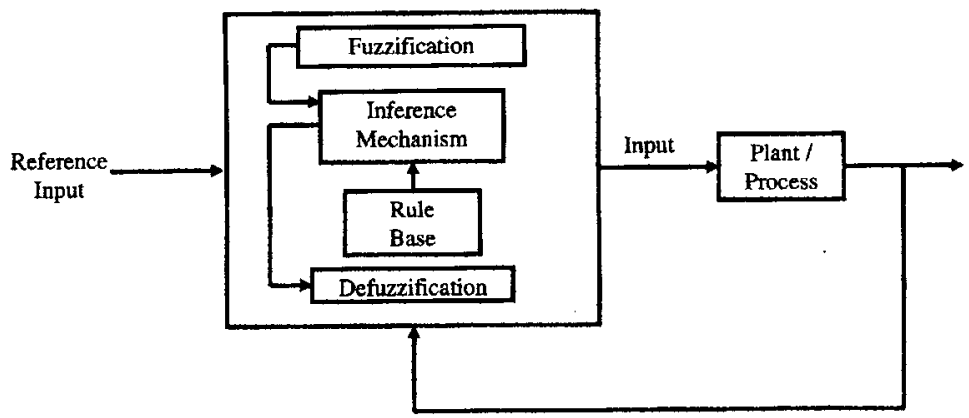

Figure 2.6 Fuzzy controller

In order fully understand how the fuzzy logic controller actually works it is best to examine its structure. Figure 2.6 describes the membership functions makeup for the inputs of the powertrain controller. The first input is the combined throttle and brake signal. The number seven on the horizontal axis denotes the maximum accelerator input, "flooring the gas pedal", and one designates the maximum braking input, "slamming on the brakes". The second input membership function set is used to give certainties to the state of charge of the battery packs, where the outermost edges saturate at .9 for the highest allowable SOC, and .1 for the lowest allowable SOC. The lowest allowable SOC should be assigned a value approximately equal to the lowest SOC corresponding to the minimum charge/discharge resistance of the battery module. The highest allowable SOC should be set to a value less than the SOC at which the charge/discharge resistance increases dramatically. For effective operation, both the minimum charge and the minimum discharge resistances should lie between the highest and lowest allowable SOC [13] as seen in Figure 2.7. 
The third set is used to describe the desired e-machine torque. Negative one designates the highest degree of running it as a generator, and one stands for operating it at its maximum potential as a motor. The linguistic descriptions used for this particular system are also seen in figure 2.6, i.e. pos_one, pos_two, etc.

Figure 2.8 also depicts the organization of the outputs for the FLC in terms of its membership functions. The first output is the actual change in the throttle command. It spans from -1.2 to 1.2 , where negative one means decrease the throttle as much as possible and positive one stands for increasing the throttle as much as possible. The second output is the actual e-machine torque and is quantitatively the same as the desired e-machine torque in figure 2.8. The rule base consists of 847 rules, these are needed for every possible combination of input membership functions $(7 \times 11 \times 11)$. Now that the structure of the controller has been illustrated, a demonstration of each of the fuzzy components will better explain its operation.
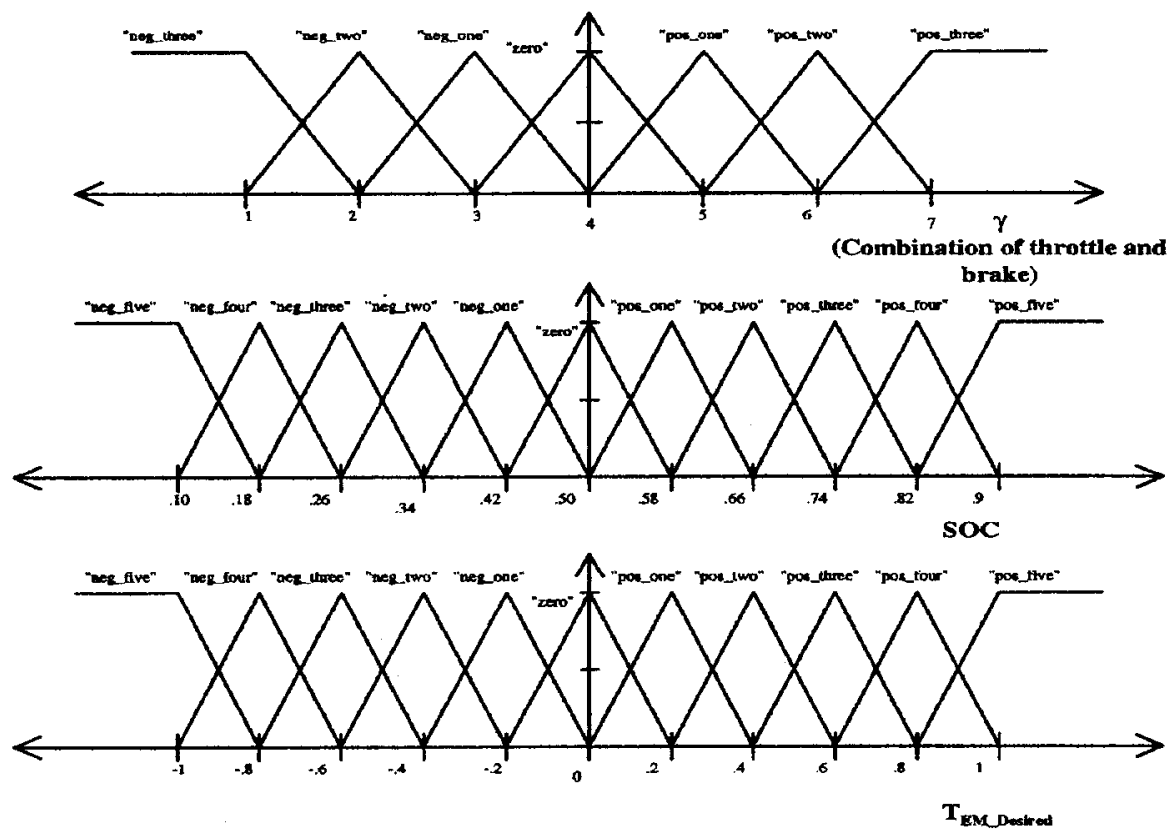

Figure 2.7 Membership function composition for inputs of FLC 


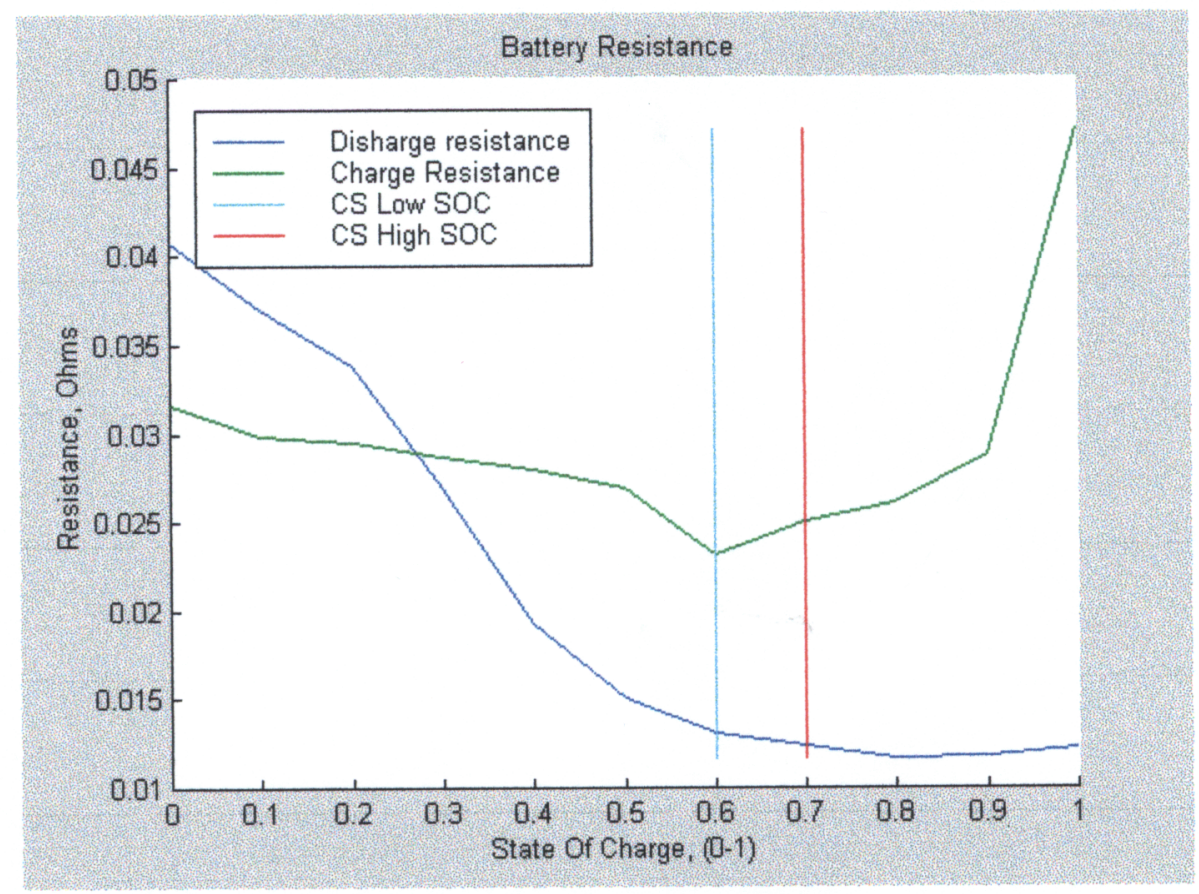

Figure 2.8 Selection of control strategy high and low SOC parameters based on battery internal resistance curves for parallel vehicles

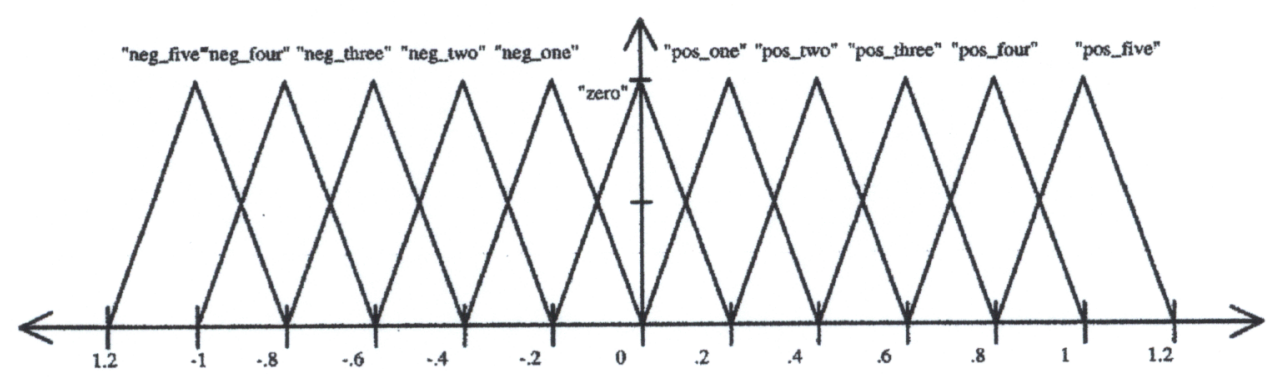

$\Delta \alpha$

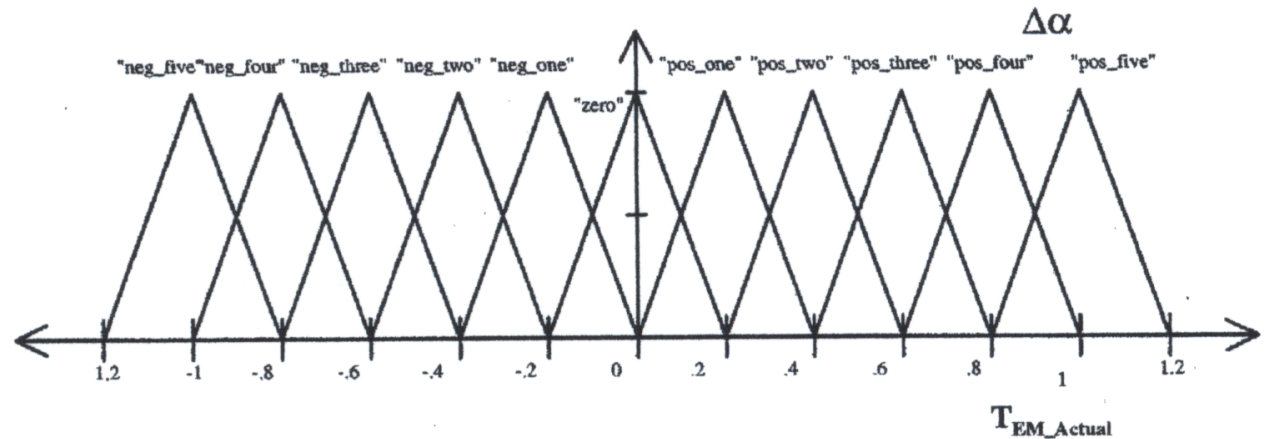

Figure 2.9 Membership composition for outputs of FLC 


\subsubsection{Fuzzification}

Fuzzification takes the input data for each linguistic variable, in this case $\gamma, \mathrm{SOC}$ and $\mathrm{T}_{\mathrm{EM}}$ Desired, and, finds the certainty value for each of the input membership functions. For example figure 2.9 shows an instant in time during the drive cycle where the input throttle command is 6.25 , the state of charge of the battery packs is .77 , and the desired emachine torque is -0.3 ( $\%$ of its maximum value).
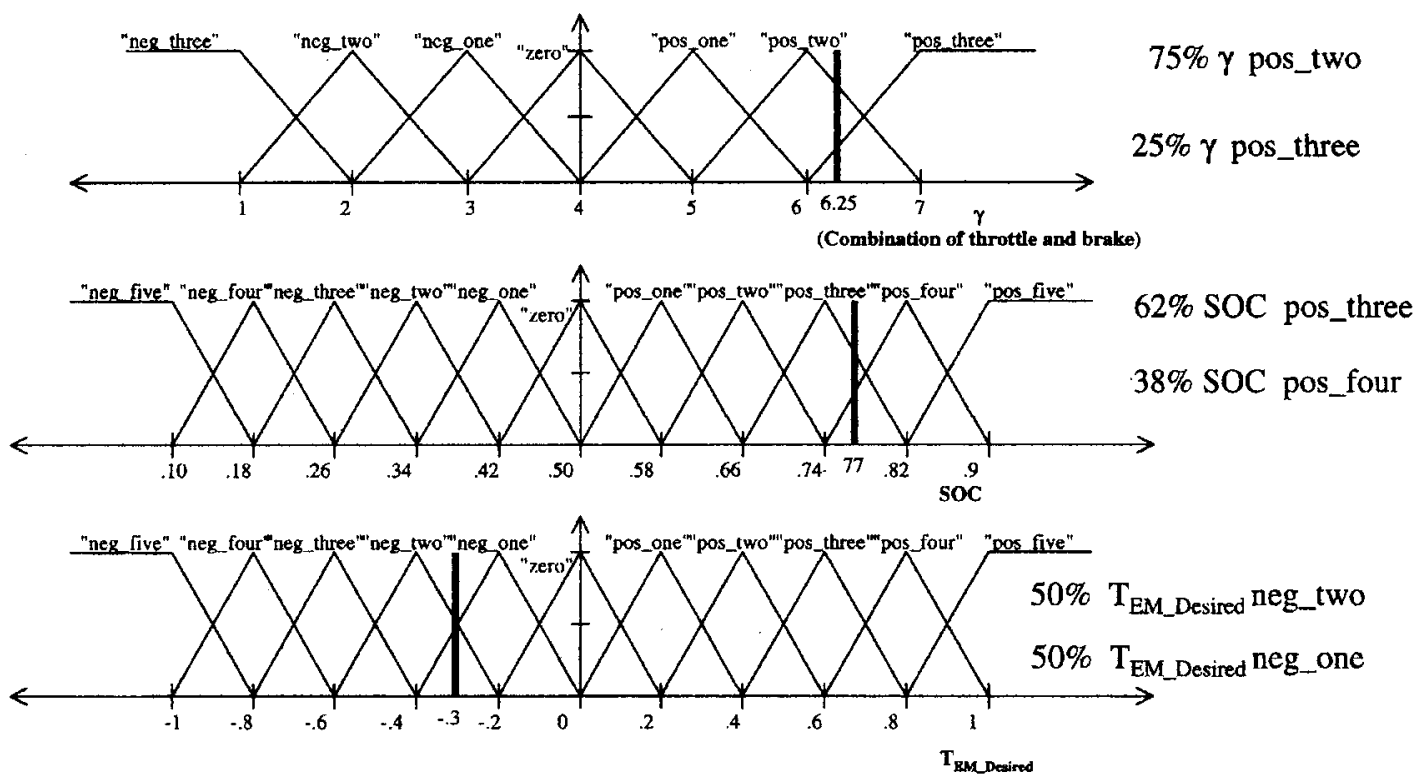

Figure 2.10 Example scenario for the supervisory hybrid vehicle fuzzy controller

The input line crosses the pos_two membership function at 0.75 and it crosses the pos three membership function at 25 . The fuzzification of the input variables would tell us that we are $75 \%$ certain that $\gamma$ is pos_two, meaning the driver wants to accelerate moderately, and $25 \%$ certain that $\gamma$ is pos three, the driver wants to accelerate heavily. For the SOC membership function one is $62 \%$ certain that the SOC is pos_three, and $38 \%$ certain that it is pos four. Therefore one is pretty sure that there is a very high SOC in 
the battery pack. Lastly the FLC is $50 \%$ certain that $\mathrm{T}_{\mathrm{EM}}$ Desired is neg two, $40 \%$ of its maximum negative torque capability, and $50 \%$ certain that it is neg_one, $20 \%$ of its maximum negative torque capability.

\subsubsection{Inference Mechanism}

The inference mechanism consists of two steps. The first one to take place is known as matching. It identifies which rules are on or which rules pertain to the current situation. Before establishing which rules are relevant, a measure of the meaning of the premises of the rules is needed. In other words the logical "and" operation needs to be quantified. The two most common methods are known as the minimum and the product. The minimum procedure uses the minimum of the three membership function certainties whereas the product multiplies the certainties together. Each rule is then said to be on at

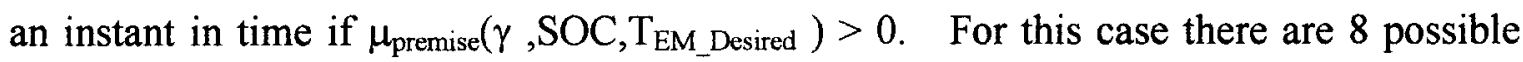
rules that are on.

1) If $\gamma$ is "pos_two" and the SOC is "pos_three" and $T_{E M}$ Desired is "neg_one" Then $\Delta \alpha$ is "zero" and TEM_Actual is "zero".

2) If $\gamma$ is "pos_two" and the SOC is "pos_three" and TEM_Desired is "neg_two" Then $\Delta \alpha$ is "zero" and T TE__Actual is "zero".

3) If $\gamma$ is "pos_two" and the SOC is "pos_four" and TEM_Desired is "neg_one" Then $\Delta \alpha$ is "neg_five" and $T_{E M \_A c t u a l}$ is "pos_five".

4) If $\gamma$ is "pos_two" and the SOC is "pos_four" and TEM_Desired is "neg_two Then $\Delta \alpha$ is

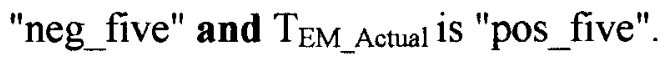


5) If $\gamma$ is "pos_three" and the SOC is "pos_three" and T TEM_Desired is "neg_one" Then $\Delta \alpha$ is "zero" and T TE_Actual is "zero".

6) If $\gamma$ is "pos_three" and the SOC is "pos_three" and $T_{\mathrm{EM}}$ Desired is "neg_two" Then $\Delta \alpha$ is "zero" and T $\mathrm{EM}_{-}$Actual is "zero"

7) If $\gamma$ is "pos_three" and the SOC is "pos_four" and TEM_Desired is "neg_one" Then $\Delta \alpha$ is "zero" and T

8) If $\gamma$ is "pos_three" and the SOC is "pos_four" and $\mathrm{T}_{\mathrm{EM} \_ \text {_esired }}$ is "neg_two" Then $\Delta \alpha$ is "zero" and T $T_{E M}$ Actual is "zero".

Once the matching process is carried out the second component of the inference mechanism establishes the conclusions from each pertinent rule at particular instant in time. The recommendation of each applicable rule will give the implied fuzzy sets. Using the minimum to represent the premise we have:

$$
\begin{aligned}
& \mu_{\text {premise(1) }}=\min \{.75, .62, .5\}=.5 \\
& \mu_{\text {premise(2) }}=\min \{.75, .62, .5\}=.5 \\
& \mu_{\text {premise(3) }}=\min \{.75, .38, .5\}=.38 \\
& \mu_{\text {premise(4) }}=\min \{.75, .38, .5\}=.38 \\
& \mu_{\text {premise(5) }}=\min \{.25, .62, .5\}=.25 \\
& \mu_{\text {premise(6) }}=\min \{.25, .62, .5\}=.25 \\
& \mu_{\text {premise(7) }}=\min \{.25, .38, .5\}=.25 \\
& \mu_{\text {premise(8) }}=\min \{.25, .38, .5\}=.25
\end{aligned}
$$


The membership functions for the inferences reached from rules 1 through 8 , the "implied fuzzy sets", are the conclusions that are implied by each rule. Each set, denoted by $\mu_{\text {rule\# }}$,is shown in figure 2.10 and are given by the following:

$$
\begin{aligned}
& \mu_{1(\Delta \alpha)}=\min \left\{.5, \mu_{\text {zero }}(\Delta \alpha)\right\}=.5 \quad \mu_{1\left(\text { TEM_Actual }_{1}\right)}=\min \left\{.5, \mu_{\text {zero }}\left(\mathrm{T}_{\mathrm{EM}_{-} \text {Actual }}\right)\right\}=.5 \\
& \mu_{2(\Delta \alpha)}=\min \left\{.5, \mu_{\text {zero }}(\Delta \alpha)\right\}=.5 \quad \mu_{2(\text { IEM_Actual })}=\min \left\{.5, \mu_{\text {zero }}\left(\mathrm{T}_{\mathrm{EM}_{-} \text {Actual }}\right)\right\}=.5 \\
& \mu_{3(\Delta \alpha)}=\min \left\{.38, \mu_{\text {neg_five }}(\Delta \alpha)\right\}=.38 \quad \mu_{3(\text { TEM_Actual })}=\min \left\{.38, \mu_{\text {pos_five }}\left(T_{\text {EM_Actual }}\right)\right\}=.38
\end{aligned}
$$

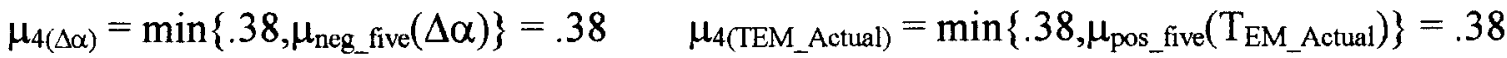

$$
\begin{aligned}
& \mu_{5(\Delta \alpha)}=\min \left\{.25, \mu_{\text {zero }}(\Delta \alpha)\right\}=.25 \quad \mu_{5 \text { (TEM_Actual })}=\min \left\{.25, \mu_{\text {zero }}\left(T_{\text {EM_Actual }}\right)\right\}=.25 \\
& \mu_{6(\Delta \alpha)}=\min \left\{.25, \mu_{\text {zero }}(\Delta \alpha)\right\}=.25 \quad \mu_{6(\text { TEM_Actual })}=\min \left\{.25, \mu_{\text {zero }}\left(\text { TEM_Actual }_{\text {TEM }}\right)\right\}=.25 \\
& \mu_{7(\Delta \alpha)}=\min \left\{.25, \mu_{\text {zero }}(\Delta \alpha)\right\}=.25 \quad \mu_{7 \text { (TEM_Actual })}=\min \left\{.25, \mu_{\text {zero }}\left(T_{\text {EM_Actual } \left._{-}\right)}\right)=.25\right. \\
& \mu_{8(\Delta \alpha)}=\min \left\{.25, \mu_{\text {zero }}(\Delta \alpha)\right\}=.25 \quad \mu_{8(\text { TEM_Actual })}=\min \left\{.25, \mu_{\text {zero }}\left(T_{E_{-}} \text {EMctual }\right)\right\}=.25
\end{aligned}
$$
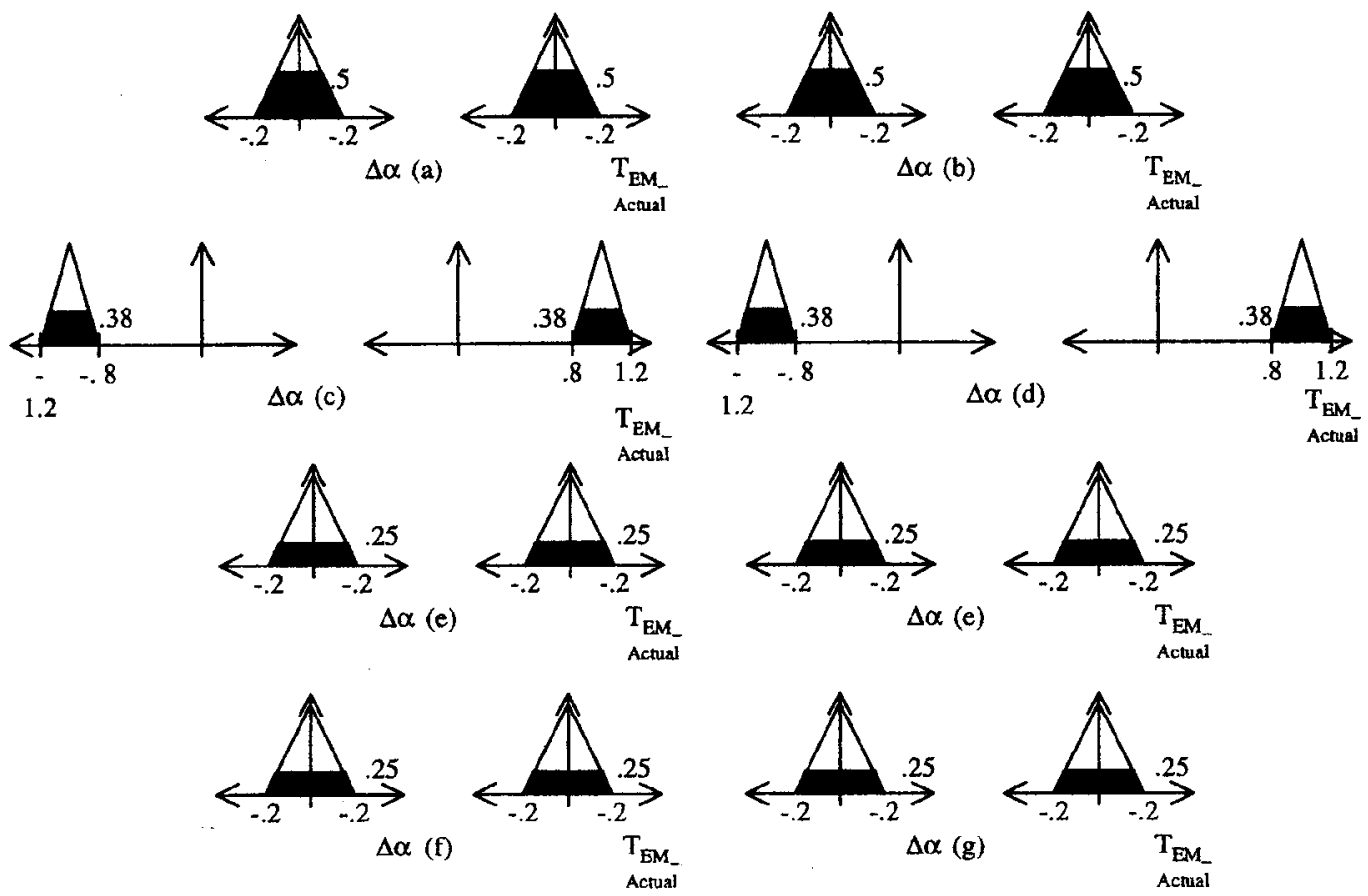

Figure 2.11 Implied fuzzy sets corresponding to each pertinent rule 


\subsubsection{Defuzzification}

The next step is defuzzification, which takes the conclusions reached by each rule that is on and converts them into one action. Defuzzification is achieved by combining the recommendations from the implied fuzzy sets. This is achieved via the center of gravity method [2]. This technique calculates the crisp control output based on the area under the implied fuzzy sets. It is defined as:

$$
\text { crisp }=\frac{\sum_{\mathrm{i}} \mathrm{b}_{\mathrm{i}} \int \mu_{(\mathrm{i})}}{\sum_{\mathrm{i}} \int \mu_{(\mathrm{i})}}
$$

where $\int \mu_{(i)}$ is the area underneath the output membership function, and $b_{i}$ is the center of the output membership function for the consequent of rule (i).

Figure 2.11 shows the sets on one axis to better convey the COG method. Notice that there are eight implied fuzzy sets, but only two of them appear in figure 2.10. This is because rules $\left(\mu_{5} \rightarrow \mu_{8}\right)$ and $\left(\mu_{1} \rightarrow \mu_{2}\right)$ have the same implied set $\left(\mu_{\text {zero }}\right)$. Since the height of the implied set for $\mu_{1}$ and $\mu_{2}$ is larger, it shows up in the figure. The remaining two rules, $\mu_{3}$ and $\mu_{4}$ also have the same implied sets $\left(\mu_{\text {neg_f }_{-}}\right)$and $\left(\mu_{\text {pos_five }}\right)$. In this scenario all eight rules are employed. Also note that the COG method will never allow a crisp output to exceed the limit of $-1<\Delta \alpha^{\text {crisp }} / \mathrm{T}_{\mathrm{EM}}$ Actual $^{\text {crisp }}<1$, even though the output membership functions have exceeded this range. $\Delta \alpha$ and TEM_Actual are calculated as follows: 


$$
\begin{gathered}
\Delta \alpha=\frac{\frac{1}{2}[2(0)(.5)(.4+.2)+4(0)(.25)(.4+.3)+2(-1)(.38)(.4+.248)]}{\frac{1}{2}[2(.5)(.4+.2)+4(.25)(.4+.3)+2(.38)(.4+.248)]}=-.28 \\
T_{E M_{-} \text {Actual }}=\frac{\frac{1}{2}[2(0)(.5)(.4+.2)+4(0)(.25)(.4+.3)+2(1)(.38)(.4+.248)]}{\frac{1}{2}[2(.5)(.4+.2)+4(.25)(.4+.3)+2(.38)(.4+.248)]}=.28
\end{gathered}
$$
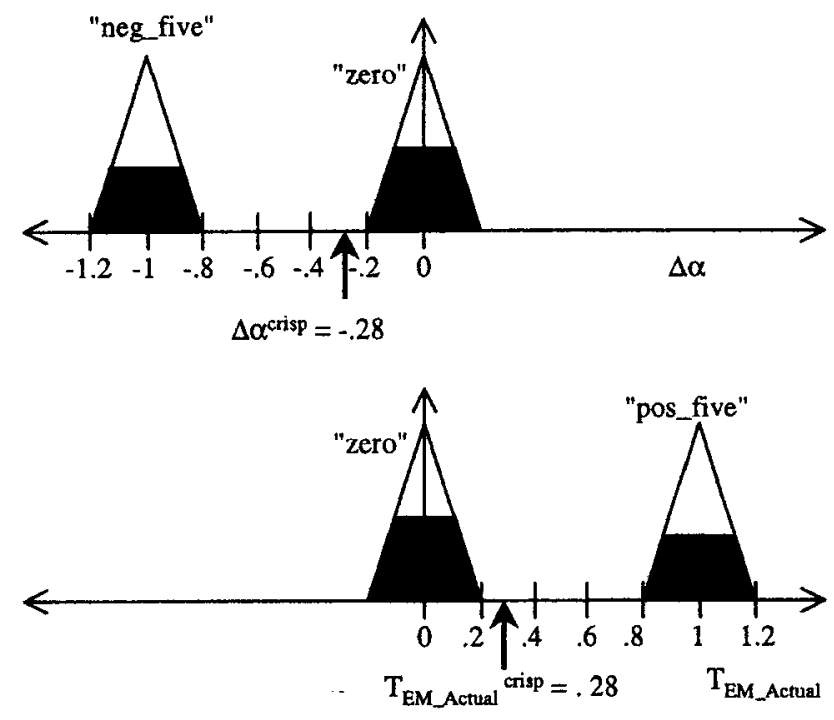

Figure 2.12 Implied fuzzy sets with crisp output 


\section{CHAPTER 3}

\section{CONTROL IMPLEMENTATION IN ADVISOR}

The first task of this research project was to implement the proposed fuzzy logic controller in NREL's advanced vehicle simulator, Advisor 2.0.2 [7,13]. This chapter provides a brief description of the simulink block diagram Advisor uses for parallelconfigured hybrids. In addition, it presents a summary of NREL's control strategy, parallel electric assist. Also all the modifications and additions made to the simulator in order to make the fuzzy logic controller compatible with Advisor are discussed.

\subsection{Description of Advisor}

Figure 3.1 is the Advisor simulink block diagram of a parallel configured hybrid electric vehicle. Notice that the majority of the subsystems have two inputs and two outputs. Each block sends on and converts a torque and speed request, and each block also passes an achievable or actual torque and speed.

The top arrows, from left-to-right, are the torque and angular velocity requests. The drive cycle first requests a given speed. Each block between the drive cycle and the fuel converter subsystems computes its required input given its required output by applying losses, speed reductions, and its performance limits. The electric assist control 
strategy block calculates the ICE's required input. It does so by employing the parallel electric assist control strategy discussed in the next section.

Next, the fuel converter uses its required torque output and speed to determine how much torque it can actually deliver and its maximum speed. Then passing information back to the left, each drivetrain component determines its actual output given the existing input, using losses computed during the input requirement pass described above. This information is then passed to the motor controller block that supplies the additional torque requirement of the drive cycle not met by the ICE. Finally, the vehicle block computes the vehicle's actual speed given the tractive force and speed limit it receives, and uses this speed to compute acceleration for the next time step. The sequence continues throughout the duration of the driving cycle. The following paragraphs provide a brief description of the drivetrain component models seen in figure 3.1 that connect to each other in order to build a parallel hybrid vehicle model. A complete explanation is given in the Advisor documentation [13].

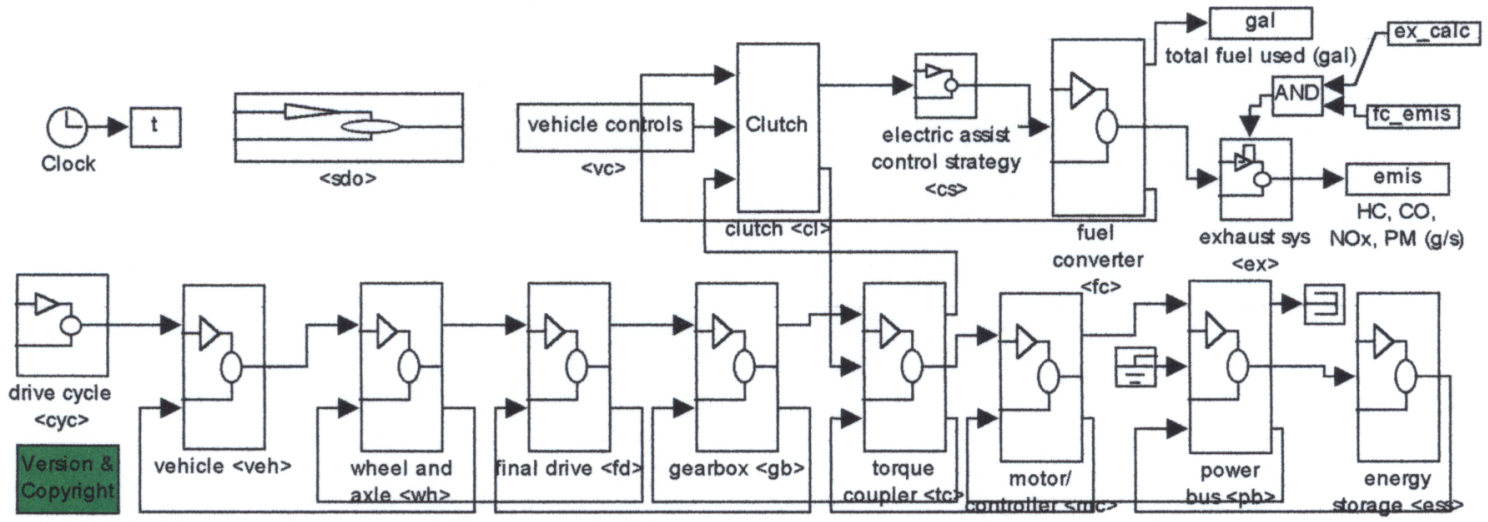

Figure 3.1 Parallel configured simulink block diagram 
The fuel converter model simulates the primary power source for the vehicle. In the case of an internal combustion engine, it is the device that converts the fuel into useable energy (mechanical shaft work) for the drivetrain.

The 'motor/controller' block translates torque and speed requests into electric power requests and converts actual power input to torque and speed output. The 'power bus' then requests power from, or distributes power to the e-machine and takes the balance from the energy storage system.

The 'energy storage system' block represents the battery pack that stores energy on board the hybrid electric vehicle. This block accepts a power request from the power bus and returns the available and actual power output from the battery, the battery voltage and current, and calculates the battery state of charge (SOC).

The 'torque coupler' block represents a belt or chain drive whereby two torque sources combine their torque's to provide to a drivetrain component such as the gearbox. The torque coupler block diagram processes a torque and speed request from the downstream drivetrain components and allocates requests of the ICE and electric machine torque sources.

The 'clutch' block generally transmits torque and speed requests from the 'gearbox' or, in the case of a parallel hybrid, the torque coupler, to the ICE. It also transmits the actual torque and speed from the ICE 'fuel converter' back to the 'torque coupler.' This block is useful wherever the vehicle control needs to interrupt torque transmission from one component to another. The vehicle controls block determines whether the clutch should be fully engaged, fully disengaged, or slipping--transmitting torque while the two sides of the clutch spin at different speeds. 
The 'gearbox' of a multi-speed transmission house gears of different gear ratios that are used to transmit torque from the engine or tractive motor to the final drive and on to the wheels. Thus it permits a number of discrete speed reductions and torque multiplication factors. The gearbox is also controlled by the vehicle controls subsystem. By modeling a driver who chooses a gear based on engine load and speed and moves the gearshift lever accordingly. Thus, generating a gear ratio command and passing it to the gearbox.

The 'final drive' block transmits torque and speed requests from the 'wheel and axle' to the 'gearbox'. It also transmits the actual torque and speed from the 'gearbox' back to the 'wheel and axle.' The 'wheel and axle' block then transmits torque and speed requests from the vehicle block, which represents the tire patch, to the 'final drive'. It also transmits actual torque and speed from the 'final drive' back to the tire patch.

Calculations in the 'vehicle' block are representative of the force balance at the tire patch. Given a speed required at the end of the time step, the tractive force and required speed averaged over the time step are requested of the wheel. Given an available tractive force and speed limit, the actual/achieved speed is computed. The vehicle controls clock also contains a traction control block that ensures the tractive force and linear speed required at the tire patch are consistent with the traction limit of the tires. That is, no more force, either positive (accelerating) or negative, will be requested than can be provided by the tire without its 'peeling out' or skidding. Also, no greater change in speed, either positive or negative, will be requested than can be caused by the limited force requirement. 
Lastly, the 'vehicle controls' block also contains the braking strategy: braking force required of front brakes $(\mathrm{N})$ and the 'front and rear brake controller (achievable)' blocks. Although not shown, this first subsystem determines how much braking force is requested of the front brakes. The balance of the required tractive force will be made up by the drivetrain to the best of its ability. Then 'front and rear brake controller (achievable)' block establishes how much braking force will be supplied by the front and rear brakes by taking into account what total braking force is required and how much braking the drivetrain is able to do.

\subsection{Parallel Electric Assist Control Strategy}

This control approach utilizes the electric machine to assist the ICE when additional driving torque is required while maintaining the state of charge in the battery packs. The conditions under which the e-machine operates is twofold. One set of rules regulates its usage while the SOC of the battery pack is above the lowest allowable limit, and one set of rules manages its running when the SOC is below the lowest acceptable limit. The highest and lowest allowable limits are dependent on the modules charging and discharging properties, which are both functions of SOC.

The following events describe the operation of the hybrid vehicle while the SOC of the batteries is above the lower threshold. If the vehicle is below a certain speed referred to as the electric launch speed, it will operate as a Zero Emissions Vehicle (ZEV). That is the e-machine will provide all of the required driving torque up to that defined velocity. The shaded area labeled engine off in figure 3.2 illustrates the electric launch speed converted to an engine rpm. Secondly, the e-machine will be used for 
torque assist if the required torque of the drive cycle is greater than the open throttle torque capability of the ICE, labeled as the maximum torque envelope in figure 3.2. Thirdly, if the torque requirement of the ICE would cause the engine to run inefficiently the engine will be turned off and the e-machine will supply the present torque request. This situation is depicted as the shaded area underneath the off torque envelope in figure 3.2 .

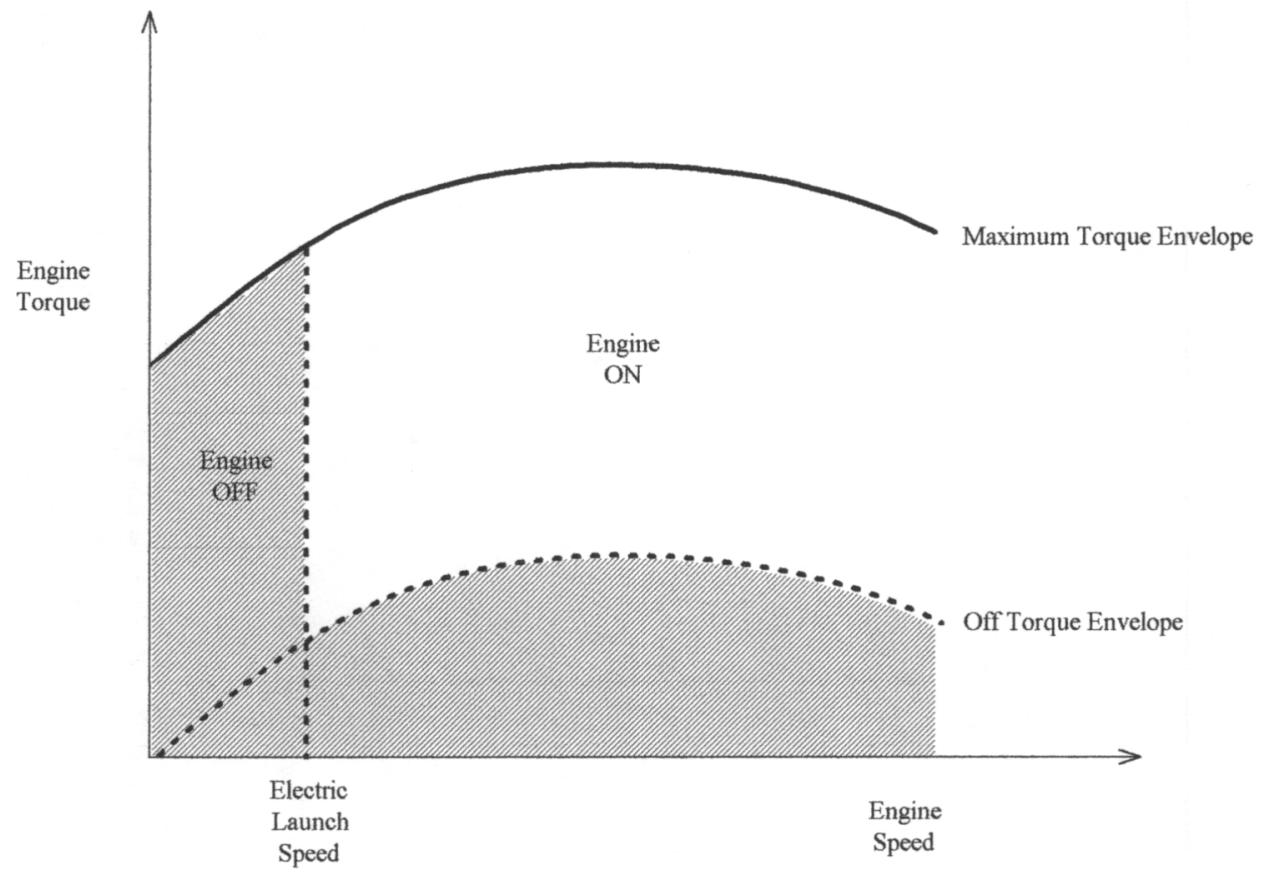

Figure 3.2 ICE operation while SOC $>$ SOC_low

The next set of rules describe the vehicle's operation while the battery SOC is below the lower limit referred to as SOC_low. The e-machine will not run as a motor it will run as a generator. The engine will add a user defined excess torque that the emachine will utilize to charge the battery module. Figure 3.3 depicts the two possible 
operating cases when the SOC is below the lower threshold. The point labeled 1 shows and instant where the additional torque request has been added to charge the battery pack. However point two shows one constraint to this rule. If the additional charge torque is not enough to allow the engine to operate above the off torque envelope, the engine will be commanded to supply slightly more torque so that it will run just above the off torque line. This prevents the engine from running inefficiently while the e-machine is being used load level. Lastly both control modes incorporate regenerative braking.

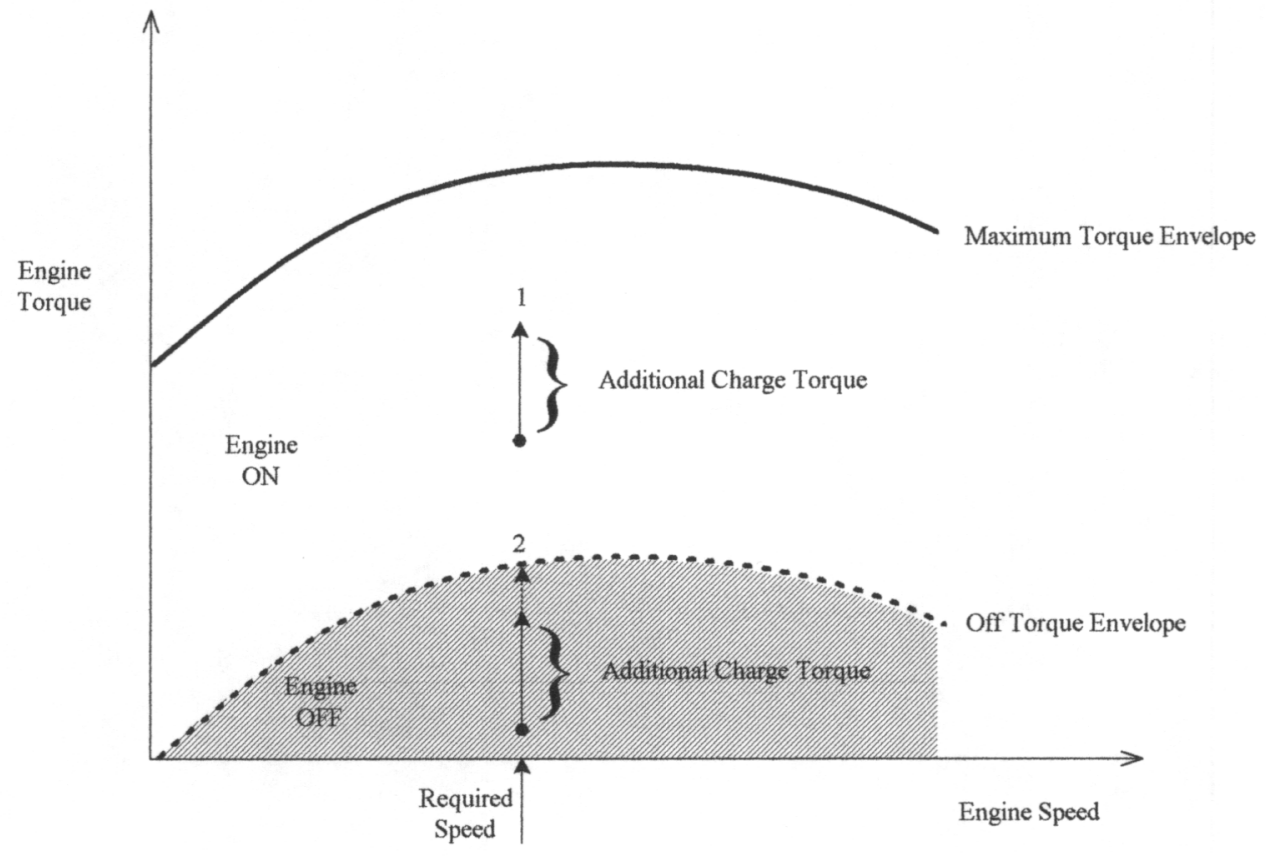

Figure 3.3 ICE operation while SOC $<$ SOC_low

\subsection{Description of Fuzzy Logic Control Strategy Block}

Figure 3.4 shows the parallel-configured simulation block diagram where the new Fuzzy Logic Control Strategy subsystem has been substituted for the electric assist control strategy block. Figure 3.5 illustrates the inner workings of the FLCS block. The 
only direct input into the subsystem, as seen in figure 3.4 , is the torque and speed required of the ICE that meets the need of the drive cycle. Since there is no control action taken on the rpm of the engine it is directly fed through to the fuel converter block.

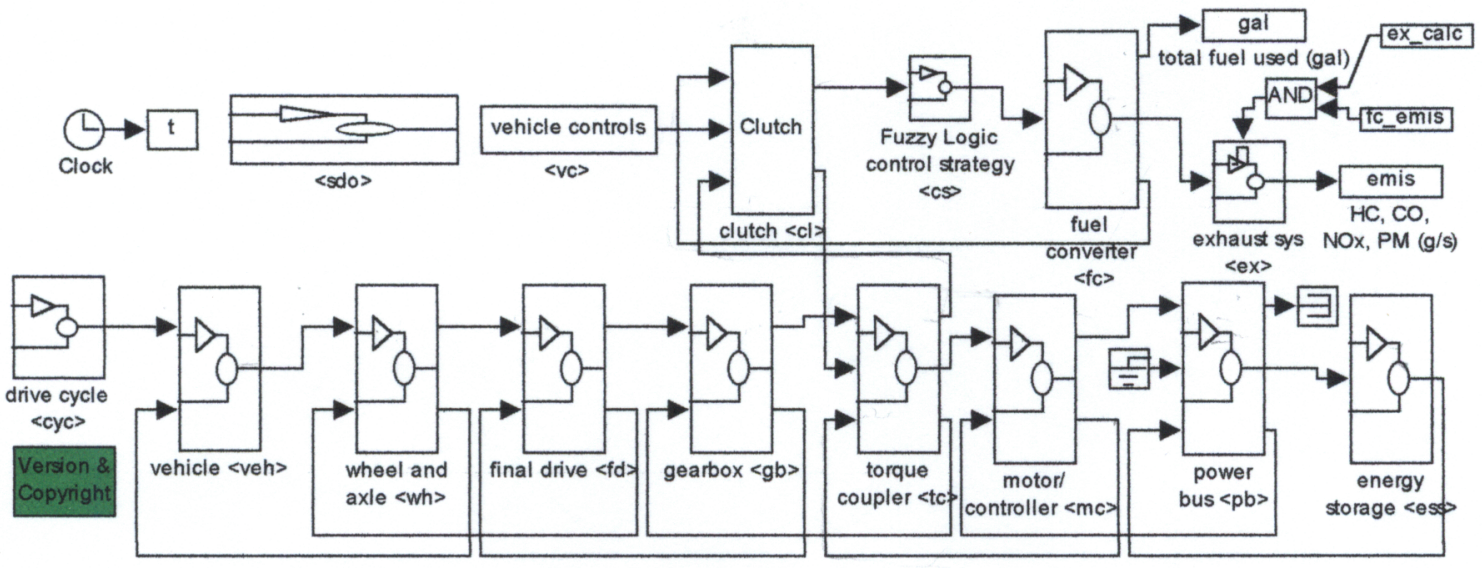

Figure 3.4 Advisor parallel simulink block diagram with FLC block

As previously stated, the first input into the actual Fuzzy Logic Controller is the combined accelerator and brake input from the driver, $\gamma$. This poses a problem because Advisor is a backward looking simulator that excludes the dynamics introduced by the driver. Therefore these values have to be estimated using the required torque into the clutch, $\alpha$, and the load at the input side of the gearbox, $\beta$. It was necessary to use both because while the torque into the clutch is the required load on the engine, it does not include any braking torque needed to estimate $\beta$, as the load at the input side of the gearbox does. This is because the clutch disengages when the vehicle decelerates preventing any undesired braking from the inertia of the engine. The Switch block in Figure 3.5 combines the two by allowing the torque input to the clutch to pass through when $\mathrm{T}_{\text {load }}$ is greater than zero, i.e. the throttle is being commanded. When $T_{\text {load }}$ is less 
than zero the switch block allows the value from the input side of the gearbox to pass through, i.e. the brake is being depressed. The $\mathrm{T}_{\text {load }}$ From block is used in conjunction with a Goto block connected to the torque required at the input side of the gearbox in the Gearbox subsystem. The maximum torque of the ICE at the present rpm then divides the

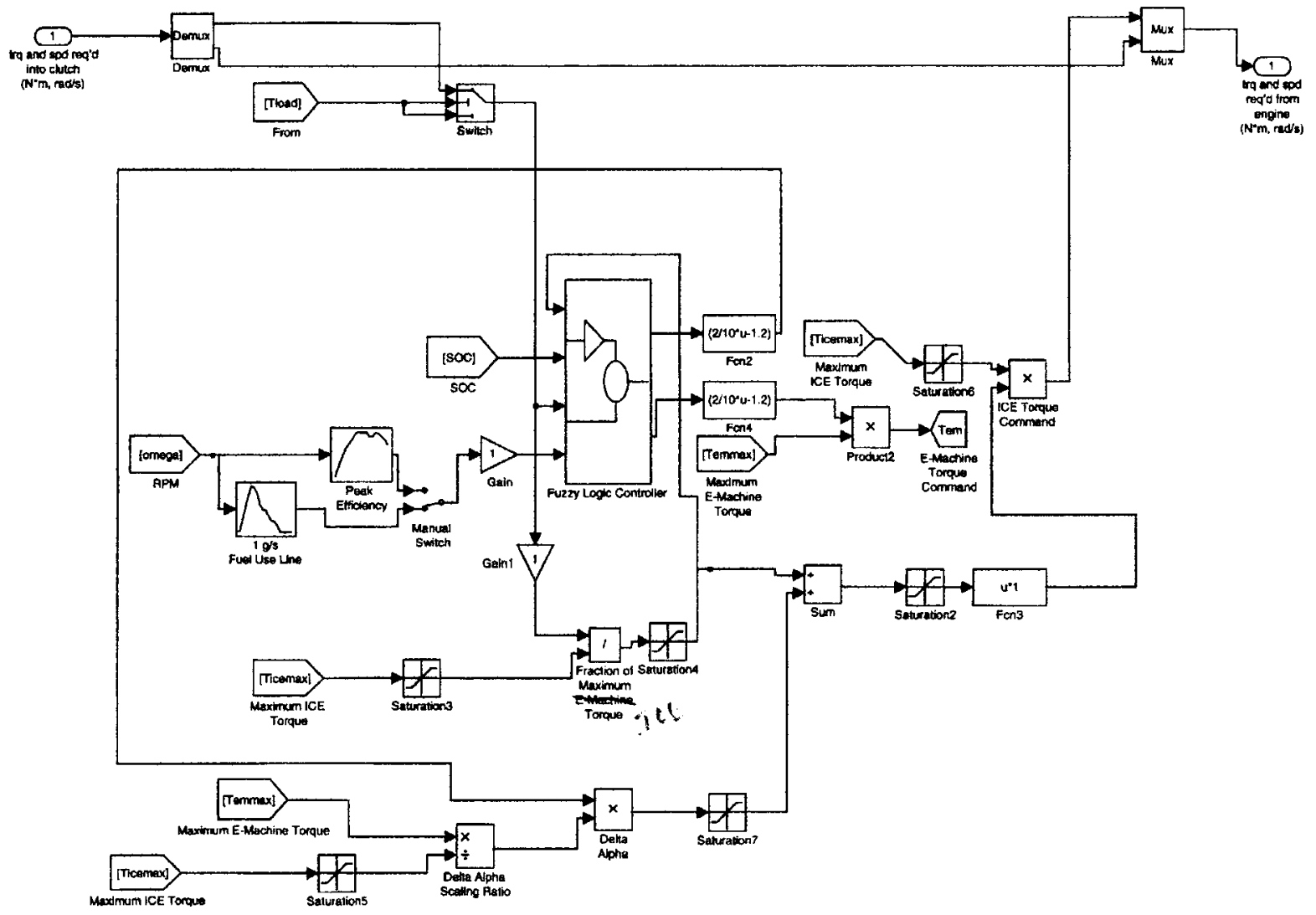

Figure 3.5 Inner workings of fuzzy logic control strategy subsystem

of the switch in order to estimate the extent to which the throttle is being depressed. For example if the required road load is fifty percent of the maximum torque capability of the engine, then the accelerator pedal is assumed to be fifty percent depressed. A saturation block follows the output of the division block, Fraction of the Maximum ICE Torque, in order to prevent the $\alpha$ signal from being greater than one. This could happen if the load from the drive cycle required of the engine is greater than the wide open throttle output of 
the engine. The torque command, $\alpha$, has now been normalized from zero to one and is input into the Fuzzy Logic Controller subsystem. Also note that the degree of the braking command, $\beta$, is input three into the FLC and will normalized within the subsystem.

There are two more required inputs into the fuzzy controller, the state of charge of the battery pack and the optimal e-machine torque. The SOC is simply imported using a From block in combination with a Goto block from the energy storage subsystem. In order to find the optimal e-machine torque the optimal ICE torque must first determined.

Figure 3.5 shows that input four into the Fuzzy Logic Controller subsystem is this quantity which is either the peak efficiency of the ICE at its present rpm, or its 1 gram per second fuel use line, depending on the control strategy. The omega From block is the angular velocity of the engine that is imported from the fuel converter subsystem. It is used to index the engines Peak Efficiency or $1 \mathrm{~g} / \mathrm{s}$ Fuel Use Line with the use of 2-D lookup tables. This is input four into the FLC subsystem and will later be used to calculate the desired e-machine torque.

The inner workings of the FLC subsystem are depicted in Figure 3.6. Input one, alpha, is sent to the function block, Alpha Scaling Function, in order for it to be properly scaled from four to seven. This is done because of the way the fuzzy code was written. The $\mathrm{C}$ code does not include internal scaling factors. Instead the external inputs all range from 1 to the total number of membership functions for that input, 7 for $\gamma$. The actual code can be seen in appendix B in its entirety. Therefore when alpha is zero the scaling function converts it to four. Beta is calculated the same way using input three to the subsystem, the road load including the braking torque. This torque is sent through the 
function clock, Beta Scaling Factor, which converts a torque of negative one hundred $\mathrm{Nm}$ to one and a braking torque of zero $\mathrm{Nm}$ to four. The Switch block allows $\alpha$ to be sent through when $T_{\text {load }}$ is positive and $\beta$ when $T_{\text {load }}$ is negative. Thus the final result is the combination of $\alpha$ and $\beta, \gamma$, being scaled from one to seven. The saturation block, Saturation 2, prevents $\gamma$ from being outside this range.

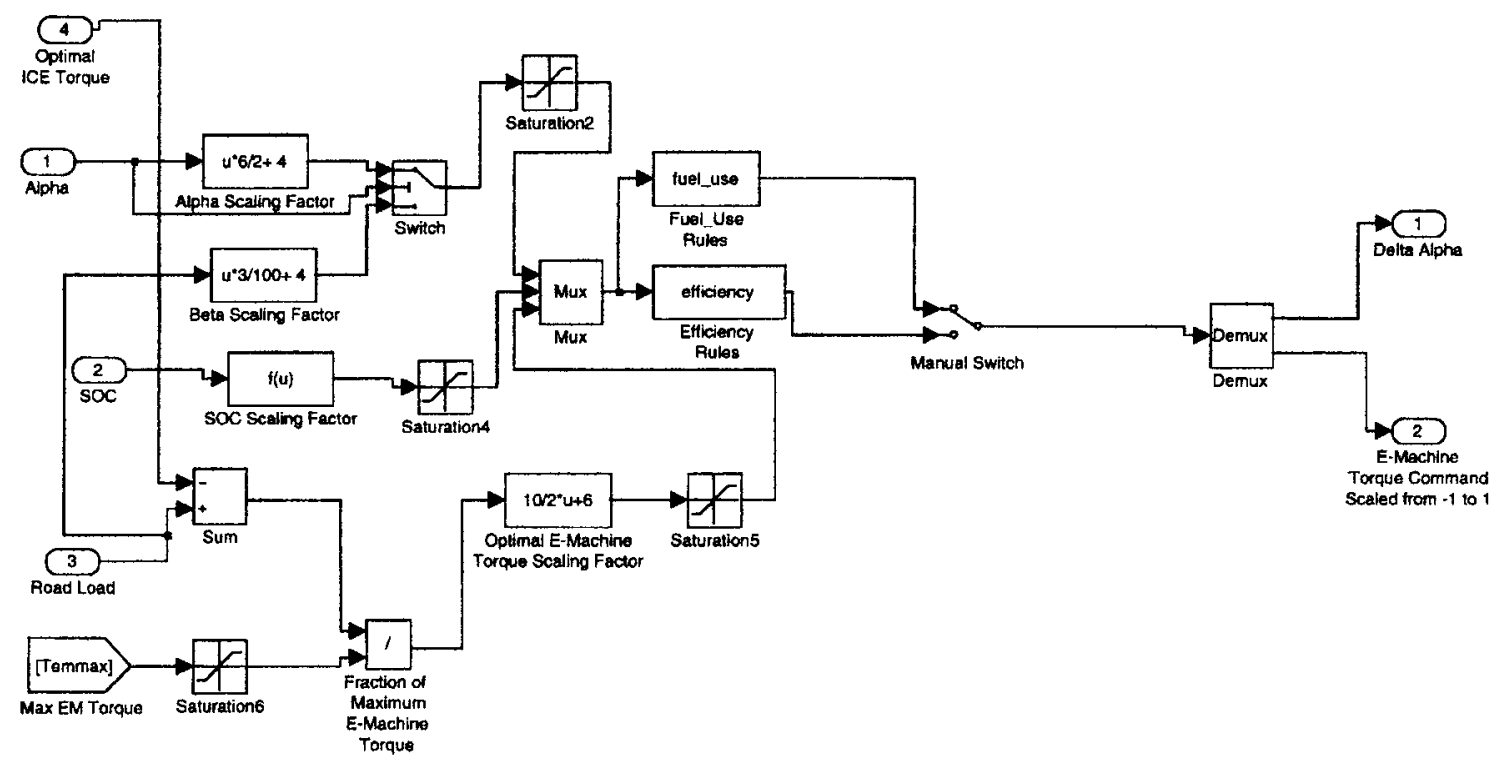

Figure 3.6 Inner workings of fuzzy logic controller subsystem

Input two into the subsystem is the state of charge of the battery pack. This is scaled similarly using the SOC Scaling Function Block. The only difference is the SOC input is scaled from one to eleven because it consists of eleven membership functions. Where the highest allowable SOC corresponds to eleven and the lowest allowable SOC corresponds to one.

The final input into the subsystem is the Optimal ICE Torque. Figure 3.6 shows that this is subtracted from the Road Load in order to determine the optimal e-machine 
torque. The maximum torque of the e-machine corresponding to its current speed then divides the output of the Sum block. The From block labeled Max EM Torque block is used in conjunction with a Goto block in the motor/controller subsystem. This normalizes the optimal e-machine torque from negative one to one. Where negative one corresponds to running it at its maximum negative torque output and positive one corresponds to running it at its maximum positive torque output. The output of the Fraction of Maximum E-Machine Torque block is then input to the Optimal E-Machine Torque Scaling Function block in order to scale it from one to eleven because this input also consists of eleven membership functions. Where an e-machine torque scaled to one corresponds to negative one and an e-machine torque scaled to eleven corresponds to one in the fuzzy logic S-function C-code given in appendix B.

Figure 3.6 then shows all three inputs fed into a Mux block and then to the two fuzzy logic S-functions. The two S-functions contain different rule bases depending on which control scheme is used. If the efficiency mode is chosen then Switchl allows the output of the Efficiency S-function to pass through, if the fuel use mode is chosen then Switch1 allows the output of the Fuel_Use S-Function to pass through. The two outputs from the FLC are then input into a Demux block and sent to an output scaling function. This is necessary because the fuzzy logic $C$ code calculates both control outputs, $\Delta \alpha$ and $\mathrm{T}_{\mathrm{EM}}$, from one to eleven. The two scaling functions return the outputs to their desired range of negative one to one. The two control outputs are then sent out of the Fuzzy Logic Controller subsystem and back into the Fuzzy Logic Control Strategy subsystem of Figure 3.5. 
The control output $\Delta \alpha$ is then sent to the product block labeled Delta Alpha. It is multiplied by the ratio of the maximum e-machine torque to the maximum ICE torque, corresponding to their current angular velocities. This is done to prevent the $\Delta \alpha$ command from exceeding the limits of the e-machine. For instance, if the supervisory controller commands the engine to increase its operating torque to a higher magnitude than the e-machine can take away by running as a generator then the vehicle will experience undesired accelerations. Multiplying $\Delta \alpha$ by this ratio will prevent this event from occurring. Next the change in throttle command is sent to the Sum block where it is either added or subtracted to the initial $\alpha$, depending on its magnitude. The Saturation 2 block prevents $\alpha$ from exceeding one, designating full throttle, and dropping below zero, no throttle. The maximum ICE torque at its current operating speed in order to command a torque to the fuel converter block then multiplies the newly controlled alpha. Then the controlled torque command to the engine is Muxed back with the required speed of the engine and sent to the Fuel Converter subsystem.

Finally, to give the commanded e-machine torque the Maximum E-Machine Torque block multiplies the second output of the Fuzzy Logic Controller subsystem, which is a fraction of the e-machines maximum torque ranging from negative one to one. The controlled output is then sent to the motor/controller subsystem to command the emachine.

\subsection{Additional Modifications to Advisor}


In order to allow the new parallel-configured simulink block diagram to work in conjunction with the existing GUI of Advisor several new M-files were created and a few existing M-files need to be modified. All of the m-files are contained in appendix A.

The following M-file script was appended to the file gui_options.m.

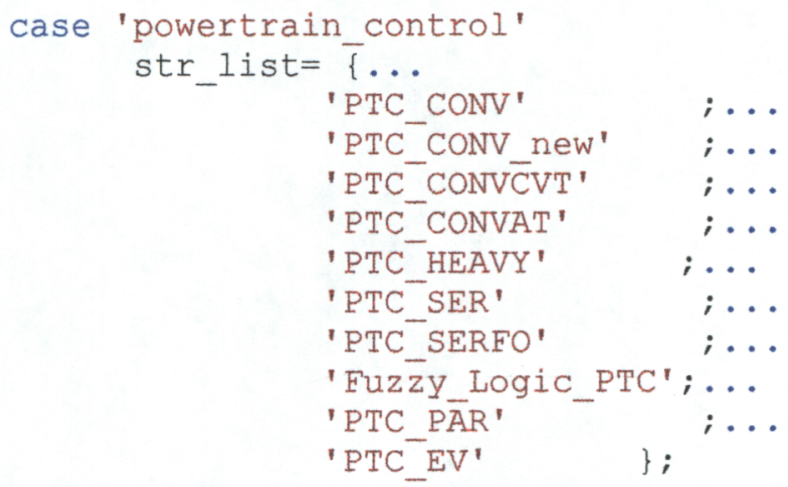

Vehicle Input
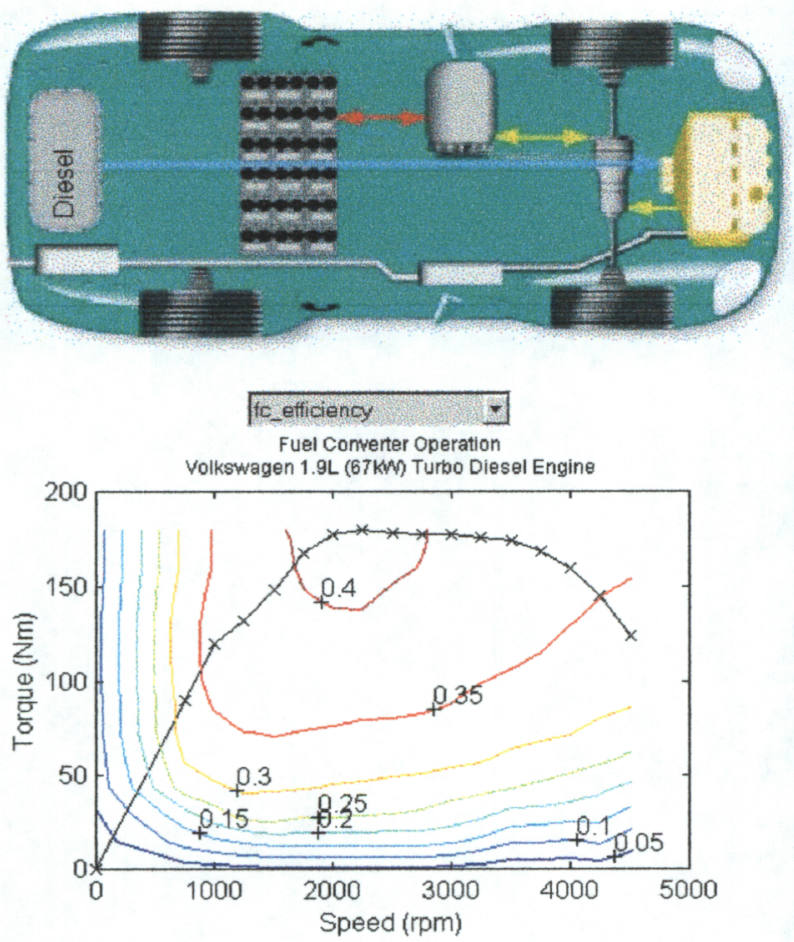

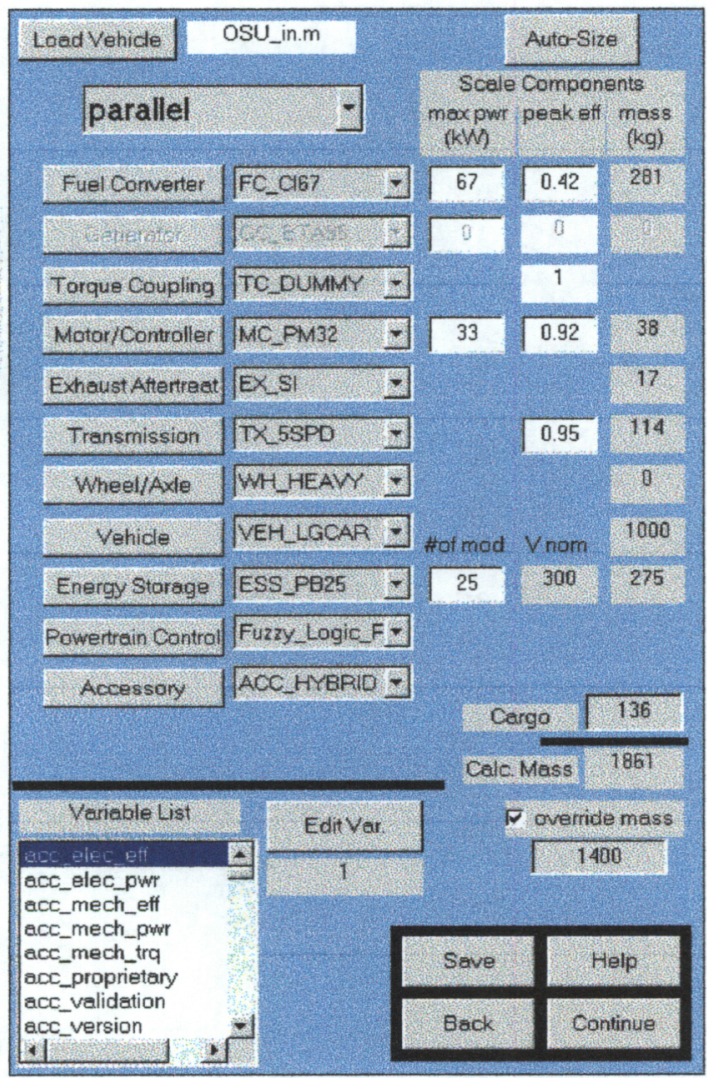

Figure 3.7 Addition of Fuzzy_Logic_PTC to powertrain controller pull-down menu 
This allows the user to select the fuzzy logic control strategy from the powertrain control pull-down menu of Advisor as seen in Figure 3.7.

The next modification ensures that the Fuzzy Logic Simulink block diagram is run in the simulation if the Fuzzy_logic_PTC is chosen from the powertrain controller pull-down menu as seen above. In order to achieve this the following script was added to gui_run_simulation.m.

if strcmp(vinf.powertrain_control.name, 'Fuzzy_Logic_PTC') parallel='BD_PAR_EFF' ;

where 'BD_PAR_EFF' is the simulink file name for the parallel configured simulink block diagram containing the fuzzy logic control strategies.

Next, two m-files were created to determine the highest efficiency line and the 1 $\mathrm{g} / \mathrm{s}$ fuel consumption line for specific ICE chosen by the user in the GUI. These files are ticeopt.m (highest efficiency) and ticefuel.m ( $1 \mathrm{~g} / \mathrm{s}$ fuel use). They are both included in appendix A. These files were necessary because they allow the user to implement both fuzzy logic control strategies on any existing ICE data available in Advisor. In order to run the simulink file 'BD_PAR_EFF' it was necessary to call these files out in the file gui run.m. This allows both $\mathrm{m}$-files to make their calculations and import their data into the Matlab workspace, which is necessary for running a simulation with the 'BD_PAR_EFF' block diagram.

The final modification was to the file chkfc.m and is as follows:

\% plot OSU parallel control strategy

if strcmp (vinf.powertrain_control.name, 'Fuzzy_Logic_PTC')

') ;

plot (fc_map_spd (test $\overline{1}$ : test 2 )*fc_spd_scale*30/pi, cameron, 'b--

str=[str,', 'Optimal ICE Torque'''];

plot (fc_map_spd*fC_spd_scale*30/pi,breslin, 'm--') 
end;

This script allows the highest efficiency and the $1 \mathrm{~g} / \mathrm{s}$ fuel use line to be displayed on the output graph for the fuel converters operation as seen in figure 3.8. This will only appear if the user chooses the Fuzzy Logic PTC.

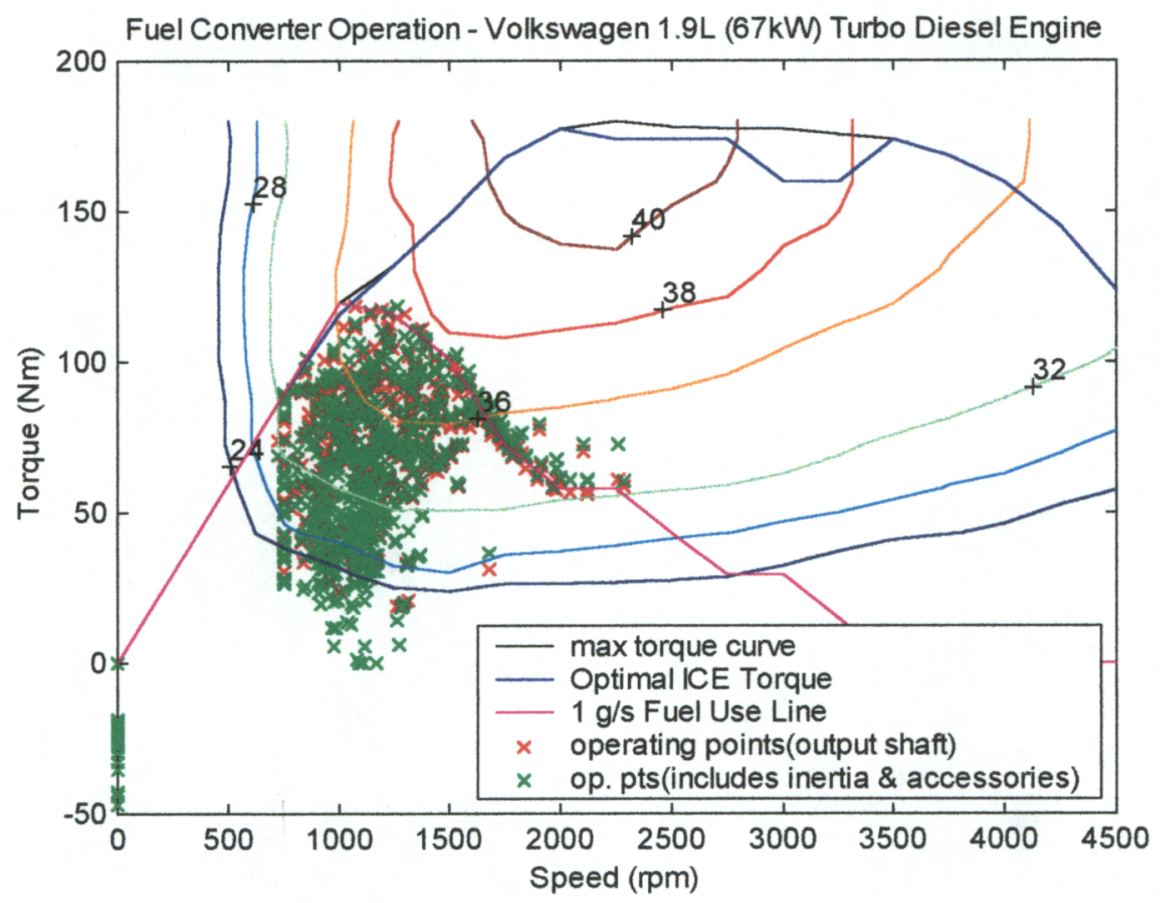

Figure 3.8 Fuel converter operation plot showing addition of highest efficiency and $1 \mathrm{~g} / \mathrm{s}$ fuel use line 


\section{CHAPTER 4}

\section{SIMULATION RESULTS}

This chapter presents the Advisor simulation results for the fuzzy logic control strategies discussed in chapter 2 . Several vehicle component configurations are used in order to understand the circumstances under which each control strategy outshines the others. Vehicle performance results for a parallel hybrid with the fuzzy logic supervisory controller are compared against simulations made with the parallel electric assist strategy, and a conventional vehicle, in order to quantify the results.

\subsection{Efficiency Mode}

The first case is used to demonstrate an instance when forcing the ICE to run at its peak point of efficiency can improve the vehicles overall fuel economy. The parallel hybrid vehicle used for this example has the component configuration displayed in figure

4.1. Simulations were also run with the same components for the existing control strategy of Advisor, parallel electric assist, and a conventional vehicle, in order to compare results.

Figures 4.2 and 4.3 show the operation of the ICE and the battery module respectively over ten FUDS drive cycles with the fuzzy logic controller. Note that the 
preponderance of these points are located near the line of maximum efficiency. The effect of forcing the ICE to run at its peak point of efficiency the majority of the time is exhibited in table 4.1 .
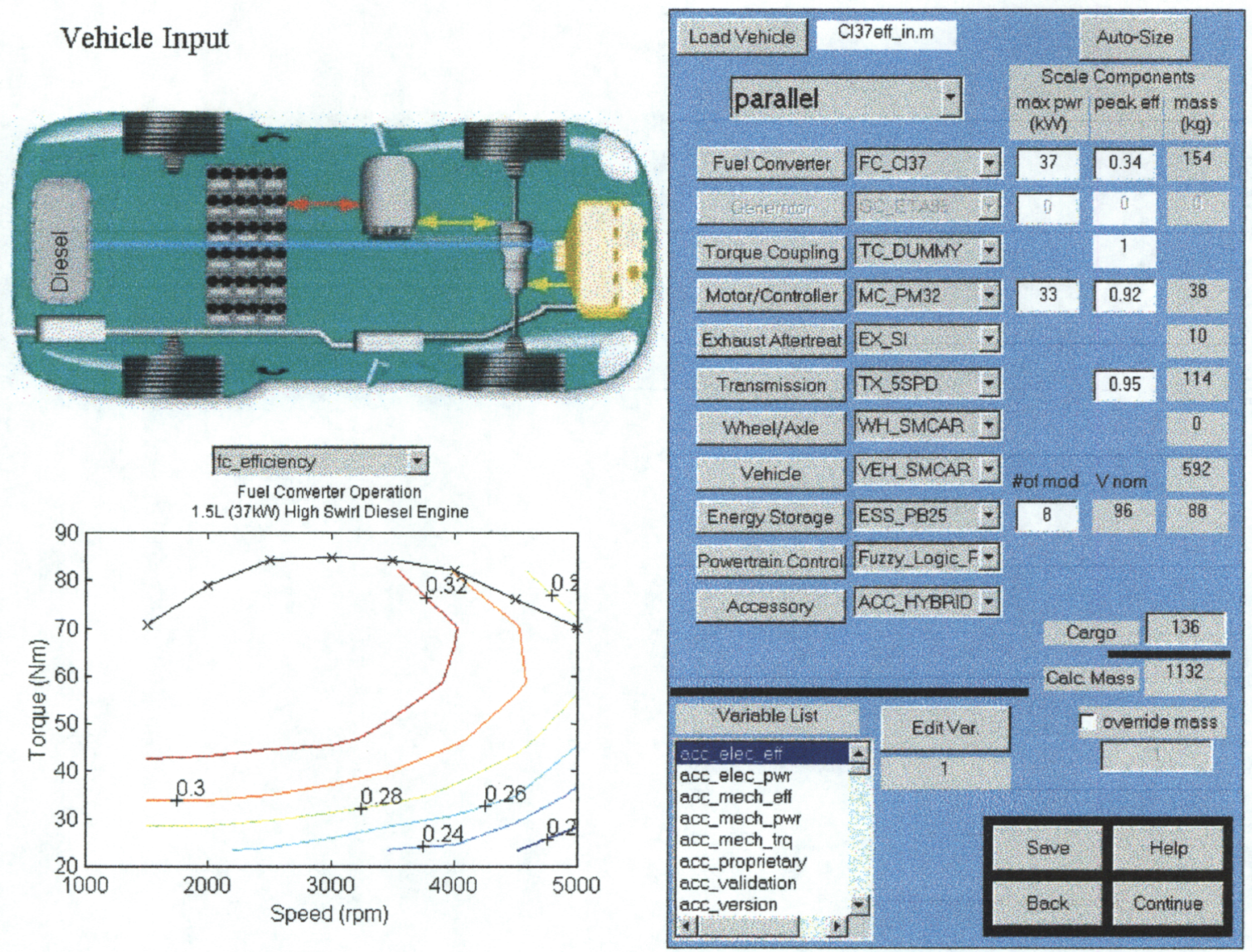

Figure 4.1 Advisor GUI displaying component configuration of efficiency mode example

Table 4.1 shows that the fuzzy logic controller achieved an average fuel economy of $49.8 \mathrm{mpg}$, compared to $36.2 \mathrm{mpg}$ for a conventional vehicle, while depleting its battery pack by only three percent as seen in figure 4.2. The existing controller, Parallel Electric Assist, achieved an equivalent fuel economy of $48.4 \mathrm{mpg}$ by depleting its battery pack by fourteen percent. For this specific vehicle configuration the FLC achieved a slightly 
higher fuel economy than the existing control strategy, while maintaining a much higher state of charge in the battery pack. Therefore expending less total energy. To convert the energy depleted from the battery pack to an equivalent amount of diesel fuel used the conversion factor [21] given in equation 4.1 is used.

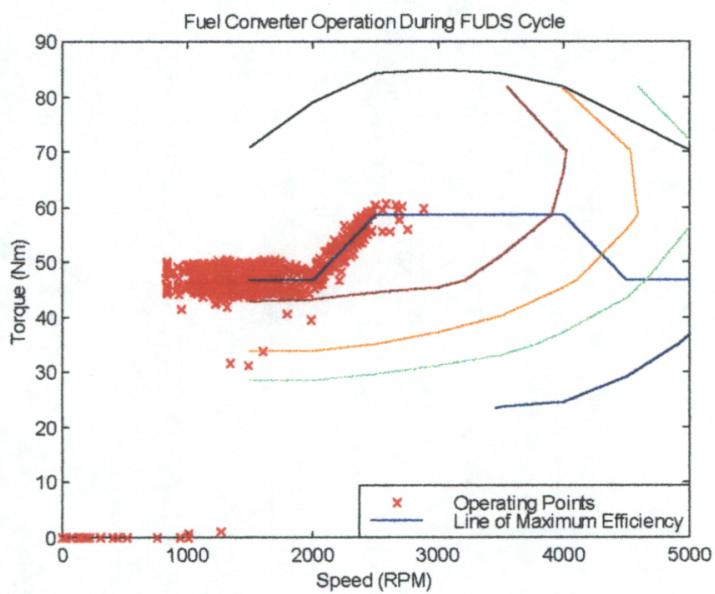

Figure 4.2 ICE operating points for FLC efficiency mode in city

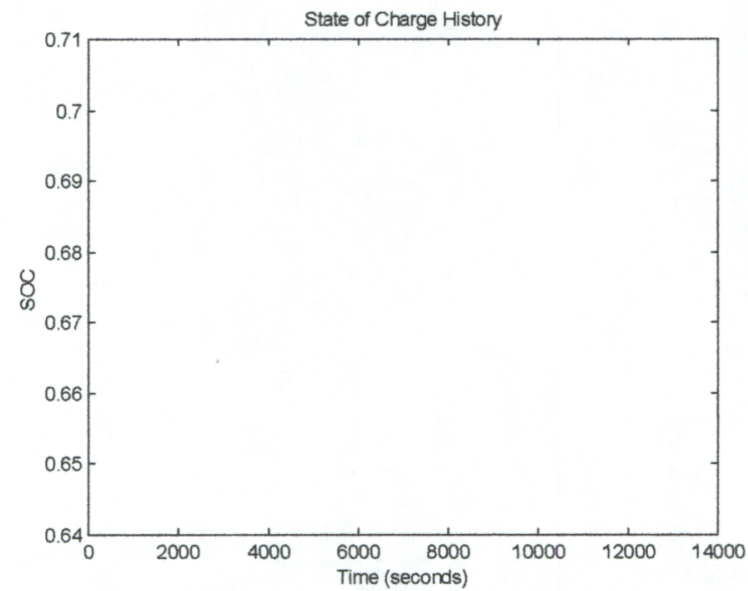

Figure 4.3 State of charge history for FLC efficiency mode in city

$$
\text { Gallons of Diesel }=.3727 * 33.1 \mathrm{kWh} \text { AC }
$$

Where AC kWh energy is computed from DC kWh energy using a 0.75 battery efficiency and a .9 charger efficiency. The calculation is shown as the MPG equivalent in table 4.1. The $\mathrm{m}$-file used to make this calculation is included in appendix A.

\begin{tabular}{|c|c|c|c|c|c|c|c|}
\hline Vehicle Type & $\begin{array}{c}\text { Control } \\
\text { Strategy }\end{array}$ & Weight (kg) & $\begin{array}{c}\text { Distance } \\
\text { Traveled } \\
\text { (miles) }\end{array}$ & $\begin{array}{c}\text { Initial } \\
\text { SOC }\end{array}$ & $\begin{array}{c}\text { Final } \\
\text { SOC }\end{array}$ & MPG & $\begin{array}{c}\text { MPG } \\
\text { equivalent }\end{array}$ \\
\hline Parallel & Fuzzy & 1132 & 74.5 & .7 & .68 & 49.8 & 49.75 \\
\hline Parallel & PAR_PTC & 1132 & 74.5 & .7 & .60 & 48.4 & 48 \\
\hline Conventional & & 1006 & 74.5 & & & 36.2 & \\
\hline
\end{tabular}

Table 4.1 Comparison of FLC to the existing parallel control strategy and a conventional vehicle in the city. 
Figures 4.4 and 4.5 display the operation of the same vehicle through ten highway drive cycles (HWFET). Table 4.2 shows that the FLC improves the equivalent fuel economy to 60 mpg compared to 58 for the existing strategy of advisor and 55 for a conventional vehicle. Note that the percent improvement compared to the conventional vehicle is less significant for this case. This is because the majority of the ICE operating points for a conventional vehicle on the highway are closer to the peak point of efficiency than in the city-driving environment.

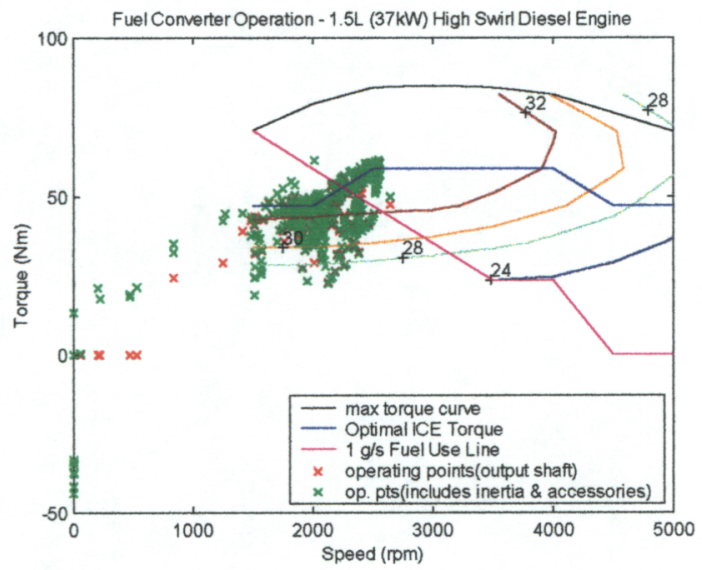

Figure 4.4 ICE operating points for FLC efficiency mode on highway

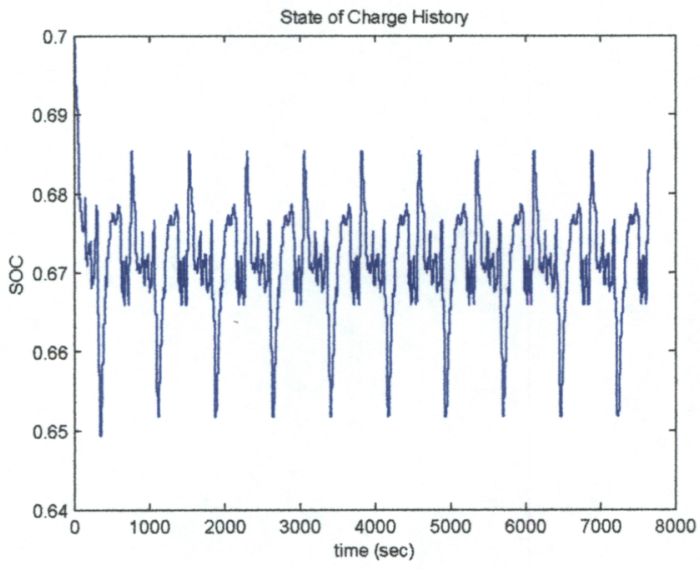

Figure 4.5 State of charge history for FLC efficiency mode on highway

\begin{tabular}{|c|c|c|c|c|c|c|c|}
\hline Vehicle Type & $\begin{array}{c}\text { Control } \\
\text { Strategy }\end{array}$ & Weight $(\mathrm{kg})$ & $\begin{array}{c}\text { Distance } \\
\text { Traveled } \\
\text { (miles) }\end{array}$ & $\begin{array}{c}\text { Initial } \\
\text { SOC }\end{array}$ & $\begin{array}{c}\text { Final } \\
\text { SOC }\end{array}$ & MPG & $\begin{array}{c}\text { MPG } \\
\text { equivalent }\end{array}$ \\
\hline Parallel & Fuzzy & 1132 & 102 & .7 & .68 & 60.2 & 60.1 \\
\hline Parallel & PAR PTC & 1132 & 102 & .7 & .60 & 58.4 & 58 \\
\hline Conventional & & 1006 & 102 & & & 55 & \\
\hline
\end{tabular}

Table 4.2 Comparison of FLC to the existing parallel control strategy and a conventional vehicle on the highway.

The next example demonstrates another case where running the ICE at its peak point of efficiency can improve the vehicles fuel economy. The vehicle has the same 
configuration as the previous case except the $\mathrm{FC} \_\mathrm{CI} 37$ fuel converter is replaced with the FC_SI41 fuel converter.

Figures 4.6 and 4.7 show the operation of the ICE and the battery module over ten FUDS drive cycles with the fuzzy logic controller. The results compared to the parallel electric assist and the conventional vehicle are given in table 4.2. The FLC achieves 38

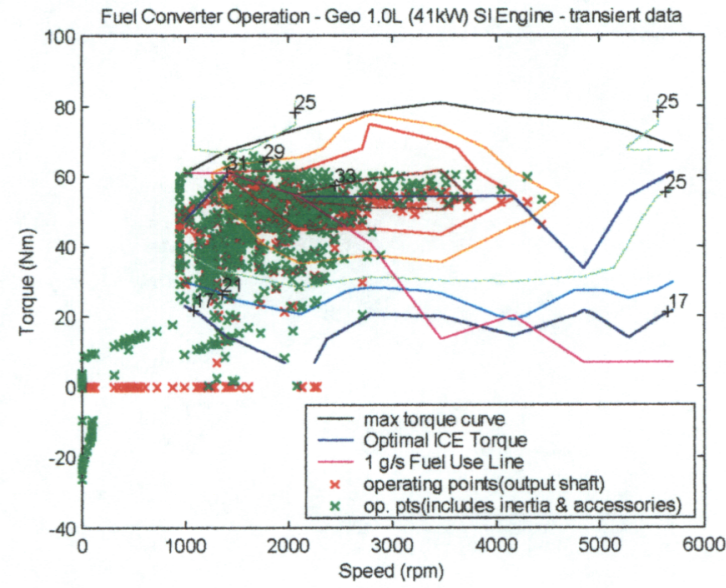

Figure 4.6 ICE operating points for FLC efficiency mode in city

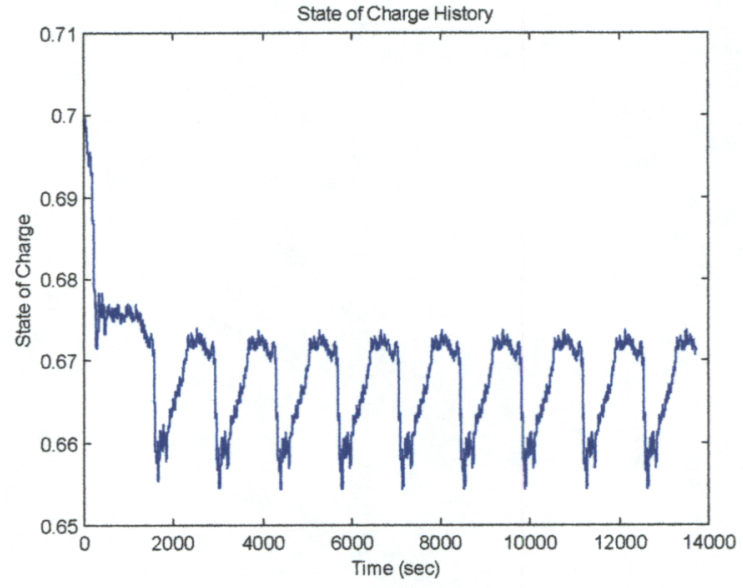

Figure 4.7 State of charge history for FLC efficiency mode in city

\begin{tabular}{|c|c|c|c|c|c|c|c|}
\hline Vehicle Type & $\begin{array}{c}\text { Control } \\
\text { Strategy }\end{array}$ & Weight $(\mathrm{kg})$ & $\begin{array}{c}\text { Distance } \\
\text { Traveled } \\
\text { (miles) }\end{array}$ & $\begin{array}{c}\text { Initial } \\
\text { SOC }\end{array}$ & $\begin{array}{c}\text { Final } \\
\text { SOC }\end{array}$ & MPG & $\begin{array}{c}\text { MPG } \\
\text { equivalent }\end{array}$ \\
\hline Parallel & Fuzzy & 1705 & 74.5 & .7 & .67 & 38.6 & 38.4 \\
\hline Parallel & PAR PTC & 1705 & 74.5 & .7 & .60 & 32 & 31.3 \\
\hline Conventional & & 1405 & 74.5 & & & 33 & \\
\hline
\end{tabular}

Table 4.3 Comparison of FLC to the existing parallel control strategy and a conventional vehicle in the city.

mpg compared to 31 for the parallel electric assist, while maintaining a SOC of .67. In this mode the vehicle achieves a better equivalent gas mileage and a higher final SOC than the existing controller does.

The next case presents the results of running the same vehicle in the highwaydriving environment. Figures 4.8 and 4.9 show the operation of the ICE and the battery 
module over ten HWFET drive cycles with the fuzzy logic controller. The results

compared to the parallel electric assist and the conventional vehicle are given in table 4.4.

This comparison also shows an improvement of $47.5 \mathrm{mpg}$ compared to $43 \mathrm{mpg}$ for a conventional vehicle and 42.5 for the parallel electric assist. This type of load leveling referred to, as the efficiency mode will only be successful in engines that do not have their highest efficiency island at or near full load.

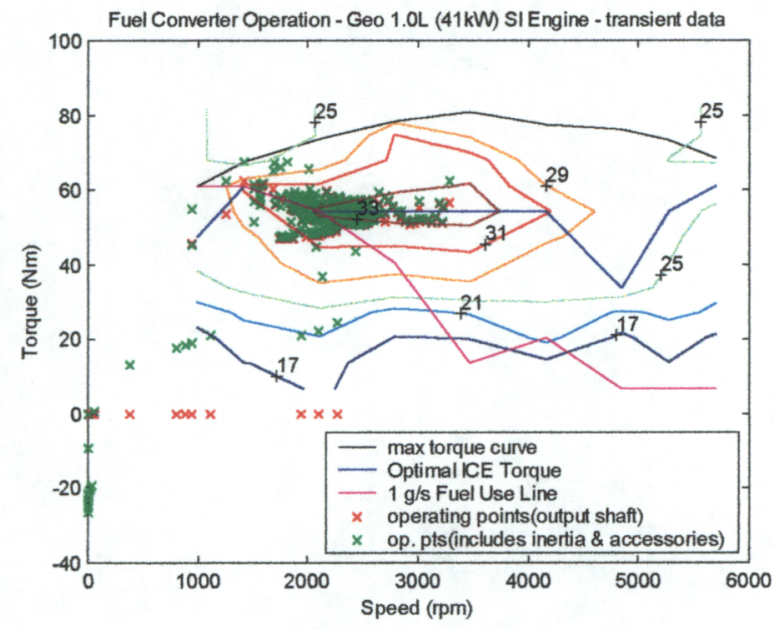

Figure 4.8 ICE operating points for FLC efficiency mode on highway

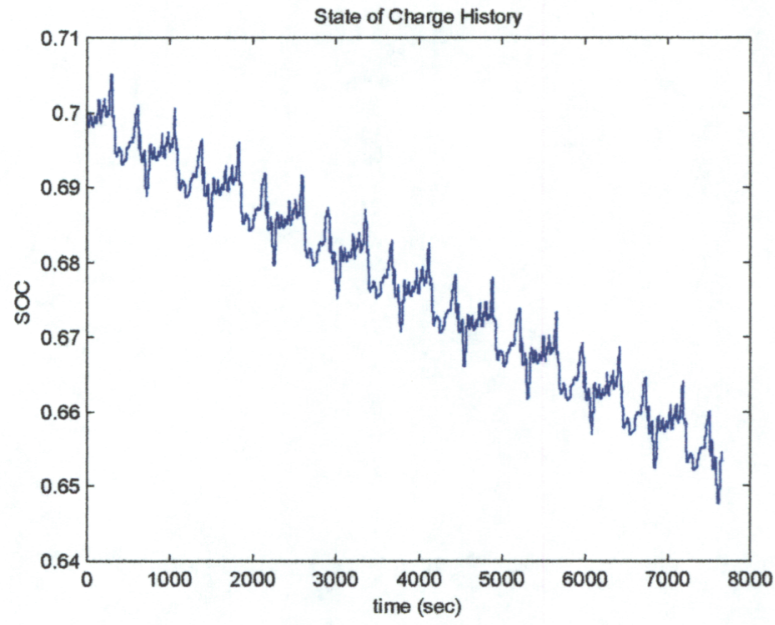

Figure 4.9 State of charge history for FLC efficiency mode on highway

\begin{tabular}{|c|c|c|c|c|c|c|c|}
\hline Vehicle Type & $\begin{array}{c}\text { Control } \\
\text { Strategy }\end{array}$ & Weight $(\mathrm{kg})$ & $\begin{array}{c}\text { Distance } \\
\text { Traveled } \\
\text { (miles) }\end{array}$ & $\begin{array}{c}\text { Initial } \\
\text { SOC }\end{array}$ & $\begin{array}{c}\text { Final } \\
\text { SOC }\end{array}$ & MPG & $\begin{array}{c}\text { MPG } \\
\text { equivalent }\end{array}$ \\
\hline Parallel & Fuzzy & 1705 & 102 & .7 & .67 & 47.5 & 47.2 \\
\hline Parallel & PAR PTC & 1705 & 102 & .7 & .60 & 42.5 & 42 \\
\hline Conventional & & 1405 & 102 & & & 43 & 43 \\
\hline
\end{tabular}

Table 4.4 Comparison of FLC to the existing parallel control strategy and a conventional vehicle on the highway.

The next example is used to demonstrate the situation where operating an oversized engine at the peak point of efficiency at full load is incorrect. The vehicle 
configuration used is that of the 1999 OSU Future Car seen in Figure 4.10. Notice that the peak efficiency of the $66 \mathrm{~kW}$ Diesel engine is at or near full load. Figures 4.11 and 4.12 show the engine and battery module operation over 10 FUDS drive cycles. Figure 4.12 shows that the final battery SOC is greater than the initial SOC. This is because the electric motor is acting as a generator the majority of the time because the torque
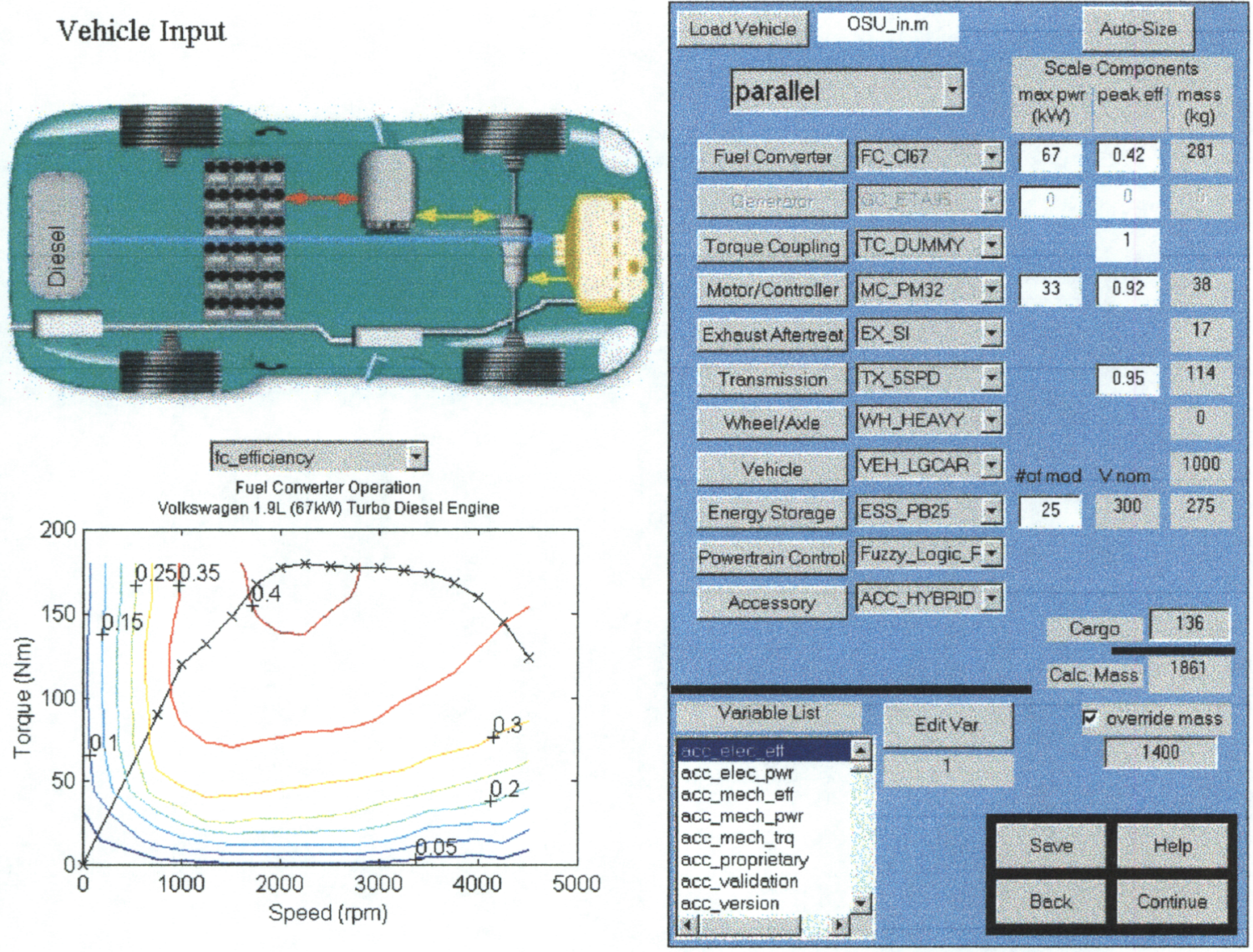

Figure 4.10 Component configuration of 1999 OSU future car

corresponding to the highest efficiency is greater than the road load. Table 4.5 shows the dramatic decrease in the equivalent mpg for oversized engine compared with a conventional vehicle. Figures 4.13 and 4.14 along with table 4.6 also show the same decrease in fuel economy when driven in the highway environment. This is because by 
running the engine at its line of highest efficiency, coupled with the losses associated

with the batteries and the e-machine, the vehicle is expending almost twice as much

energy than is required by the drive cycle. One possible remedy lies in the utilization of

the fuel use mode. This is explained in detail in the next section

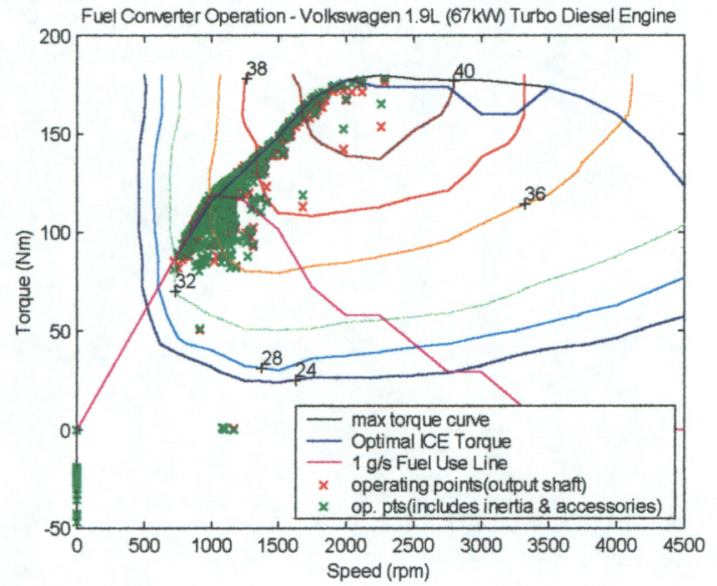

Figure 4.11 ICE operating points for FLC efficiency mode in city

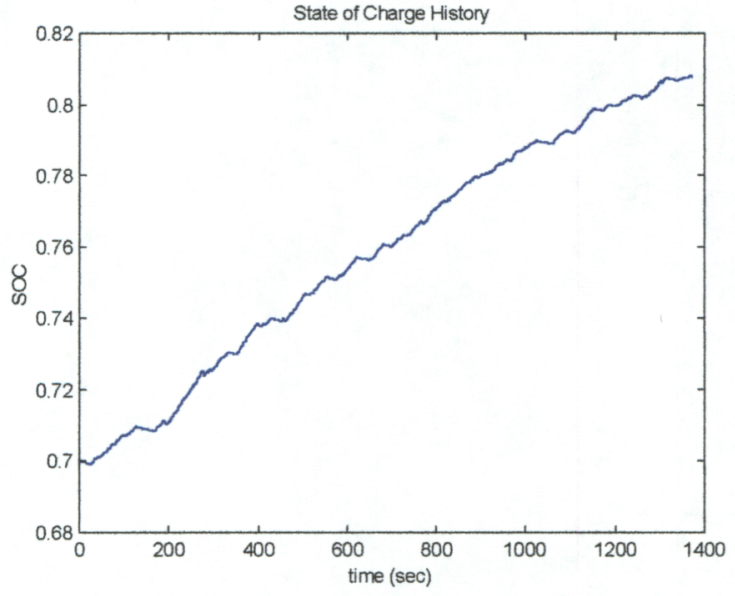

Figure 4.12 State of charge history for FLC efficiency mode in city

\begin{tabular}{|c|c|c|c|c|c|c|c|}
\hline Vehicle Type & $\begin{array}{c}\text { Control } \\
\text { Strategy }\end{array}$ & Weight (kg) & $\begin{array}{c}\text { Distance } \\
\text { Traveled } \\
\text { (miles) }\end{array}$ & $\begin{array}{c}\text { Initial } \\
\text { SOC }\end{array}$ & $\begin{array}{c}\text { Final } \\
\text { SOC }\end{array}$ & MPG & $\begin{array}{c}\text { MPG } \\
\text { equivalent }\end{array}$ \\
\hline Parallel & Fuzzy & 1400 & 74.5 & .7 & .81 & 30.5 & 33.2 \\
\hline Parallel & PAR PTC & 1400 & 74.5 & .7 & .60 & 55.1 & 54.5 \\
\hline Conventional & & 1400 & 74.5 & & & 48 & \\
\hline
\end{tabular}

Table 4.5 Comparison of FLC to the Existing Parallel Control Strategy and a Conventional Vehicle in the city.

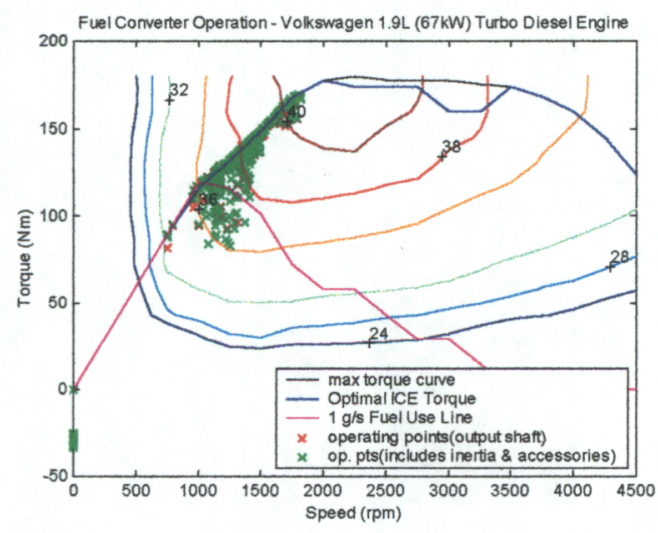

Figure 4.13 ICE operating points for FLC efficiency mode on highway

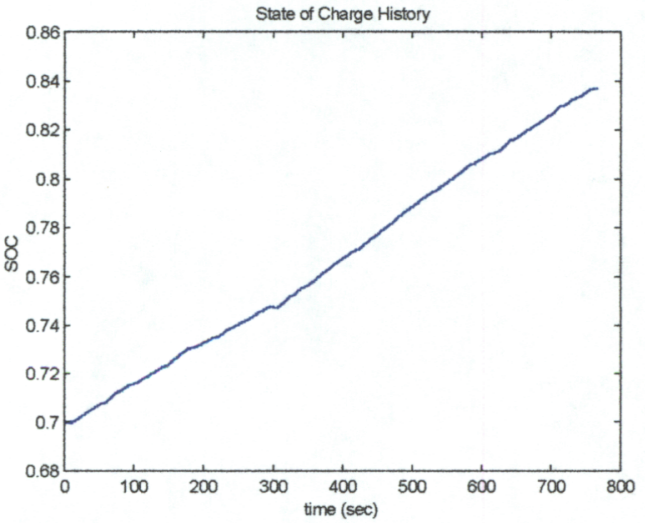

Figure 4.14 State of charge history for FLC efficiency mode on highway 


\begin{tabular}{|c|c|c|c|c|c|c|c|}
\hline Vehicle Type & $\begin{array}{c}\text { Control } \\
\text { Strategy }\end{array}$ & Weight $(\mathrm{kg})$ & $\begin{array}{c}\text { Distance } \\
\text { Traveled } \\
\text { (miles) }\end{array}$ & $\begin{array}{c}\text { Initial } \\
\text { SOC }\end{array}$ & $\begin{array}{c}\text { Final } \\
\text { SOC }\end{array}$ & MPG & $\begin{array}{c}\text { MPG } \\
\text { equivalent }\end{array}$ \\
\hline Parallel & Fuzzy & 1400 & 74.5 & .7 & .83 & 35.8 & 39 \\
\hline Parallel & PAR PTC & 1400 & 74.5 & .7 & .60 & 64 & 63.4 \\
\hline Conventional & & 1400 & 74.5 & & & 57 & \\
\hline
\end{tabular}

Table 4.6 Comparison of FLC to the existing parallel control strategy and a conventional vehicle on the highway.

\subsection{Fuel Use Mode}

The last case is used to simulate the performance of the fuel use control strategy. The vehicle consists of the components used in the 1999 OSU Future Car as seen in figure 4.10. Simulations were run over ten FUDS drive cycles and ten HWFET cycles to compare this strategy's results with that of the parallel electric assist and a conventional vehicle. The engine was also run about its constant $.9 \mathrm{~g} / \mathrm{s}$ and $1.1 \mathrm{~g} / \mathrm{s}$ fuel use lines to investigate if this had any effect on vehicle performance.

Figures 4.15 and 4.16 show the operation of the ICE and the battery module over ten FUDS drives cycles, with the fuzzy logic controller in the fuel use mode. Figures 4.17 and 4.18 also show the operation of the ICE and the battery module over ten HWFET drives cycles, with controller in the fuel use mode. Note that nearly all of the operating points of the ICE are located near or beneath the $1 \mathrm{~g} / \mathrm{s}$ fuel use line. The result of this strategy in the city and the highway, compared to the existing control policy of Advisor and a conventional vehicle are exhibited in table 4.7 and table 4.8 , respectively. The FLC achieves $55.8 \mathrm{mpg}$ in the city and $64.9 \mathrm{mpg}$ on the highway compared to 54 $\mathrm{mpg}$ in the city and $63 \mathrm{mpg}$ on the highway for the parallel electric assist. It also maintains a higher SOC of .68 as opposed to .6 with the parallel electric assist for both 
cases. In conclusion, the fuel use mode attains a slightly higher gas mileage and

maintains a significantly higher SOC than the existing controller does, therefore it

\section{consumes less total energy.}

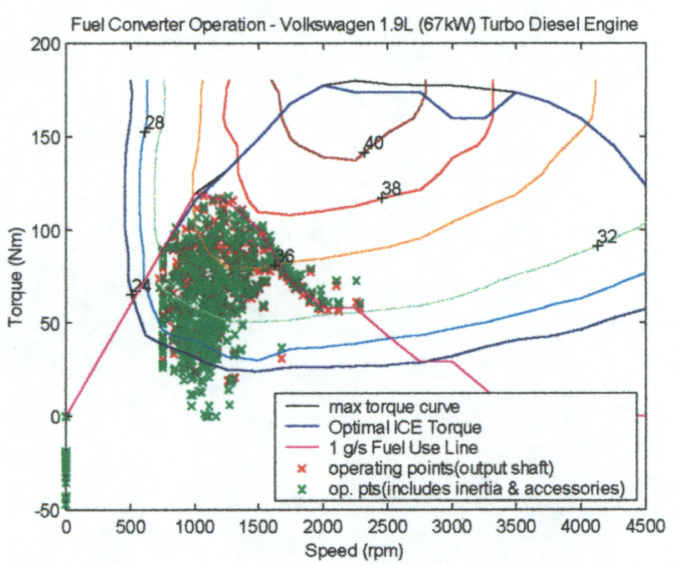

Figure 4.15 Fuel converter operation for the FLC in the fuel use mode over FUDS drive cycle

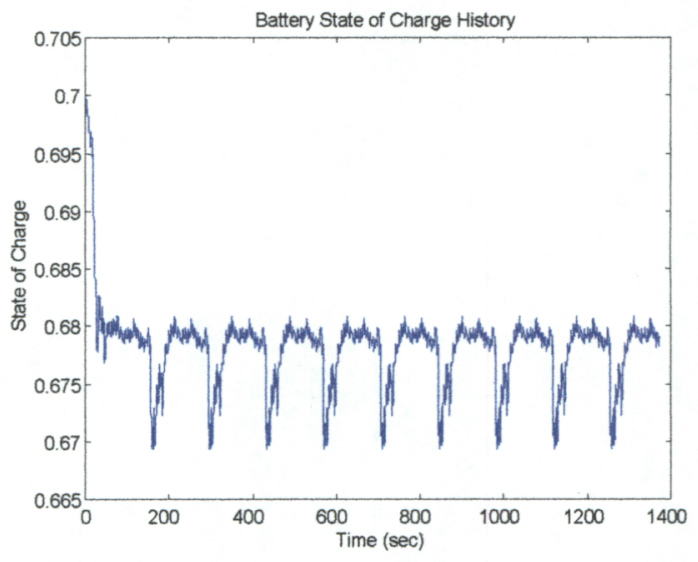

Figure 4.16 State of charge history for the FLC in the fuel use mode over FUDS drive cycle

\begin{tabular}{|c|c|c|c|c|c|c|c|}
\hline Vehicle Type & $\begin{array}{c}\text { Control } \\
\text { Strategy }\end{array}$ & Weight $(\mathrm{kg})$ & $\begin{array}{c}\text { Distance } \\
\text { Traveled } \\
\text { (miles) }\end{array}$ & $\begin{array}{c}\text { Initial } \\
\text { SOC }\end{array}$ & $\begin{array}{c}\text { Final } \\
\text { SOC }\end{array}$ & MPG & $\begin{array}{c}\text { MPG } \\
\text { equivalent }\end{array}$ \\
\hline Parallel & Fuzzy & 1400 & 74.5 & .7 & .68 & 56 & 55.8 \\
\hline Parallel & PAR PTC & 1400 & 74.5 & .7 & .60 & 55.1 & 54.5 \\
\hline Conventional & & 1400 & 74.5 & & & 48 & \\
\hline
\end{tabular}

Table 4.7 Fuel use mode over ten FUDS cycles compared with PEA and conventional vehicle in the city.

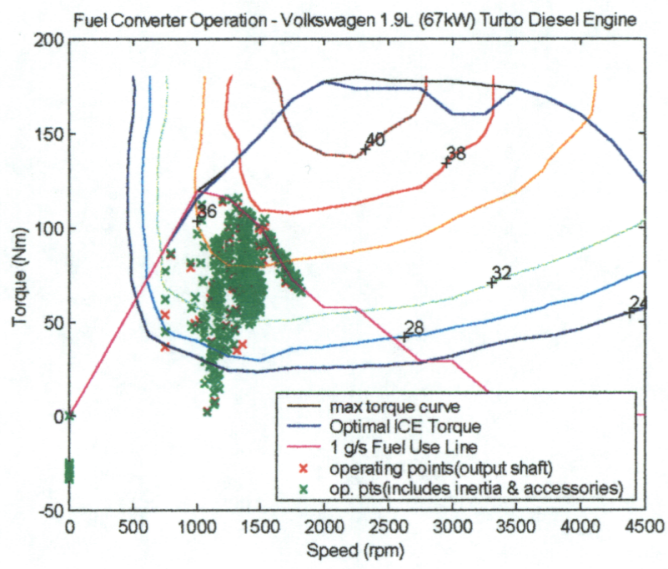

Figure 4.17 Fuel converter operation over for the FLC in the fuel use mode over HWFET drive cycle

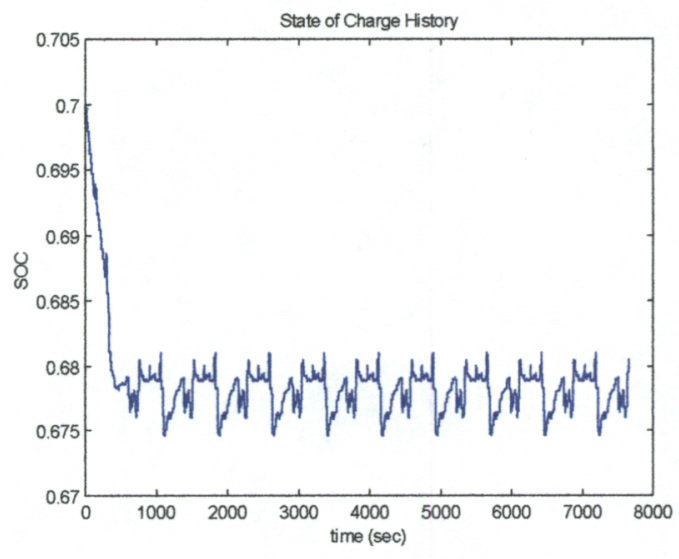

Figure 4.18 State of charge history for the FLC in the fuel use mode over HWFET 


\begin{tabular}{|c|c|c|c|c|c|c|c|}
\hline Vehicle Type & $\begin{array}{c}\text { Control } \\
\text { Strategy }\end{array}$ & Weight (kg) & $\begin{array}{c}\text { Distance } \\
\text { Traveled } \\
\text { (miles) }\end{array}$ & $\begin{array}{c}\text { Initial } \\
\text { SOC }\end{array}$ & $\begin{array}{c}\text { Final } \\
\text { SOC }\end{array}$ & MPG & $\begin{array}{c}\text { MPG } \\
\text { equivalent }\end{array}$ \\
\hline Parallel & Fuzzy & 1400 & 74.5 & .7 & .68 & 65 & 64.9 \\
\hline Parallel & PAR_PTC & 1400 & 74.5 & .7 & .60 & 64 & 63.2 \\
\hline Conventional & & 1400 & 74.5 & & & 57 & \\
\hline
\end{tabular}

Table 4.8 fuel use mode over ten HWFET cycles compared with PEA and conventional vehicle on the highway.

The next case is used to show the effect of load leveling about the engines $0.9 \mathrm{~g} / \mathrm{s}$

fuel use line. Figures 4.19 and 4.20 display the operation of the ICE and the battery module over ten FUDS drives cycles, with the Fuzzy Logic Controller in the fuel use mode. Figures 4.21 and 4.22 also show the operation of the ICE and the battery module over ten HWFET drives cycles. Mostly all of the operating points of the ICE are located near or beneath the $0.9 \mathrm{~g} / \mathrm{s}$ fuel use line. The discrepancies in results for the city and the highway, compared to the $1 \mathrm{~g} / \mathrm{s}$ fuel use line are given in table 4.9 and table 4.10 , respectively. The equivalent mpg has been slightly reduced to $55.1 \mathrm{mpg}$ for the city and 64.9 for the highway.

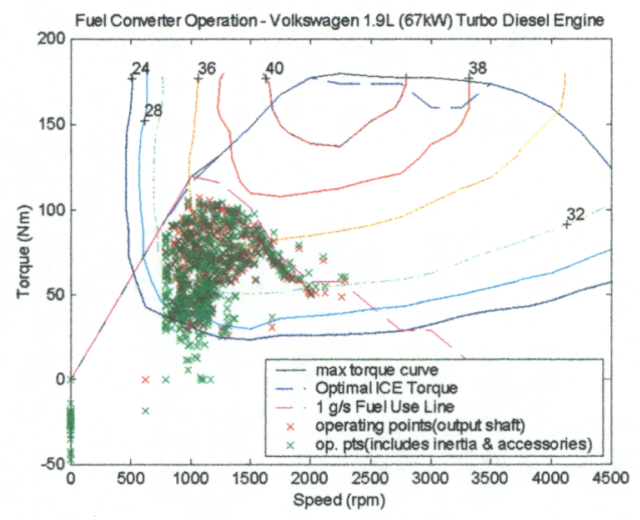

Figure 4.19 Fuel converter operation over for the FLC in the fuel use mode over FUDS drive cycle

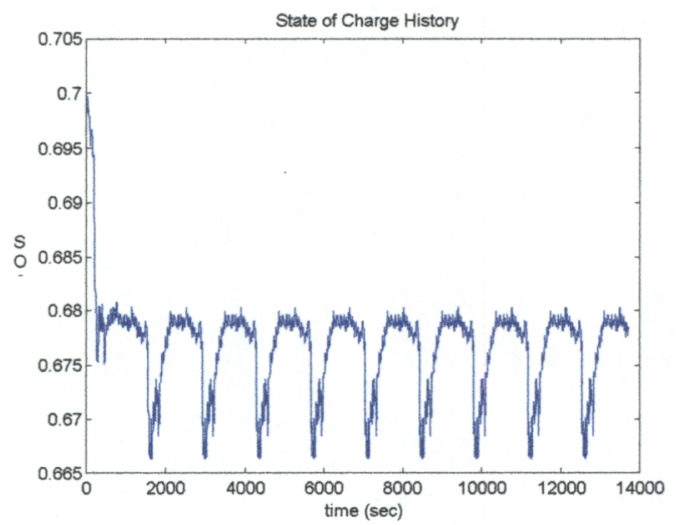

Figure 4.20 State of charge history for the FLC in the fuel use mode over FUDS drive cycle 


\begin{tabular}{|c|c|c|c|c|c|c|c|}
\hline Vehicle Type & $\begin{array}{c}\text { Control } \\
\text { Strategy }\end{array}$ & Weight (kg) & $\begin{array}{c}\text { Distance } \\
\text { Traveled } \\
\text { (miles) }\end{array}$ & $\begin{array}{c}\text { Initial } \\
\text { SOC }\end{array}$ & $\begin{array}{c}\text { Final } \\
\text { SOC }\end{array}$ & MPG & $\begin{array}{c}\text { MPG } \\
\text { equivalent }\end{array}$ \\
\hline Parallel & Fuzzy & 1400 & 74.5 & .7 & .68 & 55.2 & 55.1 \\
\hline Parallel & PAR_PTC & 1400 & 74.5 & .7 & .60 & 55.1 & 54.5 \\
\hline Conventional & & 1400 & 74.5 & & & 48 & \\
\hline
\end{tabular}

Table 4.9 Fuel use mode over ten FUDS cycles compared with PEA and conventional vehicle in the city

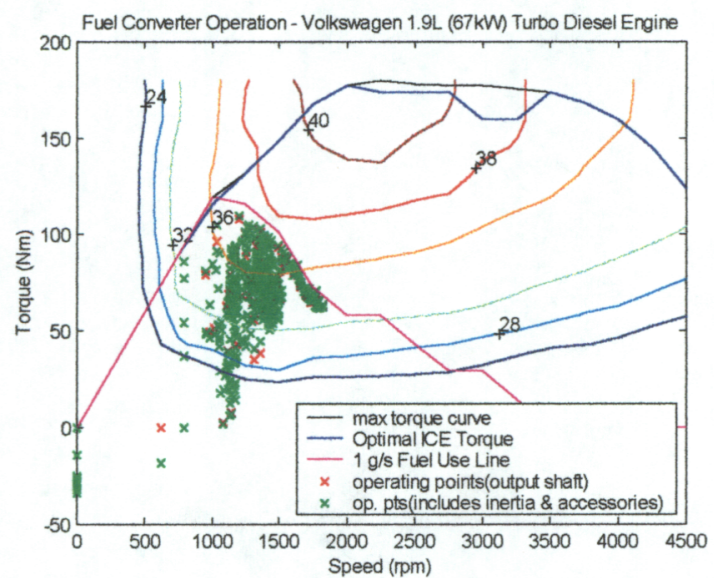

Figure 4.21 Fuel converter operation over for the FLC in the fuel use mode over HWFET drive cycle

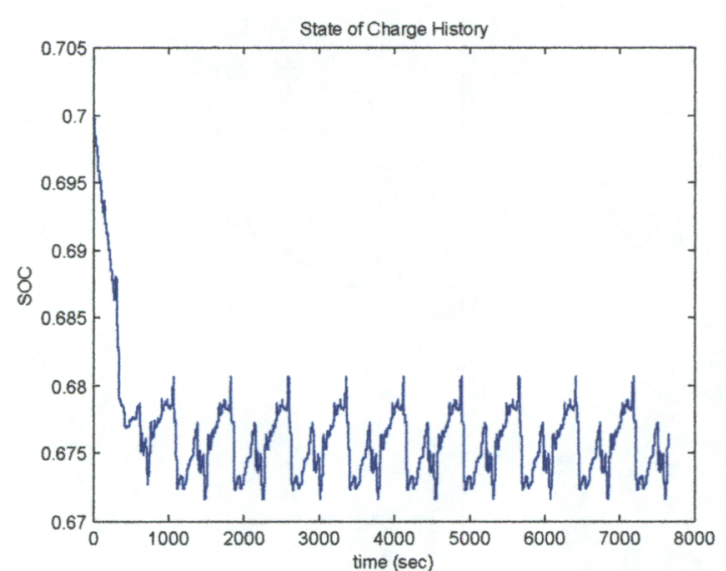

Figure 4.22 State of charge history for the FLC in the fuel use mode over HWFET drive cycle

\begin{tabular}{|c|c|c|c|c|c|c|c|}
\hline Vehicle Type & $\begin{array}{c}\text { Control } \\
\text { Strategy }\end{array}$ & Weight $(\mathrm{kg})$ & $\begin{array}{c}\text { Distance } \\
\text { Traveled } \\
\text { (miles) }\end{array}$ & $\begin{array}{c}\text { Initial } \\
\text { SOC }\end{array}$ & $\begin{array}{c}\text { Final } \\
\text { SOC }\end{array}$ & MPG & $\begin{array}{c}\text { MPG } \\
\text { equivalent }\end{array}$ \\
\hline Parallel & Fuzzy & 1400 & 102 & .7 & .68 & 64 & 63.9 \\
\hline Parallel & PAR_PTC & 1400 & 102 & .7 & .60 & 64 & 63.2 \\
\hline Conventional & & 1400 & 102 & & & 48 & \\
\hline
\end{tabular}

Table 4.10 Fuel use mode over ten HWFET cycles compared with PEA and conventional vehicle on the highway.

The final case is used to show the effect of load leveling about the engines $1.1 \mathrm{~g} / \mathrm{s}$ fuel use line. Figures 4.23 and 4.24 display the operation of the ICE and the battery module over ten FUDS drives cycles. Figures 4.25 and 4.26 also show the operation of 
the ICE and the battery module over ten HWFET drives cycles. The majority of the operating points of the ICE are located near or beneath the $1.1 \mathrm{~g} / \mathrm{s}$ fuel use line. The discrepancies in results for the city and the highway, compared to the $1 \mathrm{~g} / \mathrm{s}$ fuel use line are given in table 4.11 and table 4.12 , respectively. The equivalent mpg has been slightly increased to $56.1 \mathrm{mpg}$ for the city and 65.2 for the highway. However, since the results for both cases are only slightly different, it is concluded that there is no significant impact of load leveling about the $0.9 \mathrm{~g} / \mathrm{s}$ or the $1.1 \mathrm{~g} / \mathrm{s}$ fuel use lines rather than the $1.0 \mathrm{~g} / \mathrm{s}$ constant fuel use line.

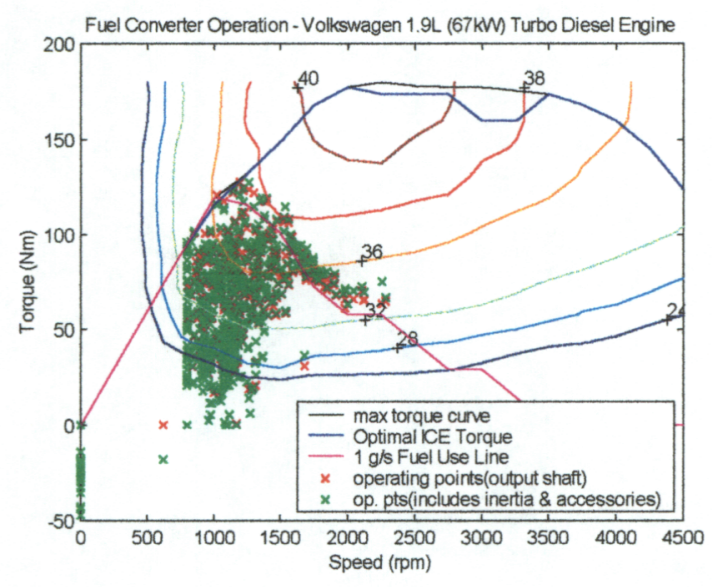

Figure 4.23 Fuel converter operation over for the FLC in the fuel use mode over HWFET drive cycle

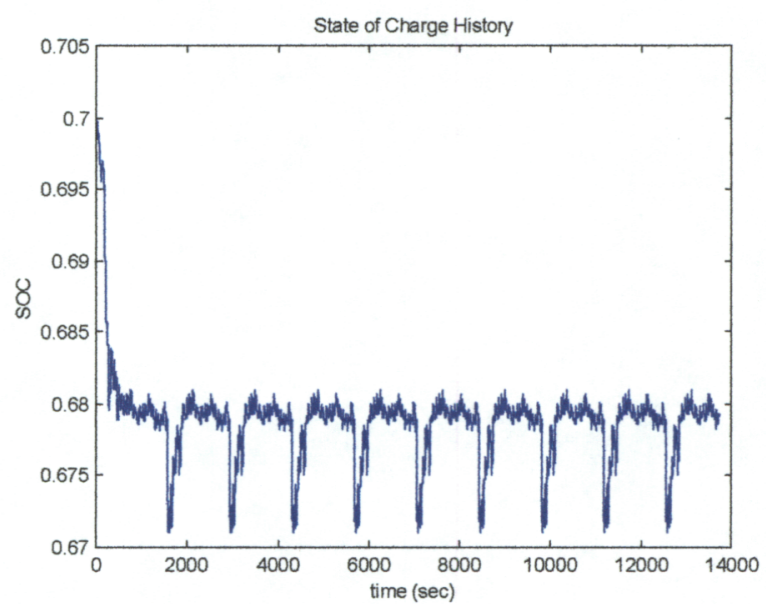

Figure 4.24 State of charge history for the FLC in the fuel use mode over HWFET drive cycle

\begin{tabular}{|c|c|c|c|c|c|c|c|}
\hline Vehicle Type & $\begin{array}{c}\text { Control } \\
\text { Strategy }\end{array}$ & Weight (kg) & $\begin{array}{c}\text { Distance } \\
\text { Traveled } \\
\text { (miles) }\end{array}$ & $\begin{array}{c}\text { Initial } \\
\text { SOC }\end{array}$ & $\begin{array}{c}\text { Final } \\
\text { SOC }\end{array}$ & MPG & $\begin{array}{c}\text { MPG } \\
\text { equivalent }\end{array}$ \\
\hline Parallel & Fuzzy & 1400 & 74.5 & .7 & .68 & 56.2 & 56.1 \\
\hline Parallel & PAR PTC & 1400 & 74.5 & .7 & .60 & 55.1 & 54.5 \\
\hline Conventional & & 1400 & 74.5 & & & 48 & \\
\hline
\end{tabular}

Table 4.11 Fuel use mode over ten FUDS cycles compared with PEA and conventional vehicle in the city 


\begin{tabular}{|c|c|c|c|c|c|c|c|}
\hline Vehicle Type & $\begin{array}{c}\text { Control } \\
\text { Strategy }\end{array}$ & Weight (kg) & $\begin{array}{c}\text { Distance } \\
\text { Traveled } \\
\text { (miles) }\end{array}$ & $\begin{array}{c}\text { Initial } \\
\text { SOC }\end{array}$ & $\begin{array}{c}\text { Final } \\
\text { SOC }\end{array}$ & MPG & $\begin{array}{c}\text { MPG } \\
\text { equivalent }\end{array}$ \\
\hline Parallel & Fuzzy & 1400 & 102 & .7 & .68 & 65.3 & 65.2 \\
\hline Parallel & PAR_PTC & 1400 & 102 & .7 & .60 & 64 & 63.2 \\
\hline Conventional & & 1400 & 102 & & & 48 & \\
\hline
\end{tabular}

Table 4.12 Fuel use mode over ten HWFET cycles compared with PEA and conventional vehicle on the highway.

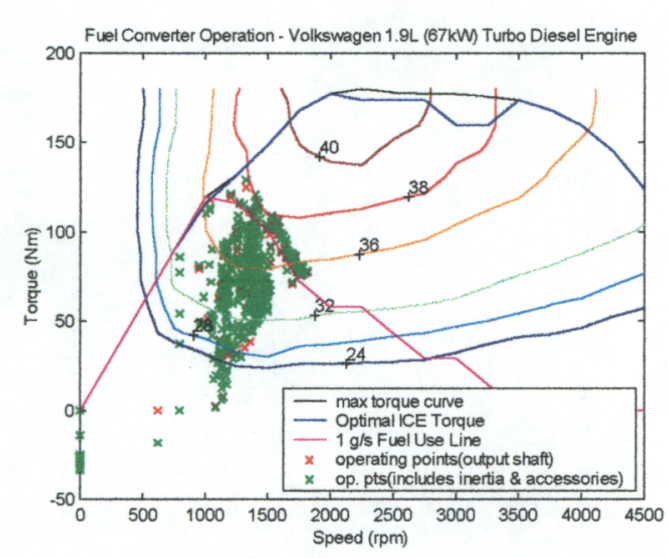

Figure 4.25 Fuel converter operation over for the FLC in the fuel use mode over HWFET drive cycle

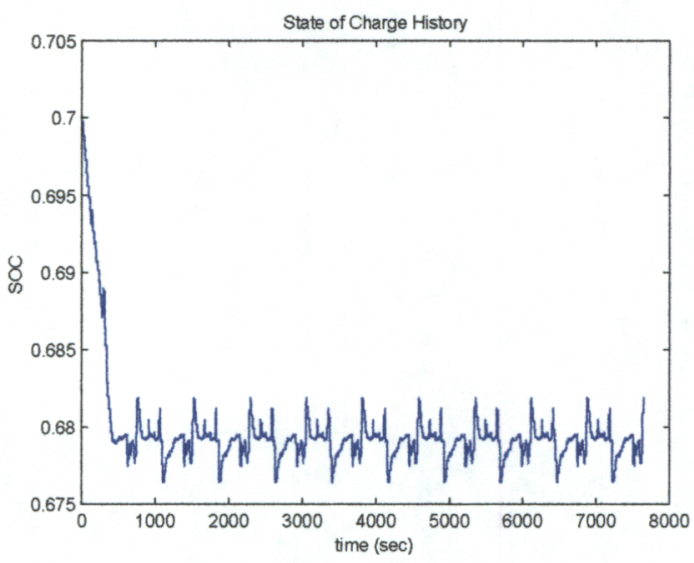

Figure 4.26 State of charge history for the FLC in the fuel use mode over HWFET drive cycle 


\section{CHAPTER 5}

\section{Control Implementation on the OSU Hybrid Electric Vehicle}

The fuzzy logic supervisory controller [3] simulated in Advisor is to be implemented in the 1999 OSU Future Car, a parallel hybrid with a 66kW Direct Injection Diesel Engine and a $36 \mathrm{~kW}$ e-machine. This was carried out with the dSpace DS1 102 Controller board. The controller software is accessed through the Simulink environment virtually eliminating all handcoding. This allows new control policies to be implemented and tested in real time quickly and easily.

\section{1 dSpace Implementation}

The entire control strategy is based upon the throttle by wire mechanism. The driver depresses the accelerator pedal, a potentiometer that sends a voltage signal to the engine control unit (ECU), which regulates the rate of fuel injection. Since the signal to the ECU is a simple voltage signal it can be interrupted and can have some control performed on it before it is sent to the ECU. Explaining why one of the inputs to the FLC previously discussed is the throttle position voltage and why one of the outputs is the change in the accelerator position voltage. Therefore the accelerator potentiometer 
signal will be manipulated in order to load level with the electric machine. The fuel use mode is the control policy to be implemented with the dSpace controller.

The controller was first built in the Simulink environment and then downloaded to the DS1 102 controller board. Figure 5.1 shows the simulink block diagram representing the FLC of the 1999 OSU Future Car.

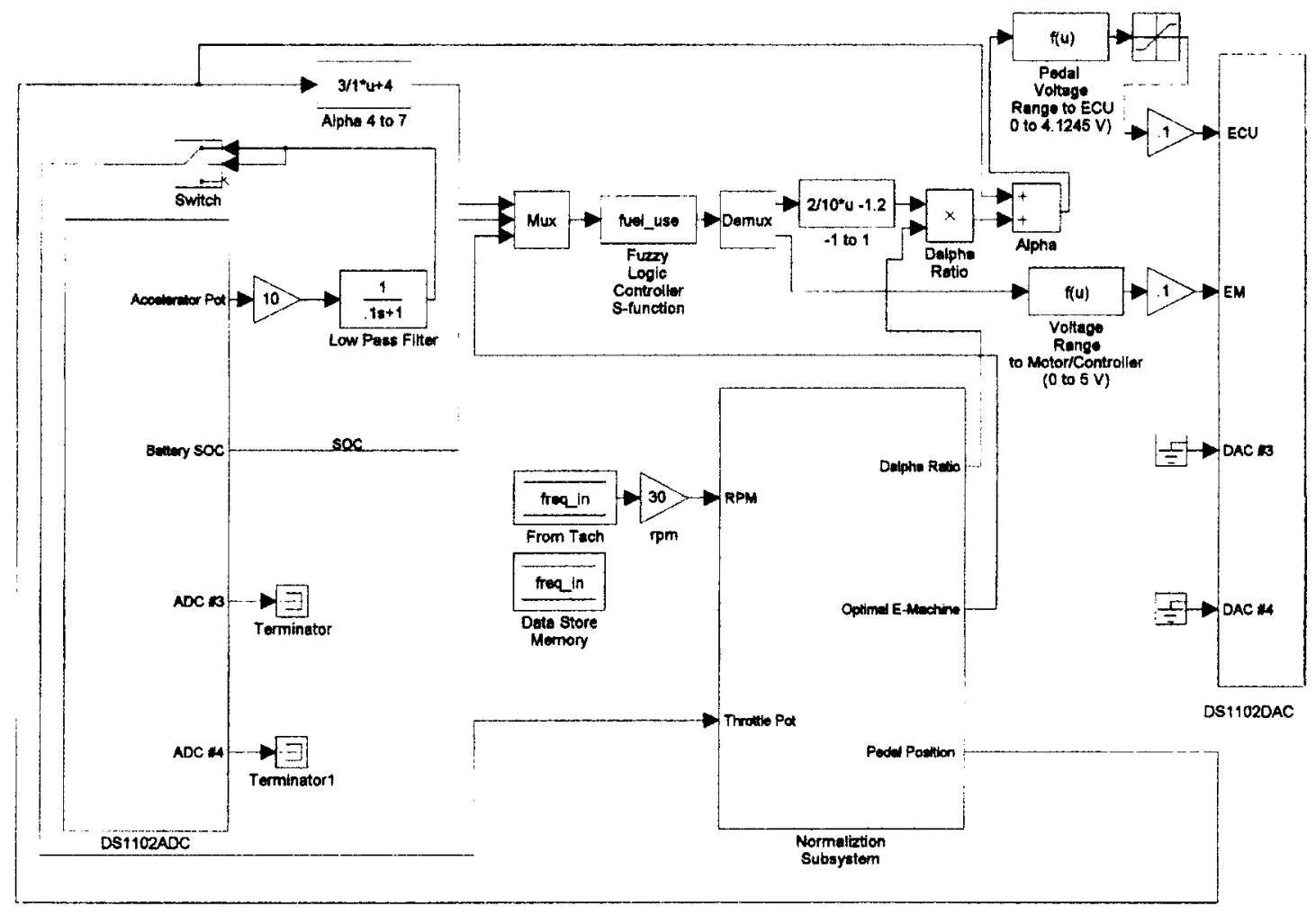

Figure 5.1 Simulink/dSpace block diagram of OSU future car supervisory controller

The DS1 102ADC block on the far left of figure 5.1 is the analog to digital converter used for analog inputs to the controller board. The first input to the board, labeled ADC \#1, is the throttle pot signal. It is first passed through a gain block of 10 . This is because a voltage of $10 \mathrm{~V}$ seen by the $\mathrm{D} / \mathrm{A}$ converter is equivalent to 1 in the $\mathrm{dSpace} /$ Simulink environment. It is then sent through a first order filter to reduce the noise inherent to the 
signal. Next it is sent through a switch that will output a zero when the pot signal is less than 0.65 Volts. This prevents any control action from taking place when the accelerator pedal is at rest because it gives off 0.6 Volts, not $0.0 \mathrm{~V}$, when it is in this position. The signal is then sent into the Normalization subsystem.

The data store named freq in is also sent to the Normalization subsystem seen in Figure 5.1 is. This signal is used to calculate the rpm of the ICE. The engine's tachometer emits a square wave pulse train whose frequency can be measured with the capture/compare input to the slave dsp of the DS1 102 board. The frequency measurement made from the capture/compare utility must then be multiplied by a gain of 30 to convert it to engine rpm. The additional C-code [17] necessary to initialize this function is given in the appendix B.

Figure 5.2 depicts the Normalization subsystem that the accelerator pot and engine rpm signals are sent. The throttle pot command is first sent to the pedal position function block in order to convert the voltage magnitude to a fraction of depression. For example when the accelerator pedal is being fully pressed down the pot outputs $4.125 \mathrm{~V}$. Once this is passed through the pedal position block it will be converted to a value of 1 , meaning the accelerator is $100 \%$ depressed.

The rpm value is used in three look-up tables. First is the ICE Maximum Torque Look-Up Table contains the wide-open throttle torque vs. speed data for the $66 \mathrm{~kW} \mathrm{VW}$ diesel engine. Next the rpm value is used to index the $1 \mathrm{~g} / \mathrm{s}$ fuel use line of the VW engine. Finally it is needed to determine the maximum e-machine torque at the current rotational speed. 


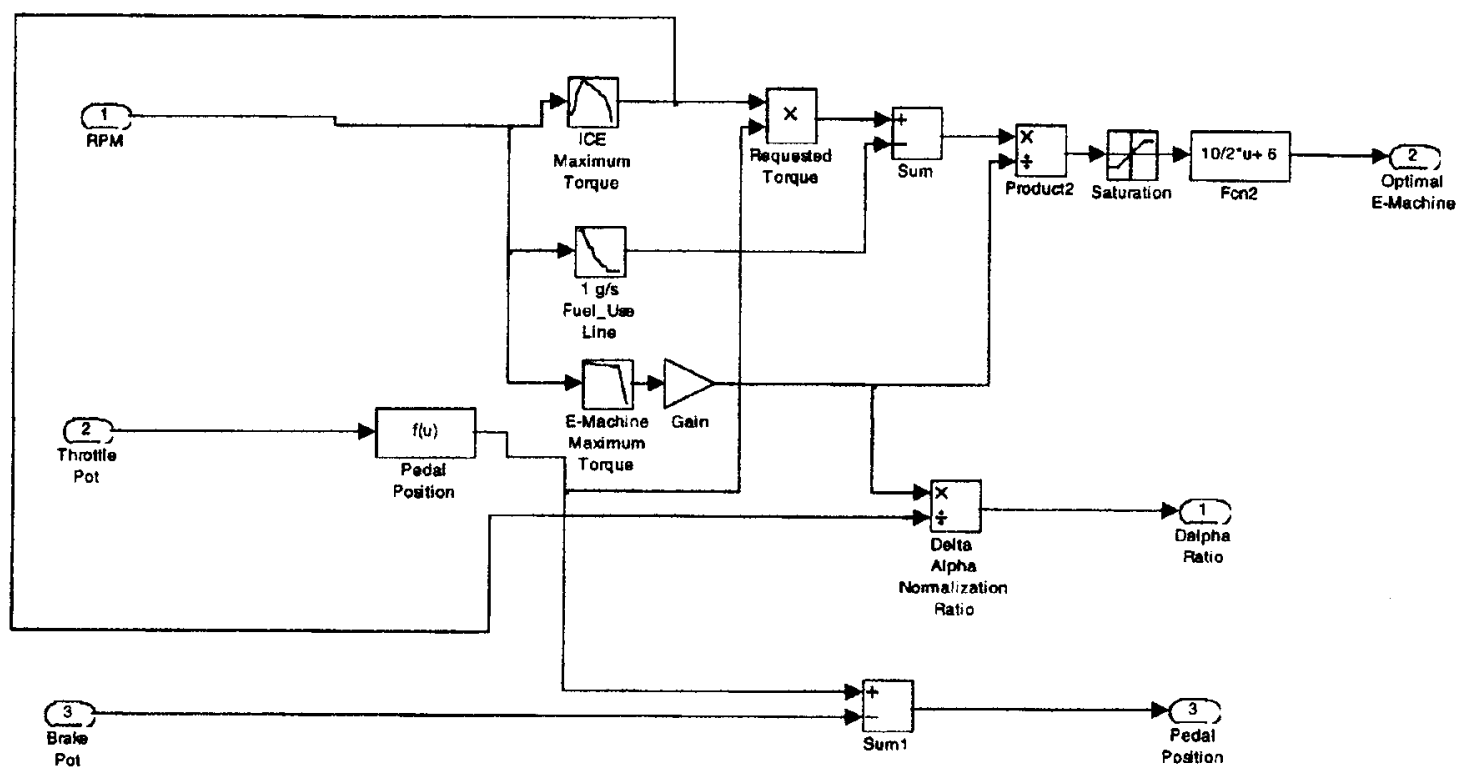

Figure 5.2 Normalization subsystem

The maximum ICE torque value is then sent to the Requested Torque product block to be multiplied by the pedal position fraction in order to estimate the current road load of the drive cycle. This is assumed to be a proper approximation because the torque command to the ECU is proportional to torque in a diesel engine.

Next the $1 \mathrm{~g} / \mathrm{s}$ fuel use line torque is subtracted from the estimated road load, by the sum block, in order to determine the desired torque of the e-machine. This torque is then divided by the maximum torque value to normalize it from -1 to 1 . Where -1 indicates running the e-machine fully as a generator and 1 represents running it as a motor with the highest allowable positive torque output. This number is then saturated to prevent it from exceeding the limits of -1 to 1 . The number is then sent through the function block, Fcn2, to convert it from 1 to 11 . Where 1 now designates full negative torque and 11 means maximum positive torque. This is necessary to make the number for the optimal e-machine torque compatible with the fuzzy logic S-function C-code 
given in the appendix B. The gain block after the E-machine lookup table is needed because the data in the table is for a $36 \mathrm{~kW}$ controller but the controller in the car is 24 $\mathrm{kW}$. Also notice that the maximum e-machine torque is divided by the maximum ICE torque in the Delta Alpha Normalization Ratio block, its use will be discussed later. Finally the optimal E-machine, $\Delta \alpha$ ratio and pedal position are all sent back to the main program of figure 5.1 .

The accelerator pedal position is then sent to the alpha function block to convert the fraction from 4 to 7 in order to make it compatible with the FLC C-code. 4 corresponding to the pedal being at rest and 7 meaning it is being floored. It is muxed together with the SOC of the battery module and the optimal e-machine torque in order to send all the inputs to the Fuzzy Logic S-function.

The S-Function computes two outputs $\Delta \alpha$ and the actual e-machine torque command. Both of these values range from 1 to 11 . The $\Delta \alpha$ value is first sent to the function block to normalize it back from -1 to 1 . It is then multiplied by the $\Delta \alpha$ ratio in order to limit the control action. This is necessary because if the FLC C-code were to output an 11 for the e-machine torque command (maximum positive torque), it will output a $\Delta \alpha$ of 1 (Maximum decrease in throttle command), making the $\alpha$ signal sent to the ECU OV. Suppose that the maximum e-machine torque is not enough to fulfill the torque demand of the driver. The ICE must supply some additional torque. The $\Delta \alpha$ ratio prevents the $\alpha$ torque command to the ECU from dropping below the value that is actually required.

The manipulated $\Delta \alpha$ command is added back to the original pedal fraction and sent to a function block that returns it back to a magnitude the ECU can understand, 0.6 
$\mathrm{V}$ for idling torque and 4.125 for maximum torque. The command is saturated to prevent it from exceeding these limits and multiplied by a gain of .1 before it is sent to the DS1102 DAC block to be converted to an analog signal. The a command must be scaled by a factor of .1 because in simulink a value of \pm 1 sent to the D/A block outputs a voltage of $\pm 10 \mathrm{~V}$ to the dSpace breakout box.

The second output to the DS1102DAC block is the torque command to the emachine controller. The command is first passed through a function block that converts the range of the command 1 to 11 (from the fuzzy code) to 0 to 3.5 . This is necessary because the motor controller requires a torque command with in this range. When the motor controller sees a command of $0 \mathrm{~V}$ it will run the e-machine at maximum negative torque and when it sees $3.5 \mathrm{~V}$ it will control the e-machine to run at full positive torque. The torque command signal is assumed to be linear throughout this range. For example if a $0 \mathrm{~V}$ reference corresponds to $-80 \mathrm{Nm}$ and $3.5 \mathrm{~V}$ corresponds to $+80 \mathrm{Nm}$ then $1.75 \mathrm{~V}$ will give an output of $0 \mathrm{Nm}$. The 0.1 gain block is again needed to make the range of $0-3.5 \mathrm{~V}$ compatible with the DS1 102 ADC.

\subsection{Environmental Issues}

All physical systems posses inherent environmental problems that make control implementation far more difficult than intended. With the OSU Future car there were two hindering problems that made implementation difficult, signal noise and electromagnetic interference generated by both the electric motor controller and the vehicle itself. These problems first needed to be dealt with before the car could be run with the dSpace controller board. 
During the course of installation of the controller into the vehicle some Electromagnetic Interference/Electromagnetic Compatibility (EMU/EMC) [15] problems were encountered. Originally the dSpace unit was placed in the trunk of the car near the motor controller. As soon as the motor would turn on the EMI from the controller would overload the DS1 102 board causing the real time control software to cease working. To eliminate this obstacle shielding [20] was placed over the motor controller to absorb the EMI and drain the currents it generated to the chassis ground. This proved not to be effective due to the magnitude of the EMI generated by the motor. Therefore the dSpace Autobox and breakout box had to be moved to the front seat, as far away as possible from the motor controller.

This also was not effective in preventing the controller board from overloading and terminating the fuzzy logic control. Therefore all the inputs to the controller had to be differential inputs in order to isolate the controller board ground from the chassis ground. The solution to the problems encountered with the controller and detailed analysis of the EMI/EMC problem is beyond the scope of this thesis.

The next problem with the implementation was the noise associated with the accelerator potentiometer signal. Since portions of the control algorithm are based on this signal it is very important it is clean. Therefore the signal was filtered with a digital first order filter with a time constant of 0.1 seconds as seen in Figure 5.1. This had to be done because the control action to the e-machine was based on this signal. A noisy torque command signal to the e-machine caused a chattering effect in its operation.

Figure 5.3 shows the effect of the filter on the signal. The magnitude of the noise is greatly reduced however another problem is created. A phase shift is now introduced 
between the driver command and what the control sees. It was concluded that this time delay was minimal and the benefit of sending a clean torque command signal to the emachine controller outweighed this problem.

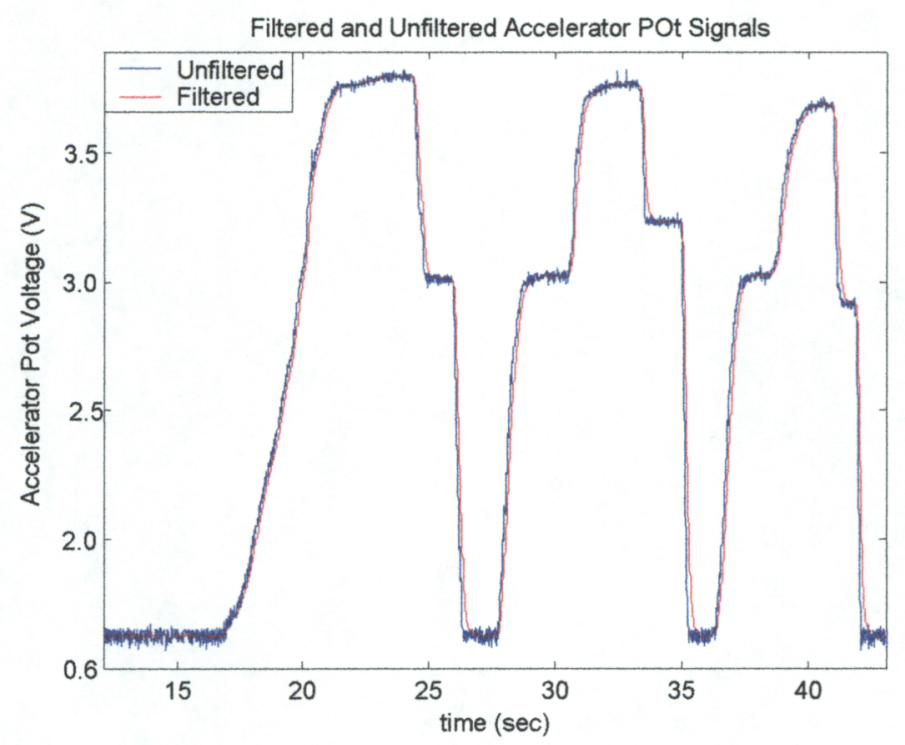

Figure 5.3 Dynamic effect of filter on accelerator pot signal 


\section{CHAPTER 6}

\section{CONCLUSIONS AND FUTURE WORK}

The fuzzy logic control strategies proved to be effective in the coordination of the drivetrain components for a parallel hybrid electric vehicle. They were designed to optimize the fuel efficiency of the ICE. This is because Ohio State University's hybrid electric vehicle is ICE dominated, meaning it has a small Degree of Hybridization $[3,8]$. The selling point of these vehicles will mainly be their ability to achieve good fuel economy. This has been dually accomplished in simulation by optimizing the efficiency of the ICE and by forcing the ICE to operate at a point with a low fuel use rate while the vehicle achieves low speeds. These two control strategies display similar results even though they are different in nature. The strategy implemented on the OSU future car is the fuel use mode because the highest point of efficiency for the $66 \mathrm{~kW}$ turbo diesel engine is at full throttle. The engine is oversized for the vehicle and for it to be continually run at its maximum torque output is not plausible. Also load leveling about the $1 \mathrm{~g} / \mathrm{s}$ fuel use line appears to operate the e-machine as little as possible. This could prolong the hybrid torque coupler lifetime, a weak point in the vehicle's design.

Future work will include the testing of the 1999 OSU Future Car. The car will be run through numerous highway and city drive cycles on the OSU chassis dynamometer in 
order to obtain fuel economy and battery data. This information is necessary to validate the simulation results achieved with Advisor. Also load-leveling strategies will be developed with the sole purpose of reducing emissions. 
Appendix A

M-files 
function gui_run_simulation(time_step)

ofunction gui_run_simulation() runs the appropriate simulation

depending on the

otype of drivetrain selected

global vinf

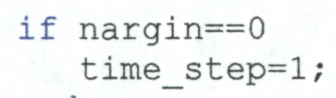

evalin('base', ['sim('' ', series, '' ', ', durstr, ', simset (''Fixedstep' ', ', nu m2str(time_step),' ') '])

end

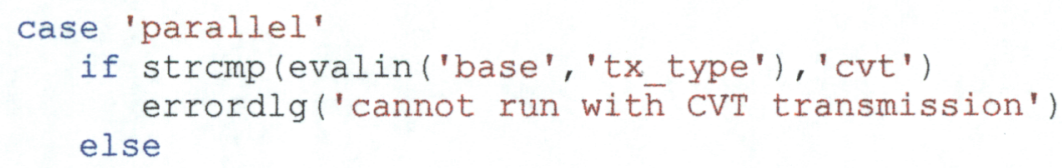


if $\operatorname{strcmp}($ evalin('base', 'tx_type'), 'cvt')

evalin('base', ['sim(''', convcvt, '' ', ', durstr, ', simset(''Fixedstep' ', ', n um2str(time_step),' ') '])

elseif strrmp (evalin('base','tx_type'), 'auto 4 speed')

evalin('base', ['sim(''', convat, ' ' ', ', durstr, ', simset(''Fixedstep' ', ', nu m2str(time_step),'))'])

else

evalin('base', ['sim(' '', conventional, ' ' ', ', durstr, ', simset(''Fixedstep' ', ', num2str(time_step),' '))'])

end

case 'fuel_cell'

evalin('base', ['sim('' ', fuelcell, '' ', ', durstr, ', simset(''Fixedstep' ', ', num2str(time_step),'))'])

case 'ev'

evalin('base', ['sim(''', ev, '' ', ', durstr, ', simset(''FixedStep' ', ', num2st r(time_step),'))'])

otherwise end

errordlg('fix the drivetrain names in gui_run_simulation')

8/28/98:vh added ev simulation call

\% 09/03/98:tm added fuelcell simulation call

\% 9/30/98:ss replaced gearbox with transmission

\% 12/22/98:ss replaced strcmp (vinf.transmission.name,'******') with strcmp (evalin ('base', 'tx_type'), '***') 

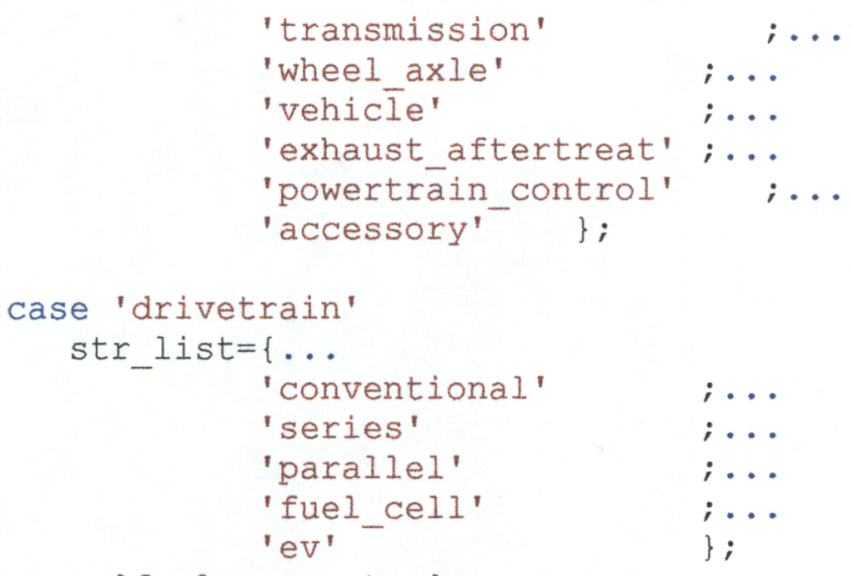

end

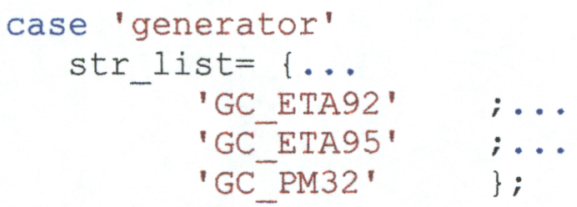




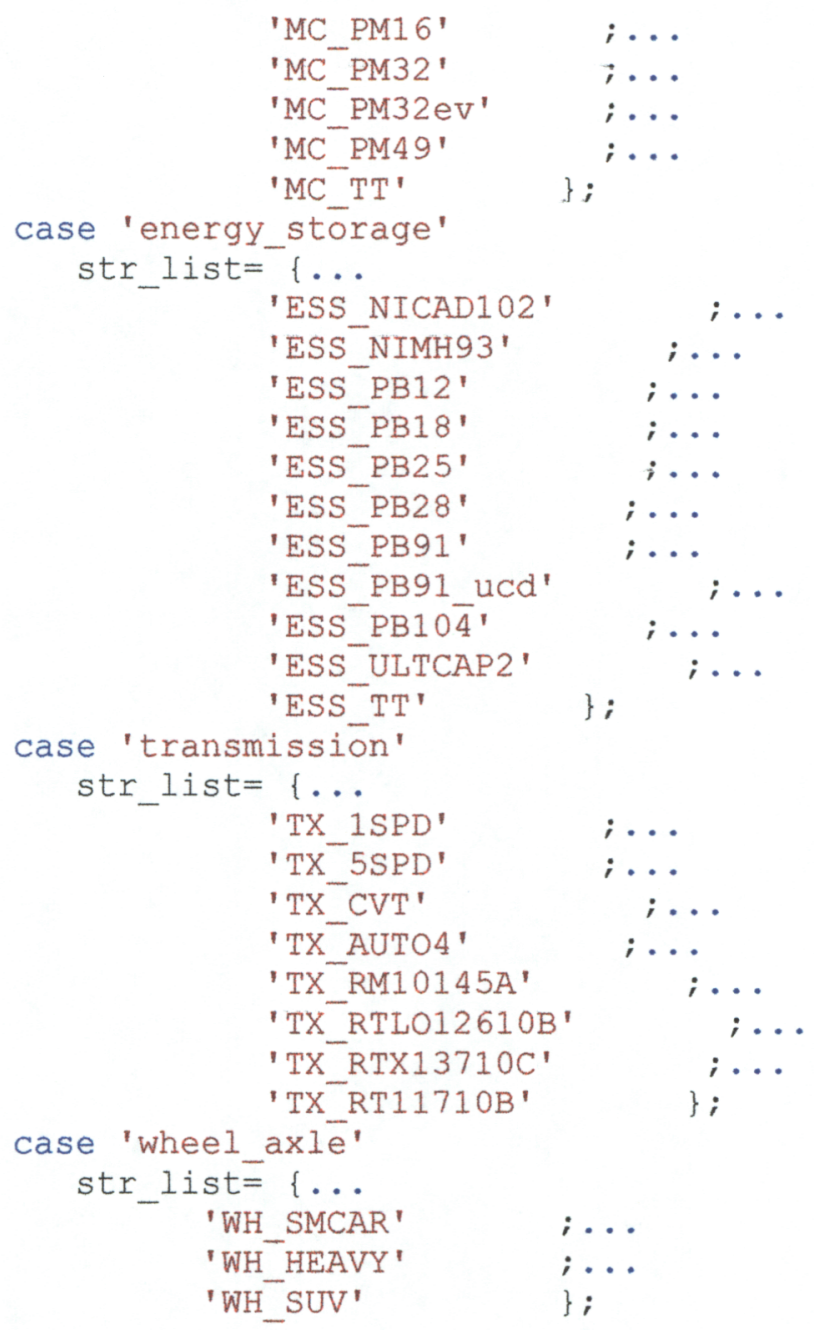

case 'vehicle'

str 1 ist $=\{\ldots$

'VEH SMCAR'

'VEH LGCAR'

'VEH SUV'

'VEH KENT800'

'VEH KENT400'

'VEH ORIONVI'

'VEH TT' \};

$$
\begin{aligned}
& \ldots \\
; \ldots & \\
; \ldots & \\
& ; \ldots \\
& ; \ldots \\
& ; \ldots
\end{aligned}
$$

case 'exhaust aftertreat' 


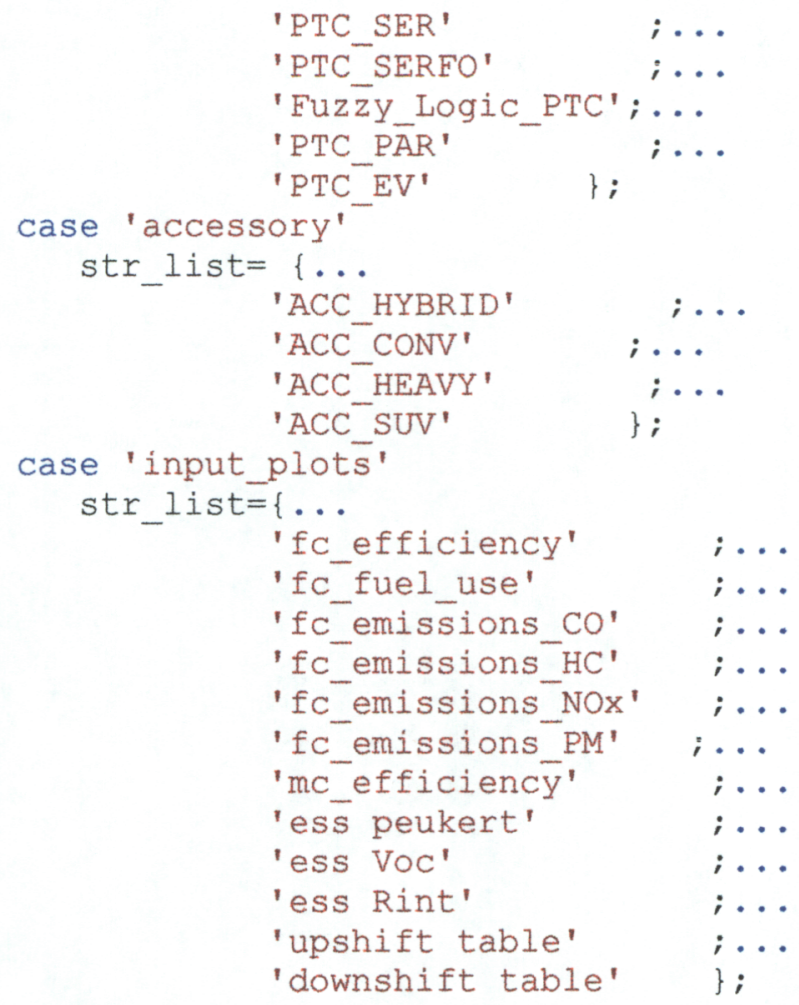

case 'cycles'

str list $=\{\ldots$

'CYC 1015'

'CYC 5PEAK'

'CYC ACCEL'

' CYC ARB02'

'CYC BUSRTE'

' $\mathrm{CYC}^{-} \mathrm{CBDBUS}$ '

' CYC CBDTRUCK'

'CYC CONSTANT'

'CYC FUDS'

'CYC HLO7'

' CYC HWFET'

' CYC L60MPH'

'CYC NEDC'

'CYC NYCC'

' CYC NYCCOMP'

'CYC NYCTRUCK'

'CYC REP05'

'CYC SCO3'

'CYC_UDDSHDV'

' CYC UNIFO1'

'CYC US06'

'CYC WVUCITY'

'CYC WVUINTER'

'CYC WVUSUB'

case 'no of cȳcles'

str_Iist $=\{\ldots$

$11 '$
13 '
15 '




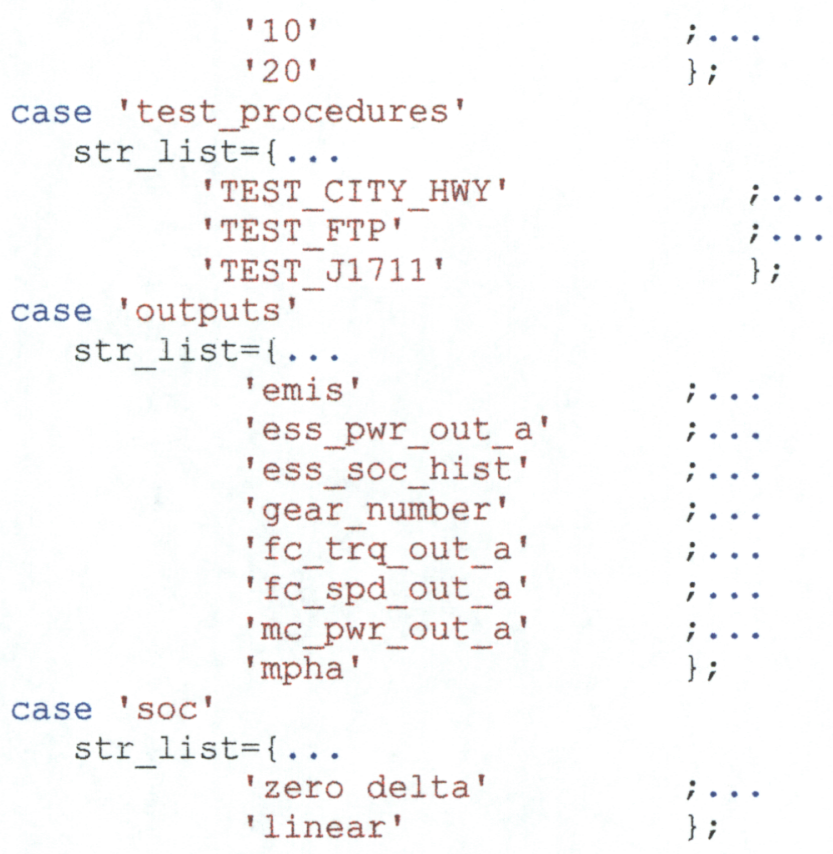


o gui_run.m

\% Commands executed when RUN button is pushed from cycle setup figure \%

powlu

ticefuel;

ticeopt;

global vinf;

deltaSOC tol=0.005; otolerance for zero delta soc correction

max_zero_delta_iter=15; 8 maximum number of zero delta soc iterations

if strcmp (vinf.test.run, 'on')

eval (vinf.test.name)

return

end

omessage to user that simulation is running

if strcmp(vinf.parametric.run, 'off') \& isfield(vinf,'run_without_gui')

$\mathrm{h}=$ waitbar $(0.2$, 'Simulation in progress. See command window for

updates.' );

end

\%if the acceleration is on, but parametric is off and cycle is not Accel, run the acceleration test

if

strcmp (vinf.acceleration.run, 'on') \&strcmp (vinf.parametric.run, 'off') \& s trcmp (vinf. cycle.name, 'CYC ACCEL')

end;

accel_test;

oif the gradeability is on, but parametric is off, run the gradeability test

if strcmp (vinf.gradeability.run, 'on') \&strcmp (vinf.parametric.run, 'off')

evalin('base', 'vinf.max grade=grade test (vinf.gradeability.speed);'); am added (55) on $9 / 16 / 9 \overline{8}$

end;

if strcmp (vinf.cycle.soc, 'on') \& strcmp (vinf.parametric.run, 'off')

if strcmp (vinf.cycle.socmenu,' 'linear') olinear soc correction

srun the simulation with the low soc value

evalin ('base', 'ess_init_soc=CS_10_soc-.01;');

gui run simulation;

evalin('base', 'gui post process');

if evalin('base', 'exist ('mpg' ')')

$\operatorname{mpg}(1)=$ evalin ('base', 'mpg');

gpm $(1)=1 / \operatorname{mpg}(1)$;

is zero

else ofor series case with no gas mileage, the gallons per mile

$$
\operatorname{gpm}(1)=0
$$


end

hc (1) =evalin ('base', 'hc_gpm'),

co (1) =evalin ('base', 'co_gpm') ;

nox $(1)=e v a l i n($ 'base', 'nox gpm');

deltasoc $(1)=e v a l i n(' b a s e '$, 'ess_soc_hist(end)-ess_soc_hist (1)');

if abs (deltaSOC(1)) >deltaSOC_tol odoesn't run another simulation if low init SOC gives zero delta

oupdate the waitbar--half way done with simulation

if risfield(vinf, 'run_without_gui')

waitbar (.45);

end

orun the simulation with the hi soc value

evalin ('base', 'ess_init_soc=cs_hi_soc+.01;');

gui run simulation;

evalin('base', 'clear mpg hc_gpm co_gpm nox_gpm');

variables left from first run

evalin('base', 'gui post process');

if evalin('base', 'exist ('mpg'')')

mpg $(2)=$ evalin ('base' , 'mpg') ;

gpm $(2)=1 / \operatorname{mpg}(2)$;

mile is zero

else $\frac{\circ}{6}$ or series case with no gas mileage, the gallons per

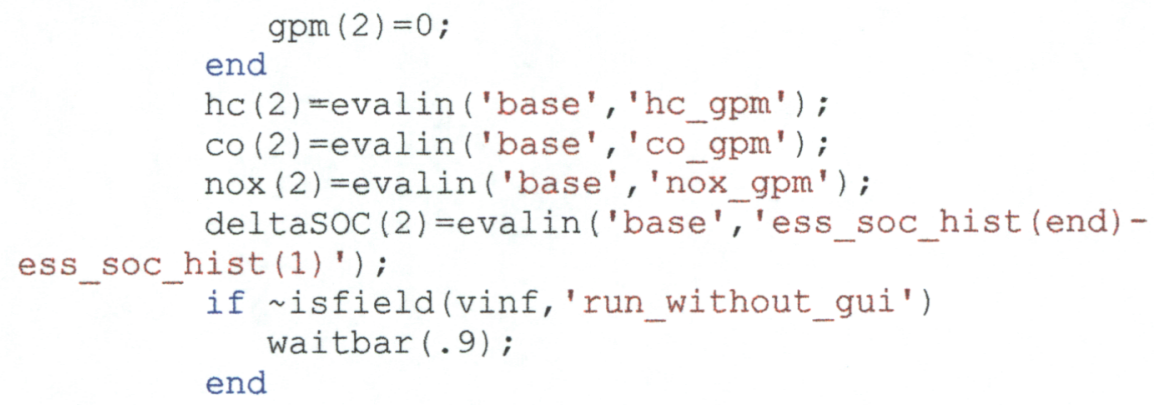

mpgge=MilesPG*42600/evalin ('base', 'fC_fuel_lhv')*749/evalin ('base', 'fC_ fuel_den'); 8 gas equivalent

hc_emis=interpl (deltasoc, hc, 0);

Co_emis=interpl (deltasoc, $\mathrm{Co}, 0)$;

nox_emis=interp1 (deltasoc, nox, 0);

oasign the linear corrected results in base assignin('base', 'mpg', MilesPG) ;

equivalent

assignin('base','mpgge',mpgge); omiles per gallon gas

assignin('base', 'hc_gpm', hc_emis);

assignin('base', 'Co_gpm', co_emis);

assignin('base', 'nox_gpm', nox_emis) ;

achieved

ofif linear did not work because positive delta soc was not

if isnan(mpg) 
evalin ('base', 'mpg=0; mpgge=0; hc_gpm=0; co_gpm=0; nox_gpm=0;') ;

evalin ('base', 'warnings $\{$ warn index $\}=$ ' 'SOC correct linear

did not work. Fuel Converter too small to charge batteries on this

cycle.'';');

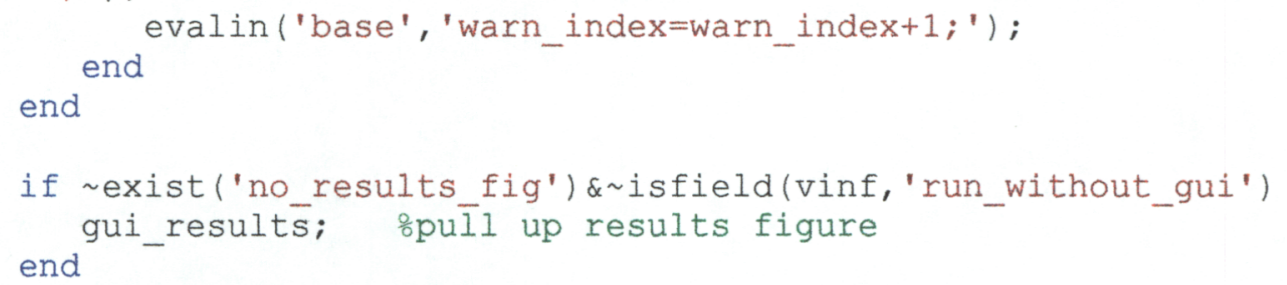

elseif strcmp(vinf.cycle.socmenu, 'zero delta') gotero Delta soc correction

evalin ('base','ess_init_soc=(Cs_10_soctcs_hi_soc) $/ 2 ; ')$; $\%$ take the average as the starting point

clear InitSOC DeltaSOC min_positive_index min_negative_index;

old_pos=0; old_neg=0;

for $i=1:$ max_zero_delta_iter

gui_run simulātion;

value

InițoC'(i)=evalin('base', 'ess init_soc'); orecord initial soC

Deltasoc $(i)=e v a l i n$ ('base', 'ess soc hist (end) -

ess_soc_hist(1)'); grecord Delta SOC

if abs(DeltaSOC(i))<deltaSOC tol obreak the for loop if reach tolerance goal

met. ']);

disp(['Delta SoC Tolerance of ', num2str(deltasoc_tol),'

disp(['Number of runs: ', num2str(i),', Deltasoc:

', num2str(DeltaSOC(i)),', Initial_SOC: ', num2str(InitsoC(i))]); break;

end $\frac{o}{8}$ if <tolerance

oreset the initial SOC

if $i>1$

min index $=$ find $($ DeltaSOC $==\min ($ DeltaSOC $)) ;$ ofind minimum

deltasoc index

if Deltasoc (min index) $<0$

negative_DelEasoc $=$ abs $(\operatorname{DeltaSOC}(\operatorname{DeltaSOC}<0))$;

min_negative_index=find (DeltaSOC==-

$1 * \min ($ negative_DelĒasoc));

positive DeltaSOC=DeltaSOC (DeltaSOC $>0)$; onew vector with

only positive delta soc's

if isempty (positive_DeltasoC)

min_positive_index=find (DeltaSOC $==\min$ (positive_DeltaSoC)) ;

end $\%$ if isempty

end $\frac{\circ}{\partial}$ if Deltasoc $<0$

end $\frac{8}{8}$ if $i>1$

if exist('min positive index') \& exist('min negative index')

if min positive index $=01 d$ pos ।

min_negative_index $=0 l d \_n e g$

$\operatorname{DSOC}(1)=\overline{\operatorname{DeltaSOC}}($ min negative index);

SOC init $(1)=\operatorname{InitSOC}(\bar{m}$ in negative index);

$\operatorname{DSO} \bar{C}(2)=\operatorname{DeltaSOC}\left(\min \_\right.$positive_ind̄ex); 


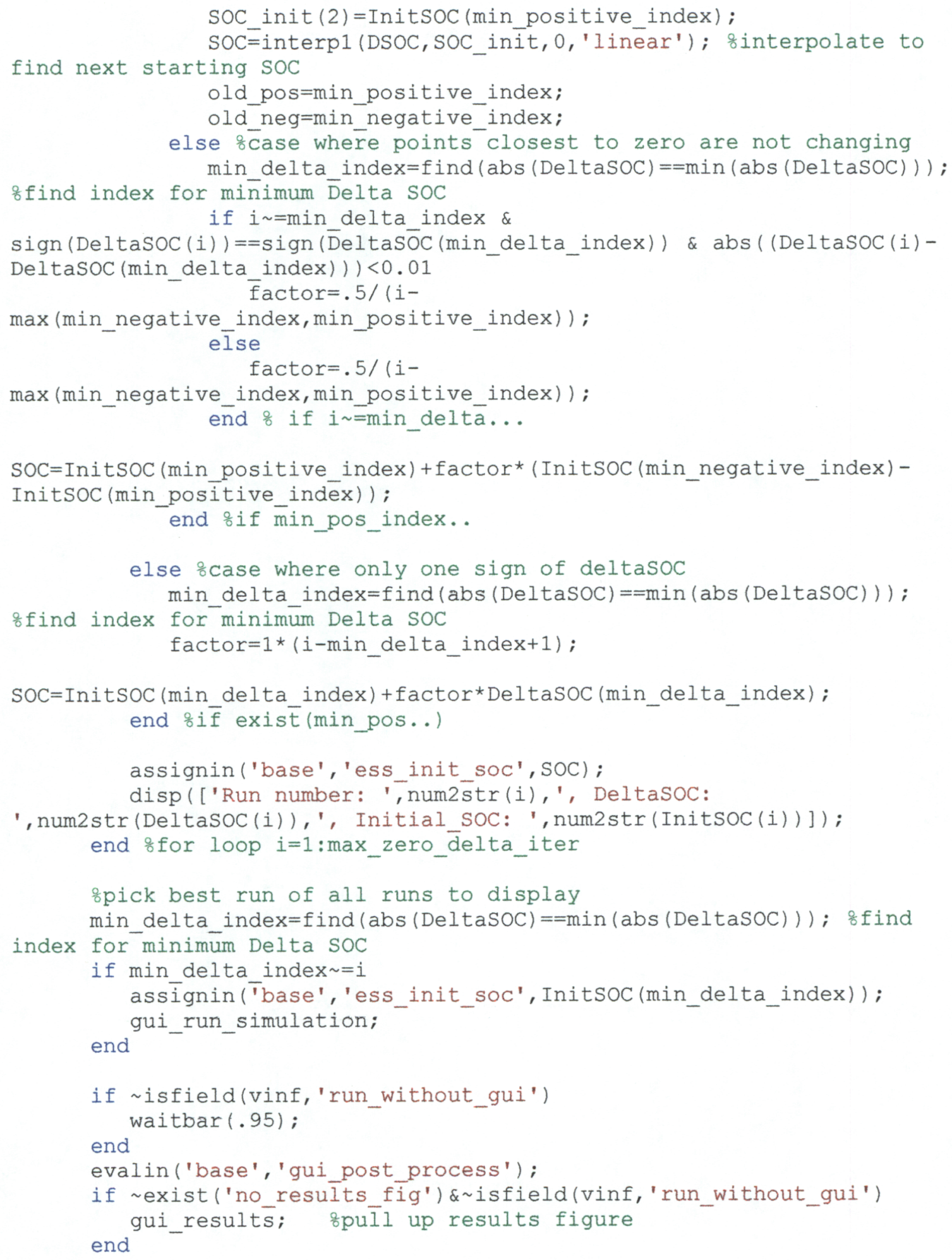


if

strcmp (vinf.cycle.run, 'on') \&strcmp (vinf. cycle.name, 'CYC_ACCEL'); sam

added vinf.cycle.run, 'on'

accel test; ofor acceleration cycle, run the acceleration test to

pick results from it

else

end

gui_run_simulation; orun the basic cycle

if risfield(vinf, 'run_without_gui')

end

waitbar (.95);

evalin('base','gui post process'); oruns the post processing

if rexist ('no results fig') \& isfield (vinf, 'run without gui')

end gui_results; ; $\quad$ ocalls up the results $\bar{f}$ igure

orun the parametric function, includes calls for grade and acceleration if checked

elseif strcmp (vinf.parametric.run, 'on')

end

parametric_execute;

if strcmp (vinf.parametric.run, 'off')\& isfield(vinf,'run_without_gui') waitbar(1);

close $(\mathrm{h})$; $\quad$ oclose the waitbar when finished

end

\%Revision history

\% 8/5/98-valerie new file

8 $8 / 6 / 98-$ sam changed vinf.acceleration to vinf.acceleration.run

8/9/98-valerie, sam add SOC correction

8/10/98-valerie, changed SOC correction algorithm

\% 8/12/98-vj, added mpgge mpgde

\% 8/13/98-valerie, clear mpg, emiss. for linear soC correct before running 2 nd time

\% 8/19/98-vj, changed SOC algorithm

8/19/98-vj, run accel cycle at .1 time step

\% 9/9/98-vj, added warning if linear SOC correction didn't work

9/14/98-vj, SOC linear now has top point at hi limit +.01

$\% 9 / 16 / 98-s s$, added (55) to grade test because grade test.m changed

$812 / 10 / 98-v j$ added if statements to see if user was running advisor using gui or

$\frac{\circ}{8}$

not to decide whether or not to display the waitbar. 
o chkfc.m

\% use to check fuel converter operation

str $=[]$;

if exist('fc_pwr') $\frac{\circ}{\partial}$ vehicle uses a fuel cell

oplot efficiency vs. power curve

figure

plot (fc_pwr*fc_spd_scale*fc_trq_scale,fc_eff*100,'k-')

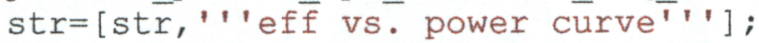

hold

o plot series follower control strategy

if exist('cs_pwr')

plot (cs_pwr/1000,interp2(fc_map_spd*fc_spd_scale,fc_map_trq*fc_trq_scal e,fc_map_eff'*100,cs_spd,cs_pwr./cs_spd), 'b-' '); st $\bar{r}=[$ str, ', ''dēsign curve'''] ;

end;

oplot actual data if it exists

if exist('fc_spd_out_a')

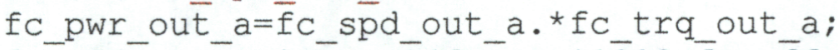

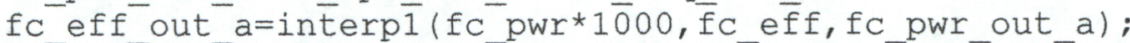

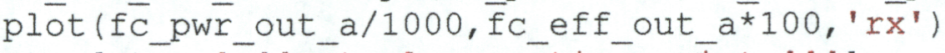

end;

str=[stri, ',' 'actual operāting points'''];

of add labels to the plot

xlabel ('Power ( $\mathrm{kW})$ ')

ylabel ('Efficiency (웅 ')

eval (['legend(', str,' 4 )'])

else of not a fuel cell vehicle

oplot max torque envelope

figure

if exist ('fc_max_trq')

plot (fc_map_spd*30/pi*fc_spd_scale,fc_max_trq*fc_trq_scale, 'k-'); str $=[$ st $\bar{r}, '$ ' $\max$ torque curve $\bar{\prime} \cdot$ ']; 
end;

hold

o plot series follower control strategy

if exist ('cs_pwr')

if $\mathrm{nnz}$ (cs spd<eps)

plot $([\overline{0}$ CS $\operatorname{spd}(:, 2:$ length (cs spd) $) * 30 / \mathrm{pi}],[0$

cs_pwr (:,2:length(cs_pwr))./cs_spd (:,2:length (cs_spd)) ], 'b-');

else

plot (cs_spd*30/pi,cs_pwr./cs_spd, 'b-');

str $=[$ str, ', ''design curve' ' '];

end;

end;

o plot parallel control strategy

if exist('Cs off trq frac') \&

strcmp (vinf.powēerträin control.name, 'PTC_PAR')

plot (fc_map_spd*fC_spd_scale*30/pi,cs_off_trq_frac*fc_max_trq*fc_trq_sc ale, 'b--');

end; str=[str,',''CS off Torque Fraction'''];

if exist('cs_min_trq_frac') \&

strcmp (vinf.powēerträin_control.name, 'PTC_PAR')

plot (fc_map_spd*fC_spd_scale*30/pi,cs_min_trq_frac*fc_max_trq*fc_trq_sc ale, 'g--');

end; str=[str,',' 'CS Minimum Torque Eraction'''];

o plot OSU parallel control strategy

if strcmp (vinf.powertrain_control.name, 'Fuzzy_Logic_PTC')

') ;

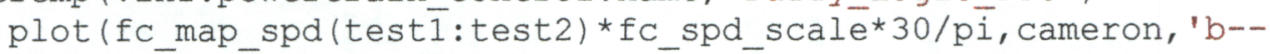

str=[str,',' 'Optimal ICE Torque' ']';

plot (fc_map_spd*fC_spd_scale*30/pi,breslin, 'm--')

str=[st $\bar{r}, ', \bar{r}$ ' g/s Fue $\bar{l}$ Use Line'''];

end;

oplot actual data if it exists

if exist ('fc trq out $a$ ')

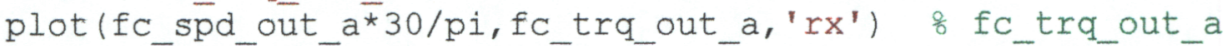

includes inertia effects

str=[str,',' 'operating points (output shaft)'''];

end;

if exist ('fc brake trq')

plot (fC sp d out a*30/pi, fC brake trq, 'gx') 若 fC brake trq does

not include iñertia effects

str=[str,',' 'op. pts (includes inertia \& accessories)''']; end;

o overlay efficiency contour map

if nnz (fC_map_trq<eps)

$\operatorname{trq}=[] ;$ 


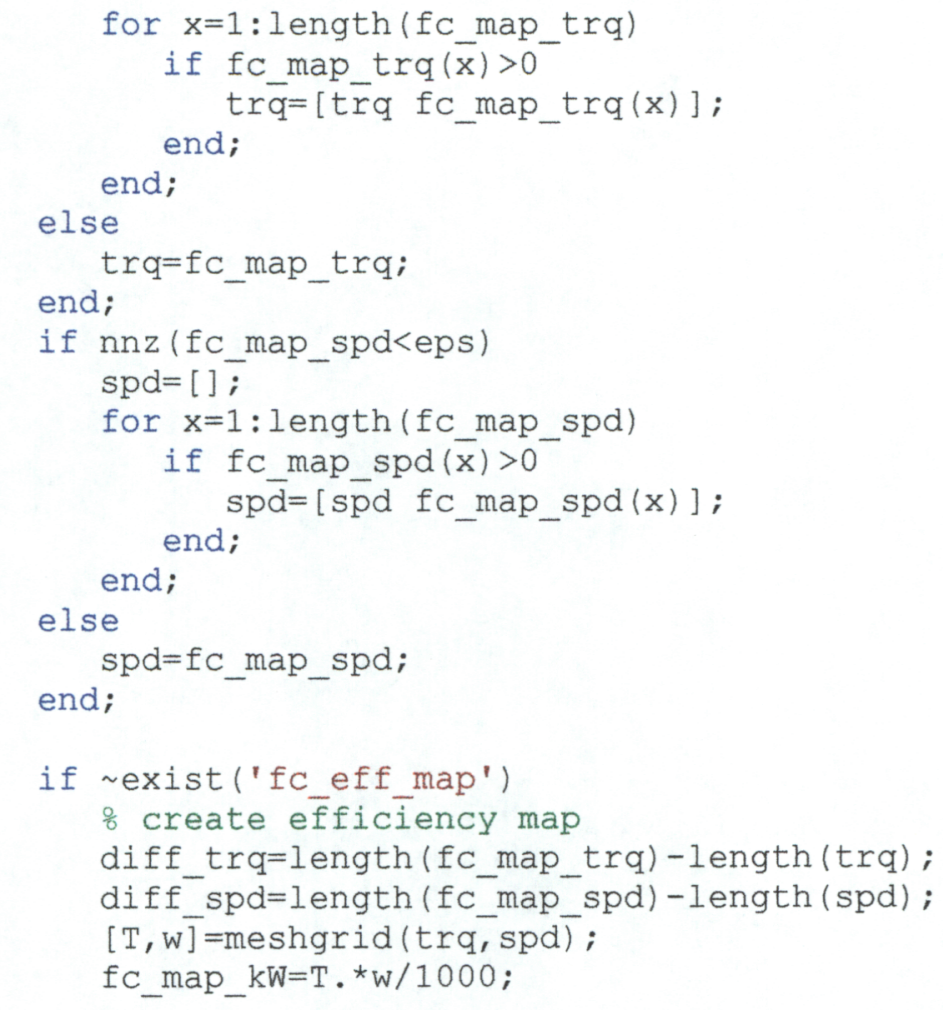

fC_eff_map $=f C \_m a p \_k W * 1000 . /$ (fC_fuel_map (diff_spd+1:length (fC_map_spd), . $\cdots$ end; diff_trq+1:length (fC_map_trq))*fC_fuel_lhv);

\& plot efficiency map temp $=$ floor $(\max (\max ($ fc eff $\operatorname{map} * 100)))-1$;

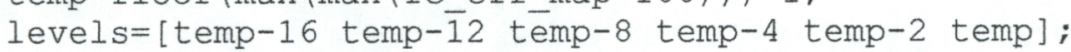

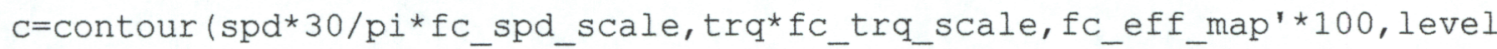
s) ; clabel (c)

o Make OSU parallel control strategy visible if strcmp (vinf.powertrain_control.name, 'Euzzy_Logic_PTC')

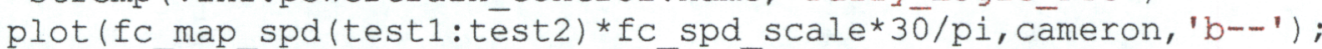
end; plot (fc_map_spd*fc_spd_scale*30/pi, $\bar{b} r e s l i n, ' m-{ }^{\prime}$ )

\% add labels to the plot xlabel ('Speed (rpm)') ylabel('Torque (Nm)') $\frac{o}{0}$ for use with fc_brake_trq eval (['legend(', str, ', 4)'])

end;

if length(['Fuel Converter Operation - ', fc description]) >75 $t t l=\{$ 'Fuel Converter Operation'; fc_description $\}$; title(ttl,'Fontsize', 7); 
else

title(['Fuel Converter Operation - ',fc_description]); end;

set(gcf,' 'NumberTitle', 'off', 'Name', 'Fuel Converter Operation')

12/31/98: tm added plot parallel control strategy section

1/20/99:ss changed ylabel to Torque (Nm) was Brake Torque (Nm) [not including inertia]

\% Ticefuel.m

oCalculates $1 \mathrm{~g} / \mathrm{s}$ fuel use line for selected ICE

fuel_size=size(fc_fuel_map);

I=zēros (1, fuel_size (1)) ;

for $i=1$ : fuel_size(1)

for $j=1$ : füel_size(2)

if fc_fue $\bar{I}_{-} \operatorname{map}(i, j)<=1.0$

$I(\bar{i})=j$;

end

end

if $I(i)>0.0$

breslin(i)=fC_map_trq(I (i));

else breslin(i) = fc_map_trq(1);

end

if breslin(i) > fC max trq(i)

breslin $(i)=f \bar{c} \_$max $\operatorname{trq}(i)$;

end

end 
\% Ticeopt.m

o Calculates the line of maximum efficiency for the selected ICE

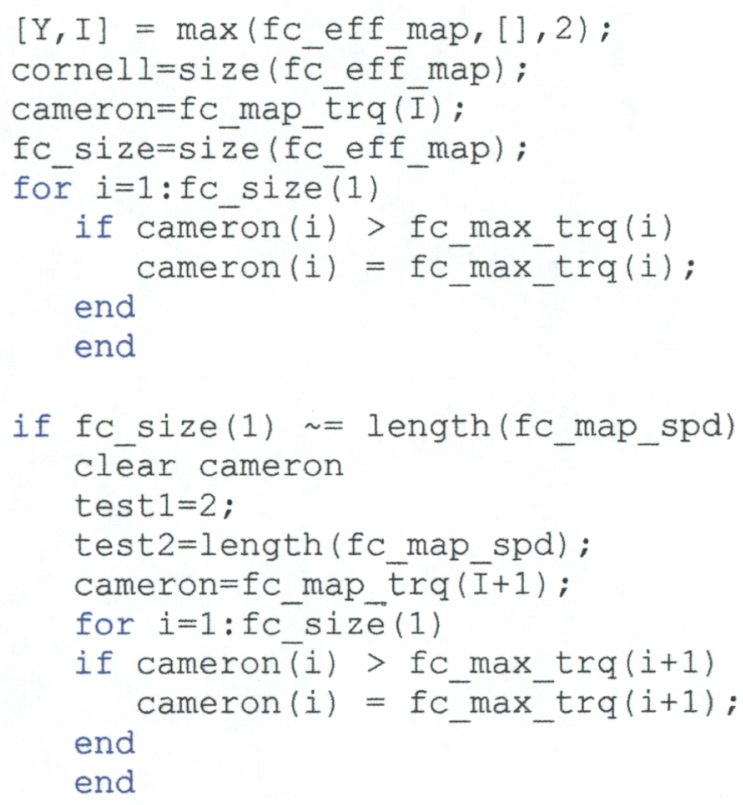


oM-file used to calculate diesel equivalent of electrical energy used

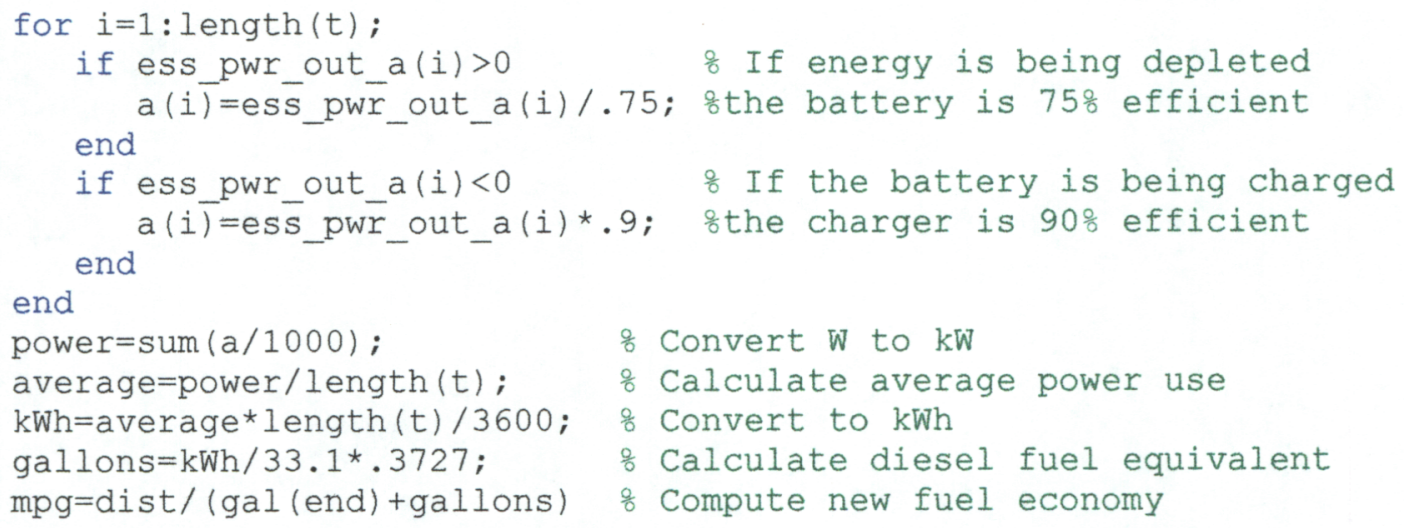


Appendix B

C-Code 


\section{Fuzzy Logic S-Function C-Code}

*

* sfuntmpl.c: C template for a level 2 S-function.

*

* | See matlabroot/simulink/src/sfuntmpl.doc for a more detailed template |

* Copyright (c) 1990-1998 by The MathWorks, Inc. All Rights Reserved.

* \$Revision: 1.18 \$

$* /$

/*

* You must specify the S_FUNCTION_NAME as the name of your S-function

* (i.e. replace sfuntmpl with the name of your S-function).

$*$ /

\#define S_FUNCTION_NAME fuel_use

\#define S_FUNCTION_LEVEL 2

\#include "simstruc.h"

\#define U(element) (*uPtrs[element]) /* Pointer to Input Port0 */

int nomsfin[3] $=\{7,11,11\}$;

int $\operatorname{minins}[3]=\{1,1,1\}$;

float inmsfcent $[3][11]=\{\{1.0,2.0,3.0,4.0,5.0,6.0,7.0,0.0,0.0,0.0,0.0\}$,

$\{1.0,2.0,3.0,4.0,5.0,6.0,7.0,8.0,9.0,10.0,11.0\}$,

$\{1.0,2.0,3.0,4.0,5.0,6.0,7.0,8.0,9.0,10.0,11.0\}\}$

float inmsfwidth[3][11] $=\{\{2.0,2.0,2.0,0.02,2.0,2.0,2.0,0.0,0.0,0.0,0.0\}$,

$\{2.0,2.0,2.0,2.0,2.0,2.0,2.0,2.0,2.0,2.0,2.0\}$,

$\{2.0,2.0,2.0,2.0,2.0,2.0,2.0,2.0,2.0,2.0,2.0\}\}$;

int nomsfout $[2]=\{11,11\}$;

float outmsfcent $[2][11]=\{\{1.0,2.0,3.0,4.0,5.0,6.0,7.0,8.0,9.0,10.0,11.0\}$,

$\{1.0,2.0,3.0,4.0,5.0,6.0,7.0,8.0,9.0,10.0,11.0\}\}$

float outmsfwidth[2][11] $=\{\{2.0,2.0,2.0,2.0,2.0,2.0,2.0,2.0,2.0,2.0,2.0\}$,

$\{2.0,2.0,2.0,2.0,2.0,2.0,2.0,2.0,2.0,2.0,2.0\}\}$;

float inmu[3][11], cont[847];

int rules[847] $[5]=\{\{1,11,11,6,1\},\{1,11,10,6,1\},\{1,11,9,6,1\},\{1,11,8,6,1\},\{1,11,7,6,1\},\{1,11,6,6,1\}$, $\{1,11,5,6,1\},\{1,11,4,6,1\},\{1,11,3,6,1\},\{1,11,2,6,1\},\{1,11,1,6,1\},\{1,10,11,6,1\},\{1,10,10,6,1\}$, $\{1,10,9,6,1\},\{1,10,8,6,1\},\{1,10,7,6,1\},\{1,10,6,6,1\},\{1,10,5,6,1\},\{1,10,4,6,1\},\{1,10,3,6,1\}$, $\{1,10,2,6,1\},\{1,10,1,6,1\},\{1,9,11,6,1\},\{1,9,10,6,1\},\{1,9,9,6,1\},\{1,9,8,6,1\},\{1,9,7,6,1\}$, $\{1,9,6,6,1\},\{1,9,5,6,1\},\{1,9,4,6,1\},\{1,9,3,6,1\},\{1,9,2,6,1\},\{1,9,1,6,1\},\{1,8,11,6,1\},\{1,8,10,6,1\}$, $\{1,8,9,6,1\},\{1,8,8,6,1\},\{1,8,7,6,1\},\{1,8,6,6,1\},\{1,8,5,6,1\},\{1,8,4,6,1\},\{1,8,3,6,1\},\{1,8,2,6,1\}$, $\{1,8,1,6,1\},\{1,7,11,6,1\},\{1,7,10,6,1\},\{1,7,9,6,1\},\{1,7,8,6,1\},\{1,7,7,6,1\},\{1,7,6,6,1\},\{1,7,5,6,1\}$, $\{1,7,4,6,1\},\{1,7,3,6,1\},\{1,7,2,6,1\},\{1,7,1,6,1\},\{1,6,11,6,1\},\{1,6,10,6,1\},\{1,6,9,6,1\},\{1,6,8,6,1\}$, 
$\{1,6,7,6,1\},\{1,6,6,6,1\},\{1,6,5,6,1\},\{1,6,4,6,1\},\{1,6,3,6,1\},\{1,6,2,6,1\},\{1,6,1,6,1\},\{1,5,11,6,1\}$, $\{1,5,10,6,1\},\{1,5,9,6,1\},\{1,5,8,6,1\},\{1,5,7,6,1\},\{1,5,6,6,1\},\{1,5,5,6,1\},\{1,5,4,6,1\},\{1,5,3,6,1\}$, $\{1,5,2,6,1\},\{1,5,1,6,1\},\{1,4,11,6,1\},\{1,4,10,6,1\},\{1,4,9,6,1\},\{1,4,8,6,1\},\{1,4,7,6,1\},\{1,4,6,6,1\}$, $\{1,4,5,6,1\},\{1,4,4,6,1\},\{1,4,3,6,1\},\{1,4,2,6,1\},\{1,4,1,6,1\},\{1,3,11,6,1\},\{1,3,10,6,1\},\{1,3,9,6,1\}$, $\{1,3,8,6,1\},\{1,3,7,6,1\},\{1,3,6,6,1\},\{1,3,5,6,1\},\{1,3,4,6,1\},\{1,3,3,6,1\},\{1,3,2,6,1\},\{1,3,1,6,1\}$, $\{1,2,11,6,1\},\{1,2,10,6,1\},\{1,2,9,6,1\},\{1,2,8,6,1\},\{1,2,7,6,1\},\{1,2,6,6,1\},\{1,2,5,6,1\},\{1,2,4,6,1\}$, $\{1,2,3,6,1\},\{1,2,2,6,1\},\{1,2,1,6,1\},\{1,1,11,6,1\},\{1,1,10,6,1\},\{1,1,9,6,1\},\{1,1,8,6,1\},\{1,1,7,6,1\}$, $\{1,1,6,6,1\},\{1,1,5,6,1\},\{1,1,4,6,1\},\{1,1,3,6,1\},\{1,1,2,6,1\},\{1,1,1,6,1\},\{2,11,11,6,3\},\{2,11,10,6,3\}$ $\{2,11,9,6,3\},\{2,11,8,6,3\},\{2,11,7,6,3\},\{2,11,6,6,3\},\{2,11,5,6,3\},\{2,11,4,6,3\},\{2,11,3,6,3\}$, $\{2,11,2,6,3\},\{2,11,1,6,3\},\{2,10,11,6,3\},\{2,10,10,6,3\},\{2,10,9,6,3\},\{2,10,8,6,3\},\{2,10,7,6,3\}$, $\{2,10,6,6,3\},\{2,10,5,6,3\},\{2,10,4,6,3\},\{2,10,3,6,3\},\{2,10,2,6,3\},\{2,10,1,6,3\},\{2,9,11,6,3\}$, $\{2,9,10,6,3\},\{2,9,9,6,3\},\{2,9,8,6,3\},\{2,9,7,6,3\},\{2,9,6,6,3\},\{2,9,5,6,3\},\{2,9,4,6,3\},\{2,9,3,6,3\}$, $\{2,9,2,6,3\},\{2,9,1,6,3\},\{2,8,11,6,3\},\{2,8,10,6,3\},\{2,8,9,6,3\},\{2,8,8,6,3\},\{2,8,7,6,3\},\{2,8,6,6,3\}$, $\{2,8,5,6,3\},\{2,8,4,6,3\},\{2,8,3,6,3\},\{2,8,2,6,3\},\{2,8,1,6,3\},\{2,7,11,6,3\},\{2,7,10,6,3\},\{2,7,9,6,3\}$, $\{2,7,8,6,3\},\{2,7,7,6,3\},\{2,7,6,6,3\},\{2,7,5,6,3\},\{2,7,4,6,3\},\{2,7,3,6,3\},\{2,7,2,6,3\},\{2,7,1,6,3\}$, $\{2,6,11,6,3\},\{2,6,10,6,3\},\{2,6,9,6,3\},\{2,6,8,6,3\},\{2,6,7,6,3\},\{2,6,6,6,3\},\{2,6,5,6,3\},\{2,6,4,6,3\}$, $\{2,6,3,6,3\},\{2,6,2,6,3\},\{2,6,1,6,3\},\{2,5,11,6,3\},\{2,5,10,6,3\},\{2,5,9,6,3\},\{2,5,8,6,3\},\{2,5,7,6,3\}$, $\{2,5,6,6,3\},\{2,5,5,6,3\},\{2,5,4,6,3\},\{2,5,3,6,3\},\{2,5,2,6,3\},\{2,5,1,6,3\},\{2,4,11,6,3\},\{2,4,10,6,3\}$, $\{2,4,9,6,3\},\{2,4,8,6,3\},\{2,4,7,6,3\},\{2,4,6,6,3\},\{2,4,5,6,3\},\{2,4,4,6,3\},\{2,4,3,6,3\},\{2,4,2,6,3\}$, $\{2,4,1,6,3\},\{2,3,11,6,3\},\{2,3,10,6,3\},\{2,3,9,6,3\},\{2,3,8,6,3\},\{2,3,7,6,3\},\{2,3,6,6,3\},\{2,3,5,6,3\}$, $\{2,3,4,6,3\},\{2,3,3,6,3\},\{2,3,2,6,3\},\{2,3,1,6,3\},\{2,2,11,6,3\},\{2,2,10,6,3\},\{2,2,9,6,3\},\{2,2,8,6,3\}$, $\{2,2,7,6,3\},\{2,2,6,6,3\},\{2,2,5,6,3\},\{2,2,4,6,3\},\{2,2,3,6,3\},\{2,2,2,6,3\},\{2,2,1,6,3\},\{2,1,11,6,3\}$, $\{2,1,10,6,3\},\{2,1,9,6,3\},\{2,1,8,6,3\},\{2,1,7,6,3\},\{2,1,6,6,3\},\{2,1,5,6,3\},\{2,1,4,6,3\},\{2,1,3,6,3\}$, $\{2,1,2,6,3\},\{2,1,1,6,3\},\{3,11,11,6,5\},\{3,11,10,6,5\},\{3,11,9,6,5\},\{3,11,8,6,5\},\{3,11,7,6,5\}$, $\{3,11,6,6,5\},\{3,11,5,6,5\},\{3,11,4,6,5\},\{3,11,3,6,5\},\{3,11,2,6,5\},\{3,11,1,6,5\},\{3,10,11,6,5\}$, $\{3,10,10,6,5\},\{3,10,9,6,5\},\{3,10,8,6,5\},\{3,10,7,6,5\},\{3,10,6,6,5\},\{3,10,5,6,5\},\{3,10,4,6,5\}$, $\{3,10,3,6,5\},\{3,10,2,6,5\},\{3,10,1,6,5\},\{3,9,11,6,5\},\{3,9,10,6,5\},\{3,9,9,6,5\},\{3,9,8,6,5\}$, $\{3,9,7,6,5\},\{3,9,6,6,5\},\{3,9,5,6,5\},\{3,9,4,6,5\},\{3,9,3,6,5\},\{3,9,2,6,5\},\{3,9,1,6,5\},\{3,8,11,6,5\}$, $\{3,8,10,6,5\},\{3,8,9,6,5\},\{3,8,8,6,5\},\{3,8,7,6,5\},\{3,8,6,6,5\},\{3,8,5,6,5\},\{3,8,4,6,5\},\{3,8,3,6,5\}$, $\{3,8,2,6,5\},\{3,8,1,6,5\},\{3,7,11,6,5\},\{3,7,10,6,5\},\{3,7,9,6,5\},\{3,7,8,6,5\},\{3,7,7,6,5\},\{3,7,6,6,5\}$, $\{3,7,5,6,5\},\{3,7,4,6,5\},\{3,7,3,6,5\},\{3,7,2,6,5\},\{3,7,1,6,5\},\{3,6,11,6,5\},\{3,6,10,6,5\},\{3,6,9,6,5\}$, $\{3,6,8,6,5\},\{3,6,7,6,5\},\{3,6,6,6,5\},\{3,6,5,6,5\},\{3,6,4,6,5\},\{3,6,3,6,5\},\{3,6,2,6,5\},\{3,6,1,6,5\}$, $\{3,5,11,6,5\},\{3,5,10,6,5\},\{3,5,9,6,5\},\{3,5,8,6,5\},\{3,5,7,6,5\},\{3,5,6,6,5\},\{3,5,5,6,5\},\{3,5,4,6,5\}$, $\{3,5,3,6,5\},\{3,5,2,6,5\},\{3,5,1,6,5\},\{3,4,11,6,5\},\{3,4,10,6,5\},\{3,4,9,6,5\},\{3,4,8,6,5\},\{3,4,7,6,5\}$, $\{3,4,6,6,5\},\{3,4,5,6,5\},\{3,4,4,6,5\},\{3,4,3,6,5\},\{3,4,2,6,5\},\{3,4,1,6,5\},\{3,3,11,6,5\},\{3,3,10,6,5\}$, $\{3,3,9,6,5\},\{3,3,8,6,5\},\{3,3,7,6,5\},\{3,3,6,6,5\},\{3,3,5,6,5\},\{3,3,4,6,5\},\{3,3,3,6,5\},\{3,3,2,6,5\}$, $\{3,3,1,6,5\},\{3,2,11,6,5\},\{3,2,10,6,5\},\{3,2,9,6,5\},\{3,2,8,6,5\},\{3,2,7,6,5\},\{3,2,6,6,5\},\{3,2,5,6,5\}$, $\{3,2,4,6,5\},\{3,2,3,6,5\},\{3,2,2,6,5\},\{3,2,1,6,5\},\{3,1,11,6,5\},\{3,1,10,6,5\},\{3,1,9,6,5\},\{3,1,8,6,5\}$, $\{3,1,7,6,5\},\{3,1,6,6,5\},\{3,1,5,6,5\},\{3,1,4,6,5\},\{3,1,3,6,5\},\{3,1,2,6,5\},\{3,1,1,6,5\},\{4,11,11,6,6\}$, $\{4,11,10,6,6\},\{4,11,9,6,6\},\{4,11,8,6,6\},\{4,11,7,6,6\},\{4,11,6,6,6\},\{4,11,5,6,6\},\{4,11,4,6,6\}$, $\{4,11,3,6,6\},\{4,11,2,6,6\},\{4,11,1,6,6\},\{4,10,11,6,6\},\{4,10,10,6,6\},\{4,10,9,6,6\},\{4,10,8,6,6\}$, $\{4,10,7,6,6\},\{4,10,6,6,6\},\{4,10,5,6,6\},\{4,10,4,6,6\},\{4,10,3,6,6\},\{4,10,2,6,6\},\{4,10,1,6,6\}$, $\{4,9,11,6,6\},\{4,9,10,6,6\},\{4,9,9,6,6\},\{4,9,8,6,6\},\{4,9,7,6,6\},\{4,9,6,6,6\},\{4,9,5,6,6\},\{4,9,4,6,6\}$, $\{4,9,3,6,6\},\{4,9,2,6,6\},\{4,9,1,6,6\},\{4,8,11,6,6\},\{4,8,10,6,6\},\{4,8,9,6,6\},\{4,8,8,6,6\},\{4,8,7,6,6\}$, $\{4,8,6,6,6\},\{4,8,5,6,6\},\{4,8,4,6,6\},\{4,8,3,6,6\},\{4,8,2,6,6\},\{4,8,1,6,6\},\{4,7,11,6,6\},\{4,7,10,6,6\}$, $\{4,7,9,6,6\},\{4,7,8,6,6\},\{4,7,7,6,6\},\{4,7,6,6,6\},\{4,7,5,6,6\},\{4,7,4,6,6\},\{4,7,3,6,6\},\{4,7,2,6,6\}$, $\{4,7,1,6,6\},\{4,6,11,6,6\},\{4,6,10,6,6\},\{4,6,9,6,6\},\{4,6,8,6,6\},\{4,6,7,6,6\},\{4,6,6,6,6\},\{4,6,5,6,6\}$, $\{4,6,4,6,6\},\{4,6,3,6,6\},\{4,6,2,6,6\},\{4,6,1,6,6\},\{4,5,11,6,6\},\{4,5,10,6,6\},\{4,5,9,6,6\},\{4,5,8,6,6\}$, $\{4,5,7,6,6\},\{4,5,6,6,6\},\{4,5,5,6,6\},\{4,5,4,6,6\},\{4,5,3,6,6\},\{4,5,2,6,6\},\{4,5,1,6,6\},\{4,4,11,6,6\}$, $\{4,4,10,6,6\},\{4,4,9,6,6\},\{4,4,8,6,6\},\{4,4,7,6,6\},\{4,4,6,6,6\},\{4,4,5,6,6\},\{4,4,4,6,6\},\{4,4,3,6,6\}$, $\{4,4,2,6,6\},\{4,4,1,6,6\},\{4,3,11,6,6\},\{4,3,10,6,6\},\{4,3,9,6,6\},\{4,3,8,6,6\},\{4,3,7,6,6\},\{4,3,6,6,6\}$, $\{4,3,5,6,6\},\{4,3,4,6,6\},\{4,3,3,6,6\},\{4,3,2,6,6\},\{4,3,1,6,6\},\{4,2,11,6,6\},\{4,2,10,6,6\},\{4,2,9,6,6\}$, $\{4,2,8,6,6\},\{4,2,7,6,6\},\{4,2,6,6,6\},\{4,2,5,6,6\},\{4,2,4,6,6\},\{4,2,3,6,6\},\{4,2,2,6,6\},\{4,2,1,6,6\}$, $\{4,1,11,6,6\},\{4,1,10,6,6\},\{4,1,9,6,6\},\{4,1,8,6,6\},\{4,1,7,6,6\},\{4,1,6,6,6\},\{4,1,5,6,6\},\{4,1,4,6,6\}$, $\{4,1,3,6,6\},\{4,1,2,6,6\},\{4,1,1,6,6\},\{5,11,11,1,11\},\{5,11,10,2,10\},\{5,11,9,3,9\},\{5,11,8,4,8\}$, 
$\{5,11,7,5,7\},\{5,11,6,6,6\},\{5,11,5,6,6\},\{5,11,4,6,6\},\{5,11,3,6,6\},\{5,11,2,6,6\},\{5,11,1,6,6\}$, $\{5,10,11,1,11\},\{5,10,10,2,10\},\{5,10,9,3,9\},\{5,10,8,4,8\},\{5,10,7,5,7\},\{5,10,6,6,6\},\{5,10,5,6,6\}$, $\{5,10,4,6,6\},\{5,10,3,6,6\},\{5,10,2,6,6\},\{5,10,1,6,6\},\{5,9,11,1,11\},\{5,9,10,2,10\},\{5,9,9,3,9\}$, $\{5,9,8,4,8\},\{5,9,7,5,7\},\{5,9,6,6,6\},\{5,9,5,6,6\},\{5,9,4,6,6\},\{5,9,3,6,6\},\{5,9,2,6,6\},\{5,9,1,6,6\}$, $\{5,8,11,1,11\},\{5,8,10,2,10\},\{5,8,9,3,9\},\{5,8,8,4,8\},\{5,8,7,5,7\},\{5,8,6,6,6\},\{5,8,5,7,5\}$, $\{5,8,4,8,4\},\{5,8,3,9,3\},\{5,8,2,10,2\},\{5,8,1,11,1\},\{5,7,11,1,11\},\{5,7,10,2,10\},\{5,7,9,3,9\}$, $\{5,7,8,4,8\},\{5,7,7,5,7\},\{5,7,6,6,6\},\{5,7,5,7,5\},\{5,7,4,8,4\},\{5,7,3,9,3\},\{5,7,2,10,2\},\{5,7,1,11,1\}$, $\{5,6,11,1,11\},\{5,6,10,2,10\},\{5,6,9,3,9\},\{5,6,8,4,8\},\{5,6,7,5,7\},\{5,6,6,6,6\},\{5,6,5,7,5\}$, $\{5,6,4,8,4\},\{5,6,3,9,3\},\{5,6,2,10,2\},\{5,6,1,11,1\},\{5,5,11,1,11\},\{5,5,10,2,10\},\{5,5,9,3,9\}$, $\{5,5,8,4,8\},\{5,5,7,5,7\},\{5,5,6,6,6\},\{5,5,5,7,5\},\{5,5,4,8,4\},\{5,5,3,9,3\},\{5,5,2,10,2\},\{5,5,1,11,1\}$, $\{5,4,11,1,11\},\{5,4,10,2,10\},\{5,4,9,3,9\},\{5,4,8,4,8\},\{5,4,7,5,7\},\{5,4,6,6,6\},\{5,4,5,7,5\}$, $\{5,4,4,8,4\},\{5,4,3,9,3\},\{5,4,2,10,2\},\{5,4,1,11,1\},\{5,3,11,2,10\},\{5,3,10,2,10\},\{5,3,9,3,9\}$, $\{5,3,8,4,8\},\{5,3,7,5,7\},\{5,3,6,6,6\},\{5,3,5,7,5\},\{5,3,4,8,4\},\{5,3,3,9,3\},\{5,3,2,10,2\},\{5,3,1,11,1\}$, $\{5,2,11,4,8\},\{5,2,10,4,8\},\{5,2,9,4,8\},\{5,2,8,5,7\},\{5,2,7,5,7\},\{5,2,6,6,6\},\{5,2,5,7,5\},\{5,2,4,8,4\}$, $\{5,2,3,9,3\},\{5,2,2,10,2\},\{5,2,1,11,1\},\{5,1,11,6,6\},\{5,1,10,6,6\},\{5,1,9,6,6\},\{5,1,8,6,6\}$, $\{5,1,7,6,6\},\{5,1,6,6,6\},\{5,1,5,7,5\},\{5,1,4,8,4\},\{5,1,3,9,3\},\{5,1,2,10,2\},\{5,1,1,11,1\}$,

$\{6,11,11,1,11\},\{6,11,10,2,10\},\{6,11,9,3,9\},\{6,11,8,4,8\},\{6,11,7,5,7\},\{6,11,6,6,6\},\{6,11,5,6,6\}$, $\{6,11,4,6,6\},\{6,11,3,6,6\},\{6,11,2,6,6\},\{6,11,1,6,6\},\{6,10,11,1,11\},\{6,10,10,2,10\},\{6,10,9,3,9\}$, $\{6,10,8,4,8\},\{6,10,7,5,7\},\{6,10,6,6,6\},\{6,10,5,6,6\},\{6,10,4,6,6\},\{6,10,3,6,6\},\{6,10,2,6,6\}$, $\{6,10,1,6,6\},\{6,9,11,1,11\},\{6,9,10,2,10\},\{6,9,9,3,9\},\{6,9,8,4,8\},\{6,9,7,5,7\},\{6,9,6,6,6\}$, $\{6,9,5,6,6\},\{6,9,4,6,6\},\{6,9,3,6,6\},\{6,9,2,6,6\},\{6,9,1,6,6\},\{6,8,11,1,11\},\{6,8,10,2,10\}$, $\{6,8,9,3,9\},\{6,8,8,4,8\},\{6,8,7,5,7\},\{6,8,6,6,6\},\{6,8,5,7,5\},\{6,8,4,8,4\},\{6,8,3,9,3\},\{6,8,2,10,2\}$, $\{6,8,1,11,1\},\{6,7,11,1,11\},\{6,7,10,2,10\},\{6,7,9,3,9\},\{6,7,8,4,8\},\{6,7,7,5,7\},\{6,7,6,6,6\}$, $\{6,7,5,7,5\},\{6,7,4,8,4\},\{6,7,3,9,3\},\{6,7,2,10,2\},\{6,7,1,11,1\},\{6,6,11,1,11\},\{6,6,10,2,10\}$, $\{6,6,9,3,9\},\{6,6,8,4,8\},\{6,6,7,5,7\},\{6,6,6,6,6\},\{6,6,5,7,5\},\{6,6,4,8,4\},\{6,6,3,9,3\},\{6,6,2,10,2\}$, $\{6,6,1,11,1\},\{6,5,11,1,11\},\{6,5,10,2,10\},\{6,5,9,3,9\},\{6,5,8,4,8\},\{6,5,7,5,7\},\{6,5,6,6,6\}$, $\{6,5,5,7,5\},\{6,5,4,8,4\},\{6,5,3,9,3\},\{6,5,2,10,2\},\{6,5,1,11,1\},\{6,4,11,1,11\},\{6,4,10,2,10\}$, $\{6,4,9,3,9\},\{6,4,8,4,8\},\{6,4,7,5,7\},\{6,4,6,6,6\},\{6,4,5,7,5\},\{6,4,4,8,4\},\{6,4,3,9,3\},\{6,4,2,10,2\}$, $\{6,4,1,11,1\},\{6,3,11,2,10\},\{6,3,10,2,10\},\{6,3,9,3,9\},\{6,3,8,4,8\},\{6,3,7,5,7\},\{6,3,6,6,6\}$, $\{6,3,5,7,5\},\{6,3,4,8,4\},\{6,3,3,9,3\},\{6,3,2,10,2\},\{6,3,1,11,1\},\{6,2,11,4,8\},\{6,2,10,4,8\}$, $\{6,2,9,4,8\},\{6,2,8,5,7\},\{6,2,7,5,7\},\{6,2,6,6,6\},\{6,2,5,7,5\},\{6,2,4,8,4\},\{6,2,3,9,3\},\{6,2,2,10,2\}$, $\{6,2,1,11,1\},\{6,1,11,6,6\},\{6,1,10,6,6\},\{6,1,9,6,6\},\{6,1,8,6,6\},\{6,1,7,6,6\},\{6,1,6,6,6\},\{6,1,5,7,5\}$, $\{6,1,4,8,4\},\{6,1,3,9,3\},\{6,1,2,10,2\},\{6,1,1,11,1\},\{7,11,11,1,11\},\{7,11,10,2,10\},\{7,11,9,3,9\}$, $\{7,11,8,4,8\},\{7,11,7,5,7\},\{7,11,6,6,6\},\{7,11,5,6,6\},\{7,11,4,6,6\},\{7,11,3,6,6\},\{7,11,2,6,6\}$, $\{7,11,1,6,6\},\{7,10,11,1,11\},\{7,10,10,2,10\},\{7,10,9,3,9\},\{7,10,8,4,8\},\{7,10,7,5,7\},\{7,10,6,6,6\}$, $\{7,10,5,6,6\},\{7,10,4,6,6\},\{7,10,3,6,6\},\{7,10,2,6,6\},\{7,10,1,6,6\},\{7,9,11,1,11\},\{7,9,10,2,10\}$, $\{7,9,9,3,9\},\{7,9,8,4,8\},\{7,9,7,5,7\},\{7,9,6,6,6\},\{7,9,5,6,6\},\{7,9,4,6,6\},\{7,9,3,6,6\},\{7,9,2,6,6\}$, $\{7,9,1,6,6\},\{7,8,11,1,11\},\{7,8,10,2,10\},\{7,8,9,3,9\},\{7,8,8,4,8\},\{7,8,7,5,7\},\{7,8,6,6,6\}$, $\{7,8,5,7,5\},\{7,8,4,8,4\},\{7,8,3,9,3\},\{7,8,2,10,2\},\{7,8,1,11,1\},\{7,7,11,1,11\},\{7,7,10,2,10\}$, $\{7,7,9,3,9\},\{7,7,8,4,8\},\{7,7,7,5,7\},\{7,7,6,6,6\},\{7,7,5,7,5\},\{7,7,4,8,4\},\{7,7,3,9,3\},\{7,7,2,10,2\}$, $\{7,7,1,11,1\},\{7,6,11,1,11\},\{7,6,10,2,10\},\{7,6,9,3,9\},\{7,6,8,4,8\},\{7,6,7,5,7\},\{7,6,6,6,6\}$, $\{7,6,5,7,5\},\{7,6,4,8,4\},\{7,6,3,9,3\},\{7,6,2,10,2\},\{7,6,1,11,1\},\{7,5,11,1,11\},\{7,5,10,2,10\}$, $\{7,5,9,3,9\},\{7,5,8,4,8\},\{7,5,7,5,7\},\{7,5,6,6,6\},\{7,5,5,7,5\},\{7,5,4,8,4\},\{7,5,3,9,3\},\{7,5,2,10,2\}$, $\{7,5,1,11,1\},\{7,4,11,1,11\},\{7,4,10,2,10\},\{7,4,9,3,9\},\{7,4,8,4,8\},\{7,4,7,5,7\},\{7,4,6,6,6\}$, $\{7,4,5,7,5\},\{7,4,4,8,4\},\{7,4,3,9,3\},\{7,4,2,10,2\},\{7,4,1,11,1\},\{7,3,11,2,10\},\{7,3,10,2,10\}$, $\{7,3,9,3,9\},\{7,3,8,4,8\},\{7,3,7,5,7\},\{7,3,6,6,6\},\{7,3,5,7,5\},\{7,3,4,8,4\},\{7,3,3,9,3\},\{7,3,2,10,2\}$, $\{7,3,1,11,1\},\{7,2,11,4,8\},\{7,2,10,4,8\},\{7,2,9,4,8\},\{7,2,8,5,7\},\{7,2,7,5,7\},\{7,2,6,6,6\},\{7,2,5,7,5\}$, $\{7,2,4,8,4\},\{7,2,3,9,3\},\{7,2,2,10,2\},\{7,2,1,11,1\},\{7,1,11,6,6\},\{7,1,10,6,6\},\{7,1,9,6,6\}$, $\{7,1,8,6,6\},\{7,1,7,6,6\},\{7,1,6,6,6\},\{7,1,5,7,5\},\{7,1,4,8,4\},\{7,1,3,9,3\},\{7,1,2,10,2\},\{7,1,1,11,1\}\}$;

* Need to include simstruc.h for the definition of the SimStruct and

* its associated macro definitions

$* 1$ 
\#include "simstruc.h"

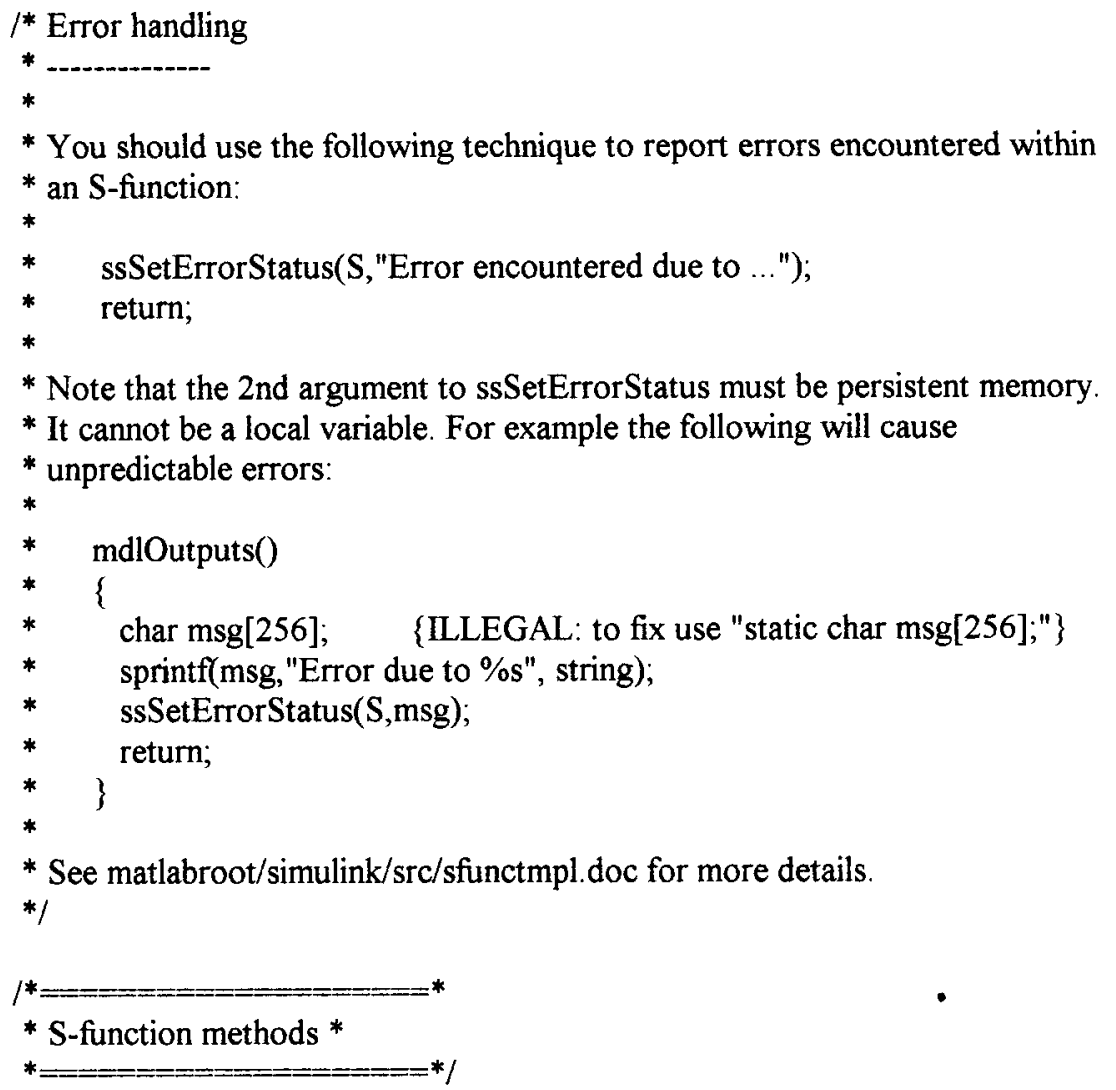

/* Function: mdlInitializeSizes

* Abstract.

* The sizes information is used by Simulink to determine the S-function

* block's characteristics (number of inputs, outputs, states, etc.).

*I

static void mdlInitializeSizes(SimStruct ${ }^{*}$ S)

\{

/* See sfuntmpl.doc for more details on the macros below */

ssSetNumSFcnParams(S, 0); /* Number of expected parameters */

if (ssGetNumSFcnParams(S) != ssGetSFcnParamsCount(S)) \{

/* Return if number of expected != number of actual parameters */

)

return;

ssSetNumContStates $(\mathrm{S}, 0)$;

ssSetNumDiscStates(S, 0);

if (!ssSetNumInputPorts(S, 1)) return;

ssSetInputPortWidth(S, 0, 3);

ssSetInputPortDirectFeedThrough(S, 0, 1); 
if (!ssSetNumOutputPorts $(\mathrm{S}, 1)$ ) return; ssSetOutputPortWidth(S, 0, 2);

ssSetNumSampleTimes(S, 1); ssSetNumRWork(S, 0); ssSetNumIWork(S, 0); ssSetNumPWork $(\mathrm{S}, 0)$; ssSetNumModes $(\mathrm{S}, 0)$;

ssSetNumNonsampledZCs $(\mathbf{S}, 0)$;

ssSetOptions(S, 0);

\}

/* Function: mdlInitializeSampleTimes

* Abstract:

* This function is used to specify the sample time(s) for your

* S-function. You must register the same number of sample times as

* specified in ssSetNumSampleTimes.

*1

static void mdlInitializeSampleTimes(SimStruct $\left.{ }^{*} \mathrm{~S}\right)$

\{

ssSetSampleTime(S, 0, CONTINUOUS_SAMPLE_TIME);

ssSetOffsetTime(S, 0, 0.0);

\}

\#define MDL INITIALIZE_CONDITIONS /* Change to \#undef to remove function */ \#if defined(MDL_INITIALIZZE_CONDITIONS)

/* Function: mdlInitializeConditions

* Abstract:

* In this function, you should initialize the continuous and discrete

* states for your S-function block. The initial states are placed

* in the state vector, ssGetContStates(S) or ssGetRealDiscStates(S).

* You can also perform any other initialization activities that your

* S-function may require. Note, this routine will be called at the

* start of simulation and if it is present in an enabled subsystem

* configured to reset states, it will be call when the enabled subsystem

* restarts execution to reset the states.

*I

static void mdlinitializeConditions $\left(\operatorname{SimStruct}{ }^{*} \mathrm{~S}\right)$

\{

\#endif $/ *$ MDL_INITIALIZE_CONDITIONS */

\#define MDL_START /* Change to \#undef to remove function */

\#if defined(MDL_START)

/* Function: mdistart

* Abstract:

* This function is called once at start of model execution. If you 
* have states that should be initialized once, this is the place

* to do it.

*/

static void mdlStart(SimStruct *S)

\{

\#endif /* MDL_START */

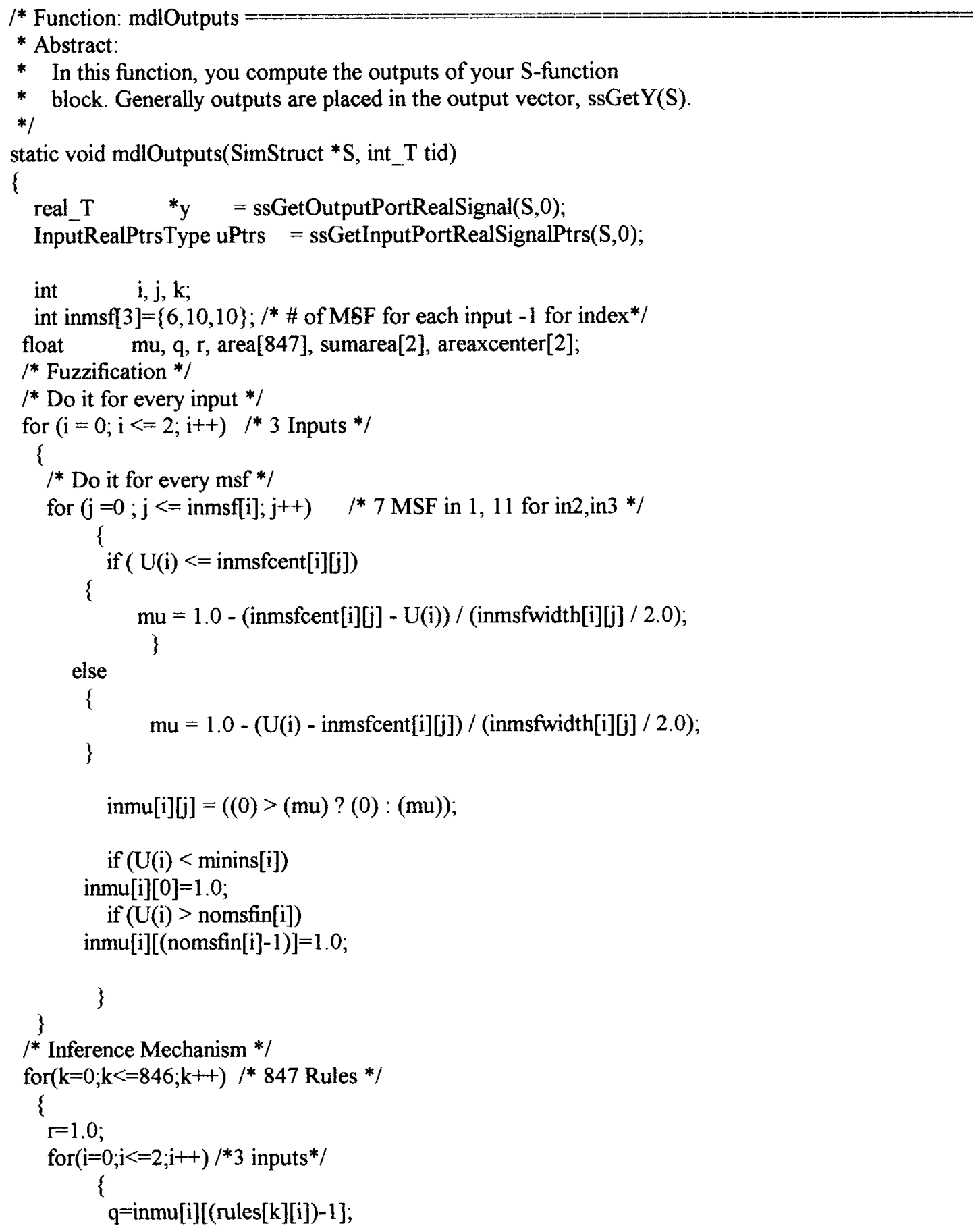




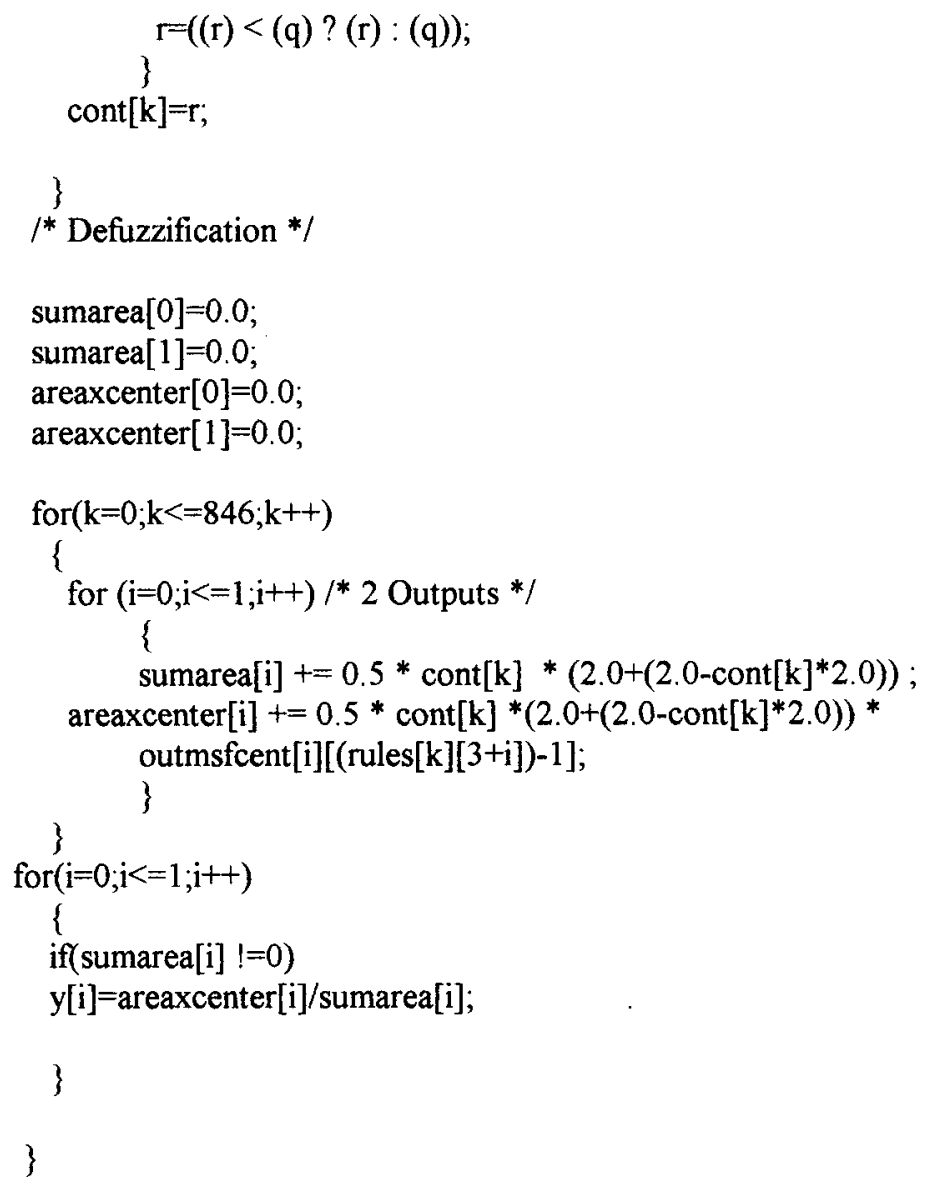

* This function is called once for every major integration time step.

* Discrete states are typically updated here, but this function is useful

* for performing any tasks that should only take place once per

* integration step.

$*$ /

static void mdlUpdate(SimStruct ${ }^{*} S$, int $\mathrm{T}$ tid)

\{

\#endif /* MDL_UPDATE */

\#define MDL_DERIVATIVES /* Change to \#undef to remove function */ \#if defined(MDL_DERIVATIVES)

/* Function: mdiDerivatives

* Abstract:

* In this function, you compute the S-function block's derivatives.

* The derivatives are placed in the derivative vector, ssGetdX(S). 


$$
\text { */ }
$$

static void indIDerivatives(SimStruct $\left.{ }^{*} S\right)$

\{

\}

\#endif/*MDL_DERIVATIVES */

/* Function: mdlTerminate

* Abstract:

* In this function, you should perform any actions that are necessary

* at the termination of a simulation. For example, if memory was

* allocated in mdlInitializeConditions, this is the place to free it.

*/

static void mdlTerminate(SimStruct *S)

\{

\}

$l^{*}=$

* See sfuntmpl.doc for the optional S-function methods *

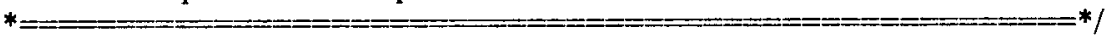

$1^{*}=$

* Required S-function trailer *

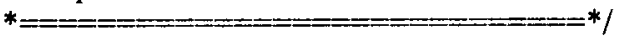

\#ifdef MATLAB_MEX_FILE /* Is this file being compiled as a MEX-file? */

\#include "simulink. c" $/$ " MEX-file interface mechanism */

\#else

\#include "cg_sfun.h" $/ *$ Code generation registration function */

\#endif 


\section{DSpace Frequency Measurement Initialization C-Code}

/**************************************************************************

Include file Powertrain_Controller.usr:

Definition of functions for user defined initialization, system $\mathrm{I} / \mathrm{O}$, and background process code.

Generated by dSPACE RTI1102 3.1 (23-Apr-1998)

on Thu Feb 18 14:46:55 1999

Copyright (c) 1997 dSPACE GmbH, GERMANY

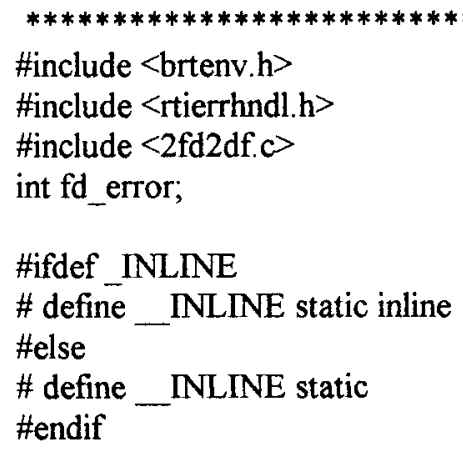


_INLINE void usr_output(void)

\}

static void usr_terminate(void)

\{

static void usr_background(void)

\{

\#undef _ INLINE 


\section{REFERENCES}

[1] R.Q. Riley, Alternative Cars of the $21^{\text {st }}$ Century- A New Personal Transportation Paradigm, SAE, Warrendale, PA, 1994.

[2] K. Passino and S. Yurkovich, Fuzzy Control. Menlo Park, CA: Addison Wesly Longman 1998.

[3] B. M. Baumann, Intelligent Control Strategies for Hybrid Vehicles using Neural Networks and Fuzzy Logic, Master Thesis, The Ohio State University, Columbus, $\mathrm{OH}$, 1997.

[4] J. M. Mendel, "Fuzzy Logic Systems for Engineering", Proceedings of the IEEE, Vol. 83, No. 3, pp. 345-377, March 1995.

[5] Y. F. Li, C. C. Lau, "Development of Fuzzy Algorithms for Servo Systems", IEEE Control Systems Magazine, pp. 65-71, April 1989.

[6] Cuddy, M.R., Wipke, K. B., Analysis of the Fuel Economy Benefit of Drivetrain Hybridization. SAE Technical Paper Series, 970289, 1997.

[7] R.D. Senger, "Validation of ADVISOR as a Simulator Tool for a series Hybrid Electric Vehicle using the Virginia Tech FutureCar Lumina", Master's Thesis, Virginia Tech University, 1997.

[8] Wasacz, B., Janes, N., Guezennec, Y., Rizzoni, G., The 1996 Ohio State University FutureCar. SAE Technical Paper Series SP-1234, 1997: p. $39-52$

[9] Schluter, F., Waltermann, P., Hierarchical Control Structures for Hybrid Vehicles - Modeling, Simulation, and Optimization. Advances in Automotive Control, 1995, March. First International Federation of Automatic Control Workshop.

[10] Hochgraf C.G., Ryan M.J., and Wiegman H.L., "Engine Control Strategy for a Series Hybrid Electric Vehicle Incorporating Load Leveling and Computer Controlled Energy Management", SAE Journal SAE/SP-96/1156, pp.11-24.

[11] Guzzella L., Amstutz A., and Grob F., "Optimal Operation Strategies For Hybrid 
Powertrains", Advances in Automotive Control, First International Federation of Automatic Control Workshop, March 1995

[12] Ross, M., Wei, W., Fuel Economy Analysis for a Hybrid Concept Car Based on Buffered Fuel-Engine Operating at an Optimum Point. SAE Technical Paper, 950958, 1995.

[13] Burch S., Cuddy M., Johnson V., Markel T., Rausen D., Sprik S., Wipke K., NREL Advisor 2.1 Documentation, March 19, 1999.

[14] Jung-Ik-Ha, Euh-Suh-Koo, Hyeoun-Dong-Lee, Joohn-Sheok-Kim, Seuung-KiSul, "Advanced Control Strategy of Parallel Hybrid Low Emission Electric Vehicle", IEEE Power Electronics in Transportation, pp.71-76, 1996.

[15] Clayton R. Paul, Introduction to Electromagnetic Compatibility, John Wiley \& Sons, Inc., New York, 1992.

[16] Euh-Suh-Koo, Hyeoun-Dong-Lee, Seung-Ki-Sul, Joohn-Sheok-Kim, "Torque Control Strategy for a Parallel Hybrid Vehicle Using Fuzzy Logic", Conference Record of 1998 IEEE Industry Applications Conference, vol. 3, pp. 1715-1720.

[17] Real-Time Interface to Simulink ${ }^{\circledR} 2$ RTI1102 User's Guide, dSpace Digital Signal Processing and Control Engineering GmbH, 1997.

[18] Hyeong-Dong-Lee, Deung-Ki-Sul, "Fuzzy-Logic-Based Torque Control Strategy for Parallel-Type Hybrid Electric Vehicle", IEEE Transactions on Industrial Electronics, vol.45, no.4, pp.625-632, 1998.

[19] Timothy C. Moore, "Tools and Strategies for Hybrid-Electric Drivesystem Optimization". SAE paper $961660,1996$.

[20] Ralph Morrison, Grounding and Shielding Techniques in Instrumentation, John Wiley \& Sons, Inc., New York, 1967.

[21] Future Truck 2000 Rules and Regulations, Argonne National Laboratory Center for Transportation Research. 1999.

[22] K.L. Butler, K.M. Stevens, M. Ehsani, "A Versatile Computer Simulation Tool for Design and Analysis of Electric and Hybrid Drive Trains." SAE Technical Paper Series, 970199, 1997

[23] Clarence W. Ellers, Near Term Improvement of Passenger Car Drive Train Efficiency, SAE Paper 961661, 1996.

[24] Thomas Mayer, Dierk Schroeder, " Robust Control of a Parallel Hybrid Drivetrain with a CVT", SAE Paper 960233, 1996. 